Supplement of Biogeosciences, 13, 4439-4459, 2016

http://www.biogeosciences.net/13/4439/2016/

doi:10.5194/bg-13-4439-2016-supplement

(C) Author(s) 2016. CC Attribution 3.0 License.

(c) (i)

Supplement of

\title{
Underestimation of boreal soil carbon stocks by mathematical soil carbon models linked to soil nutrient status
}

Boris Ťupek et al.

Correspondence to: Boris Ťupek

The copyright of individual parts of the supplement might differ from the CC-BY 3.0 licence. 


\section{Content:}

1 Model source codes ... pp. 2-54

2 Tables $\mathrm{S} 1 \ldots \mathrm{S} 3$...pp. 55-57

3 Figures $\mathrm{S} 1$... S12 ... pp. 58-67

\section{Source codes of the Yasso07, Q, and CENTURY model}

\subsection{Yasso07 model}

https://code.google.com/p/yasso07ui/source/browse/trunk/y07_subroutine.f90

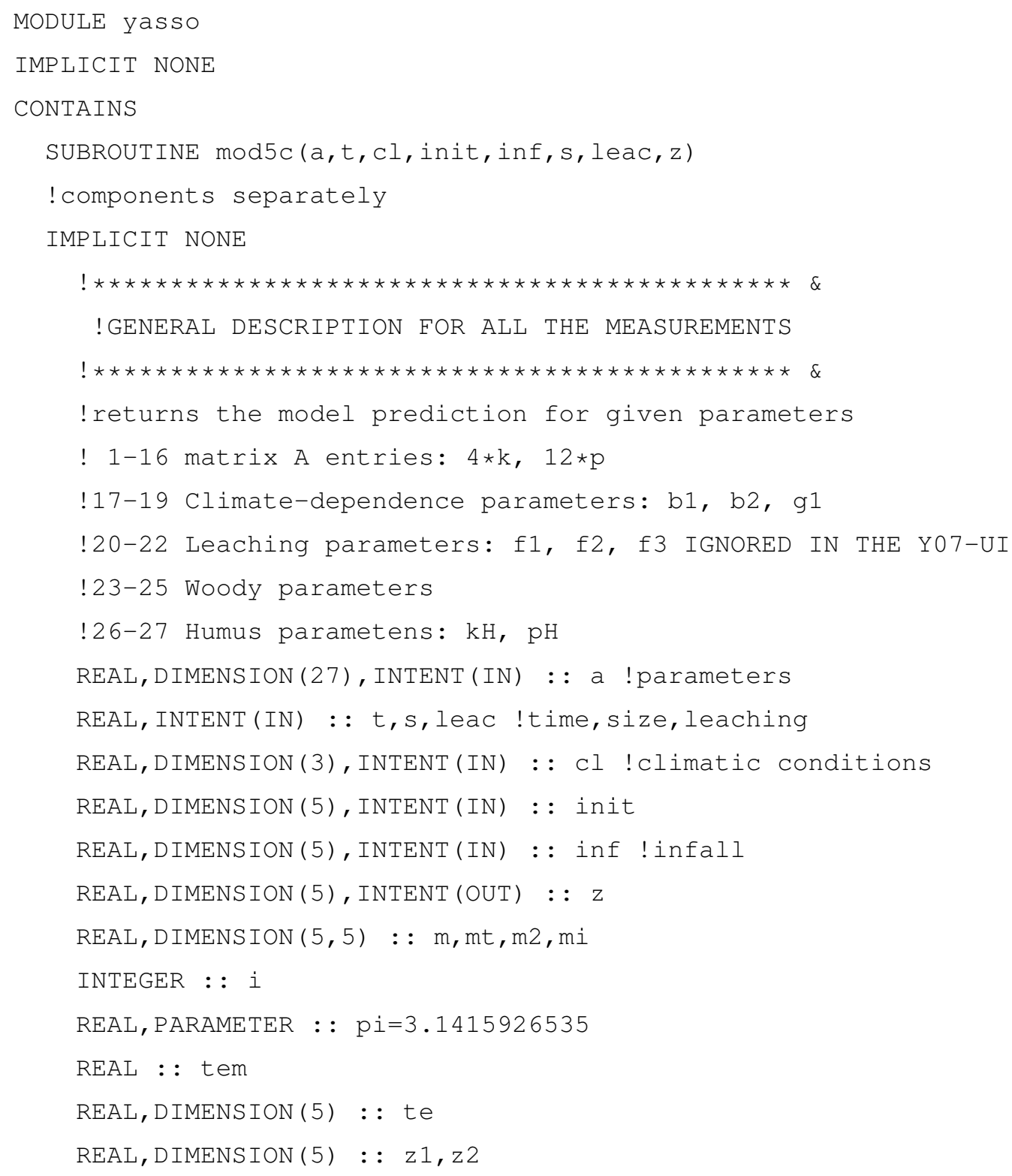




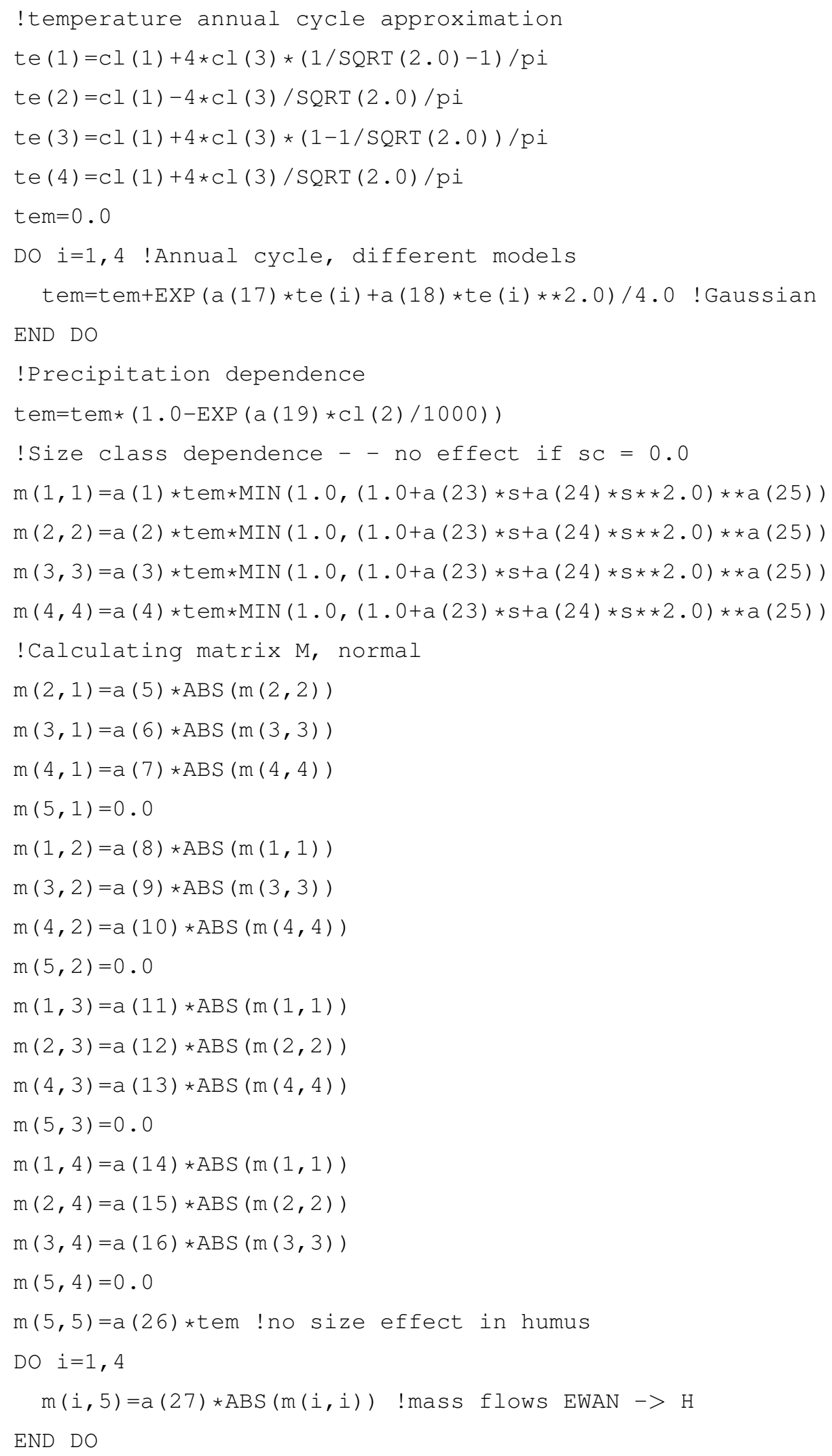




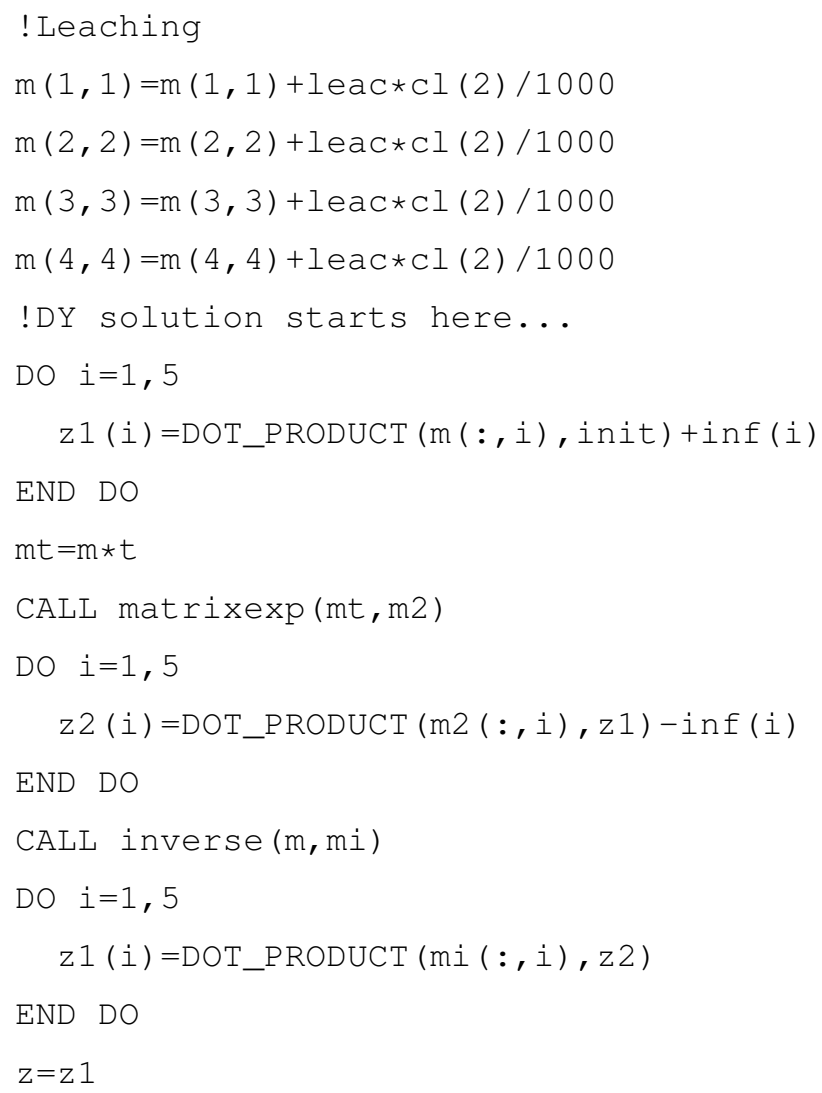




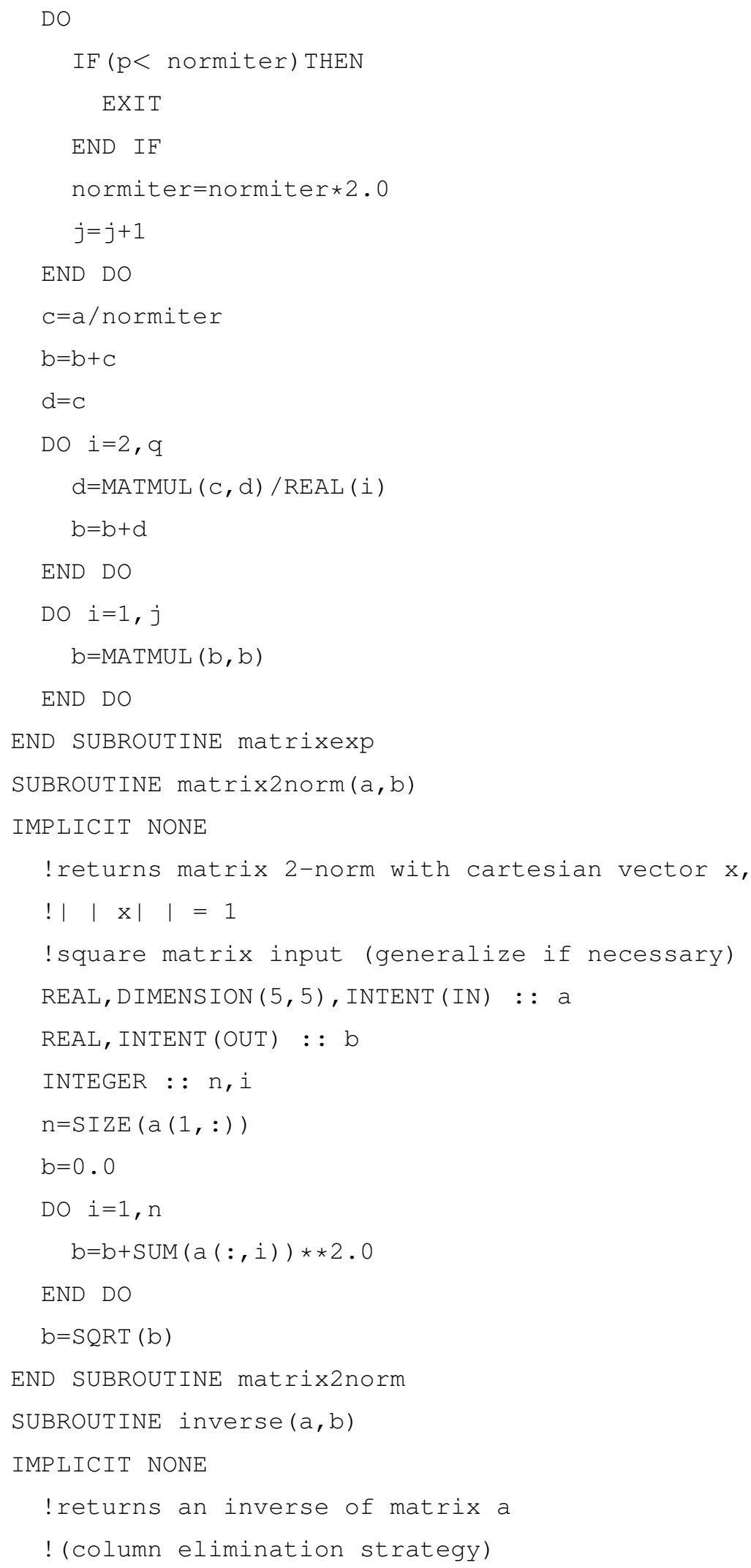




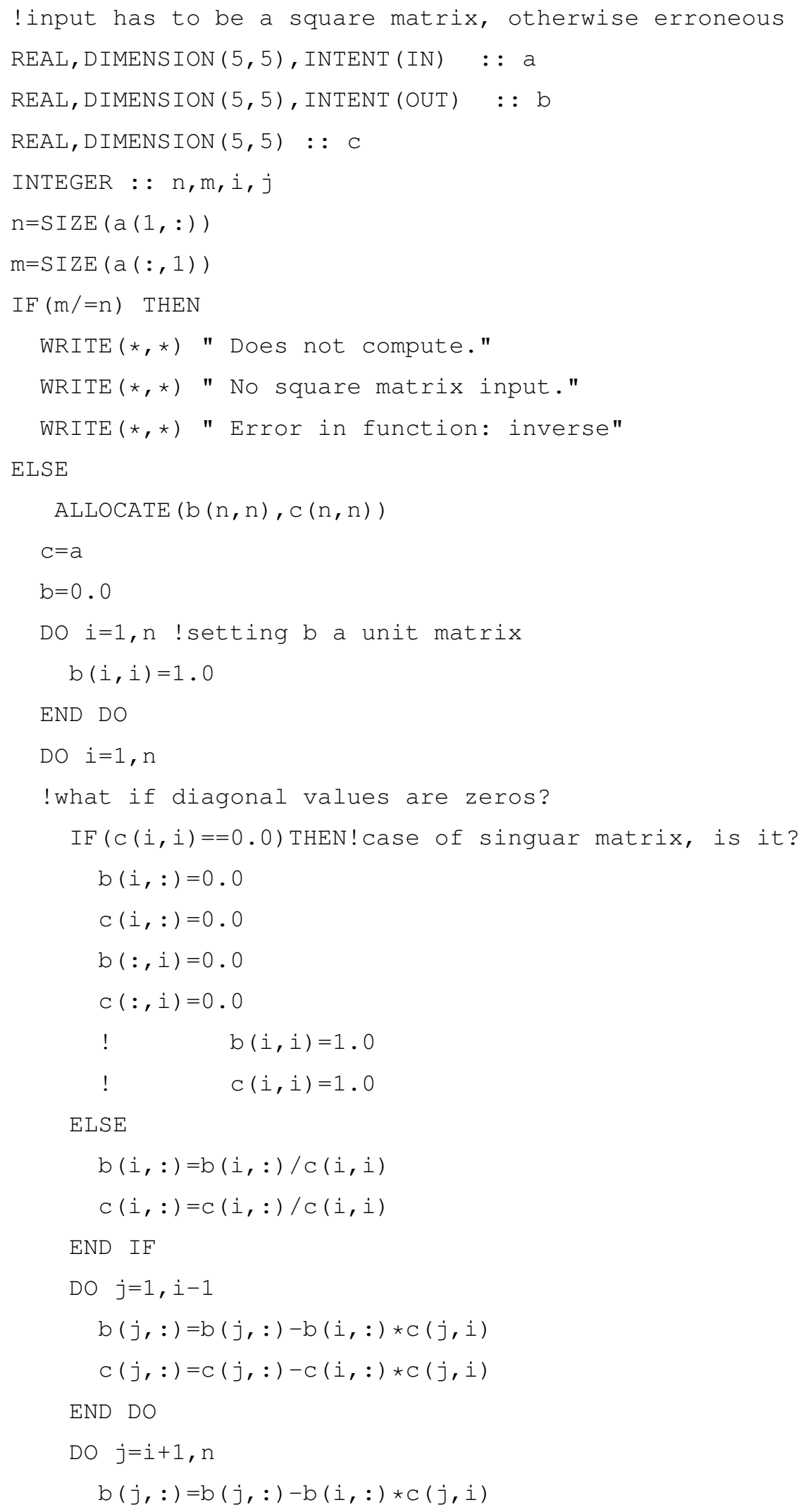




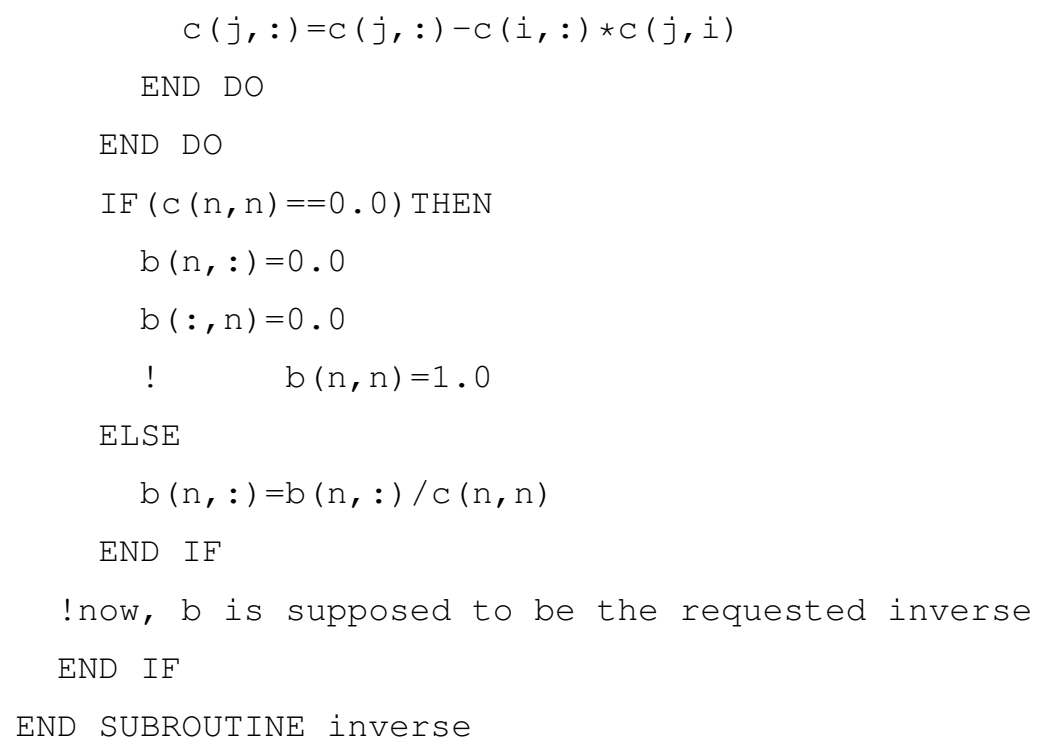

\subsection{Q model}

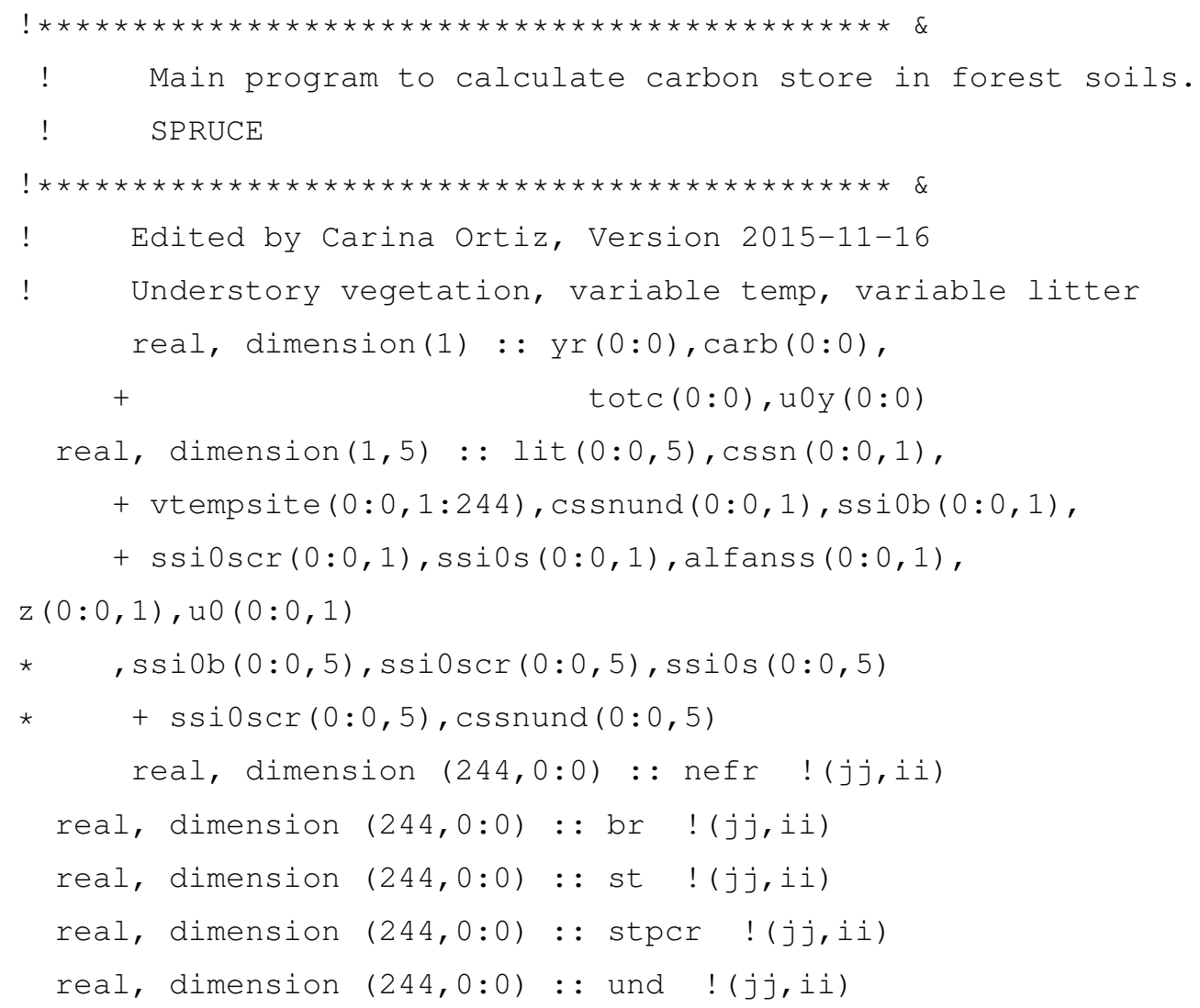




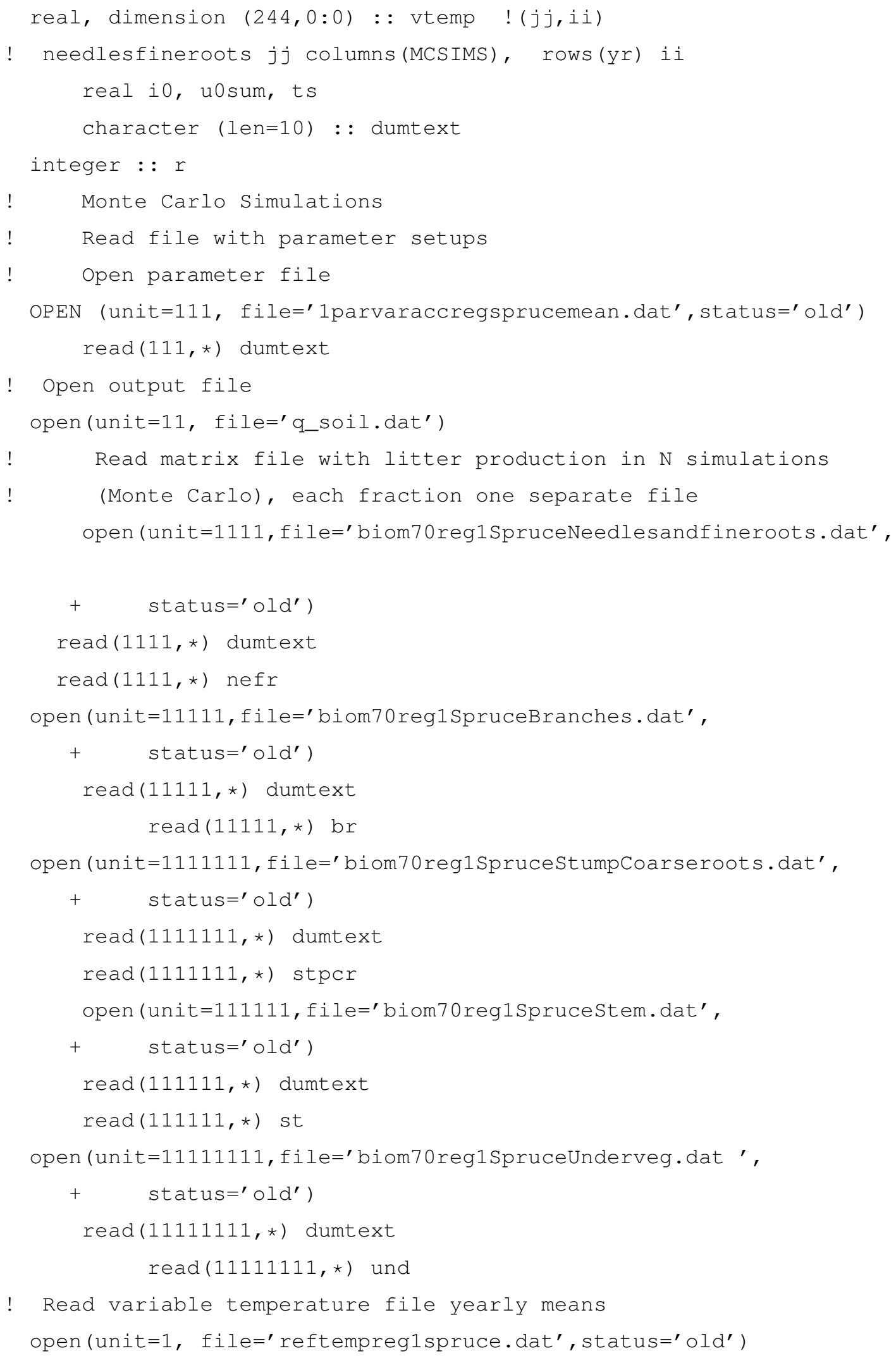




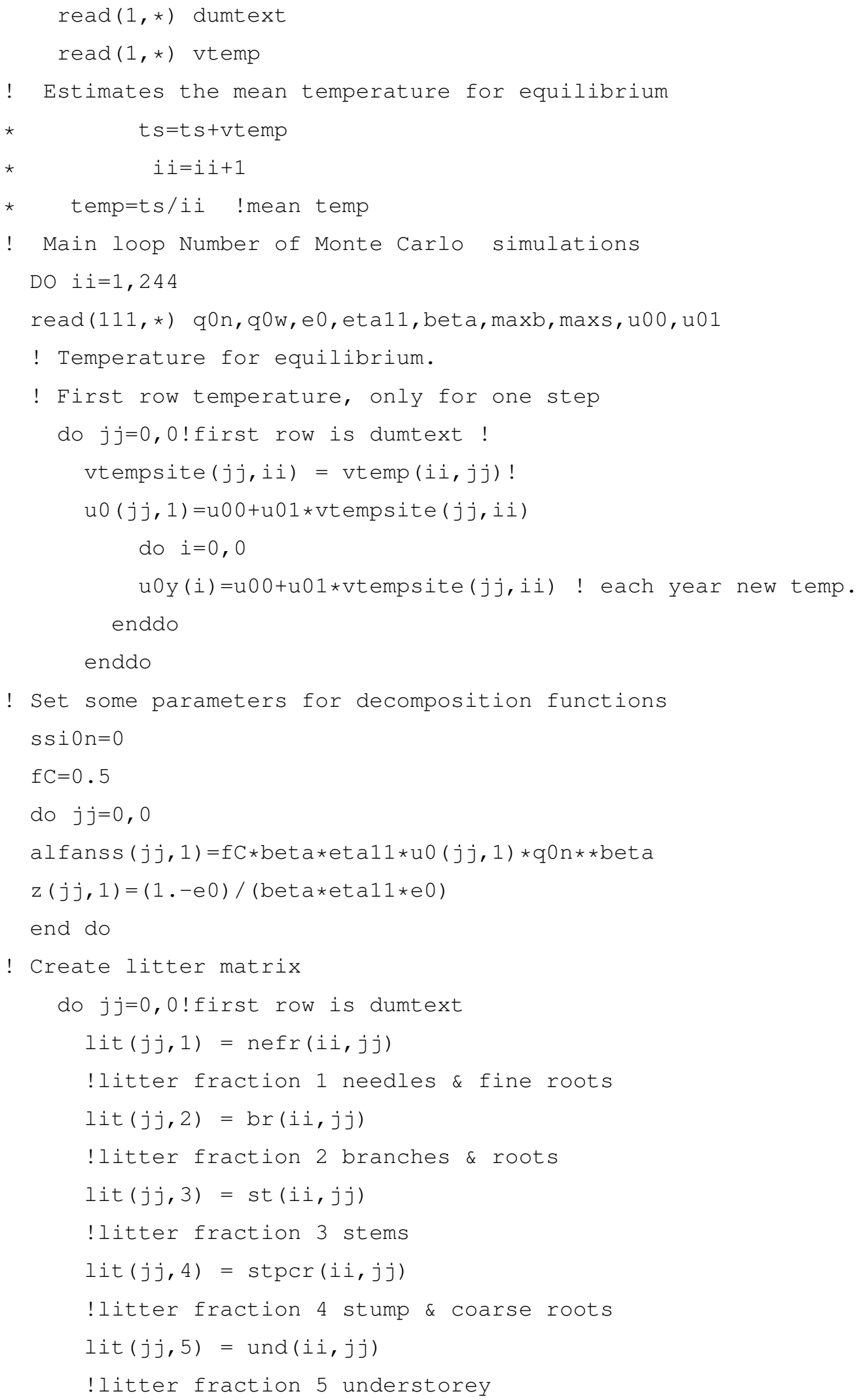




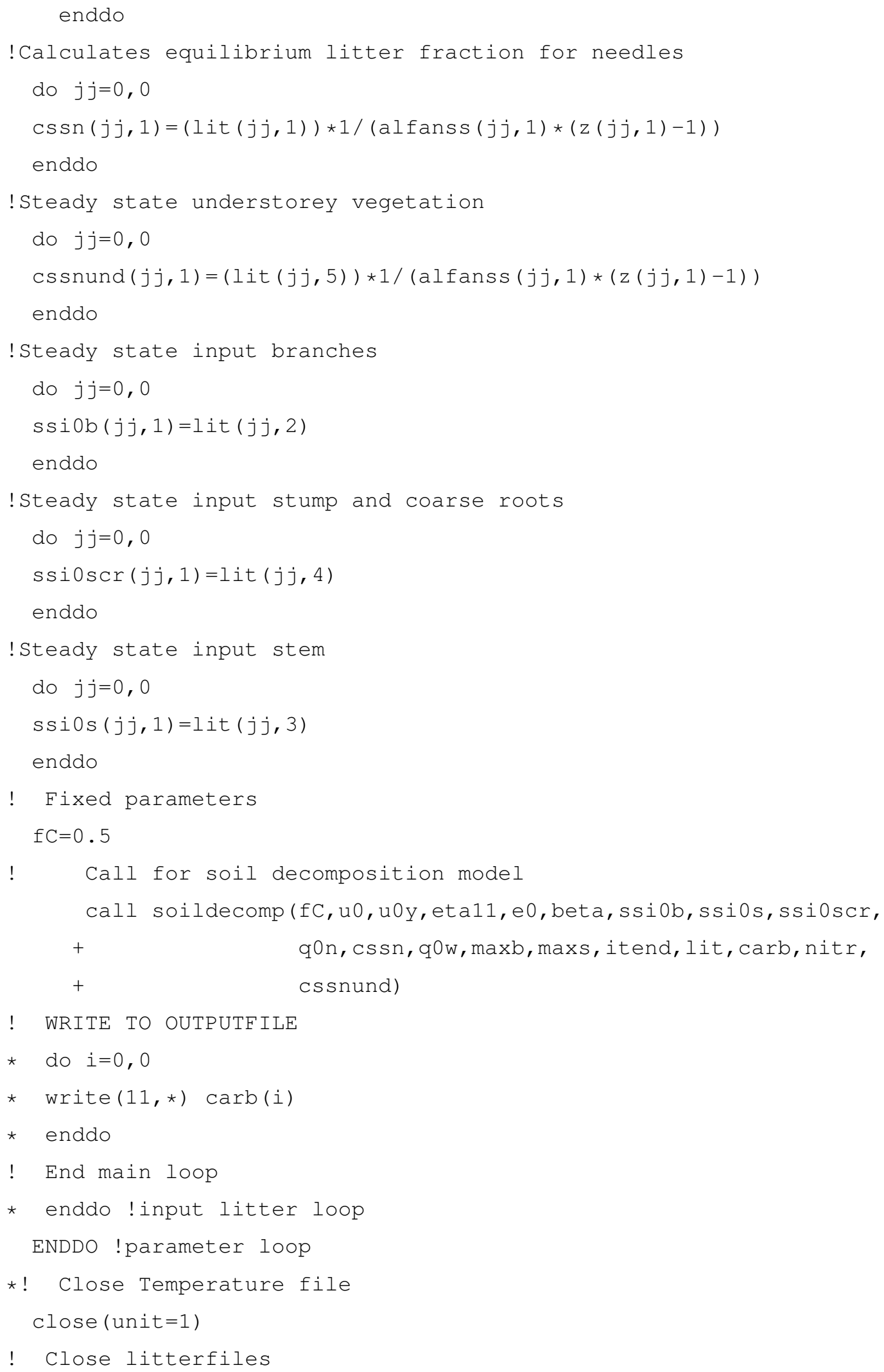




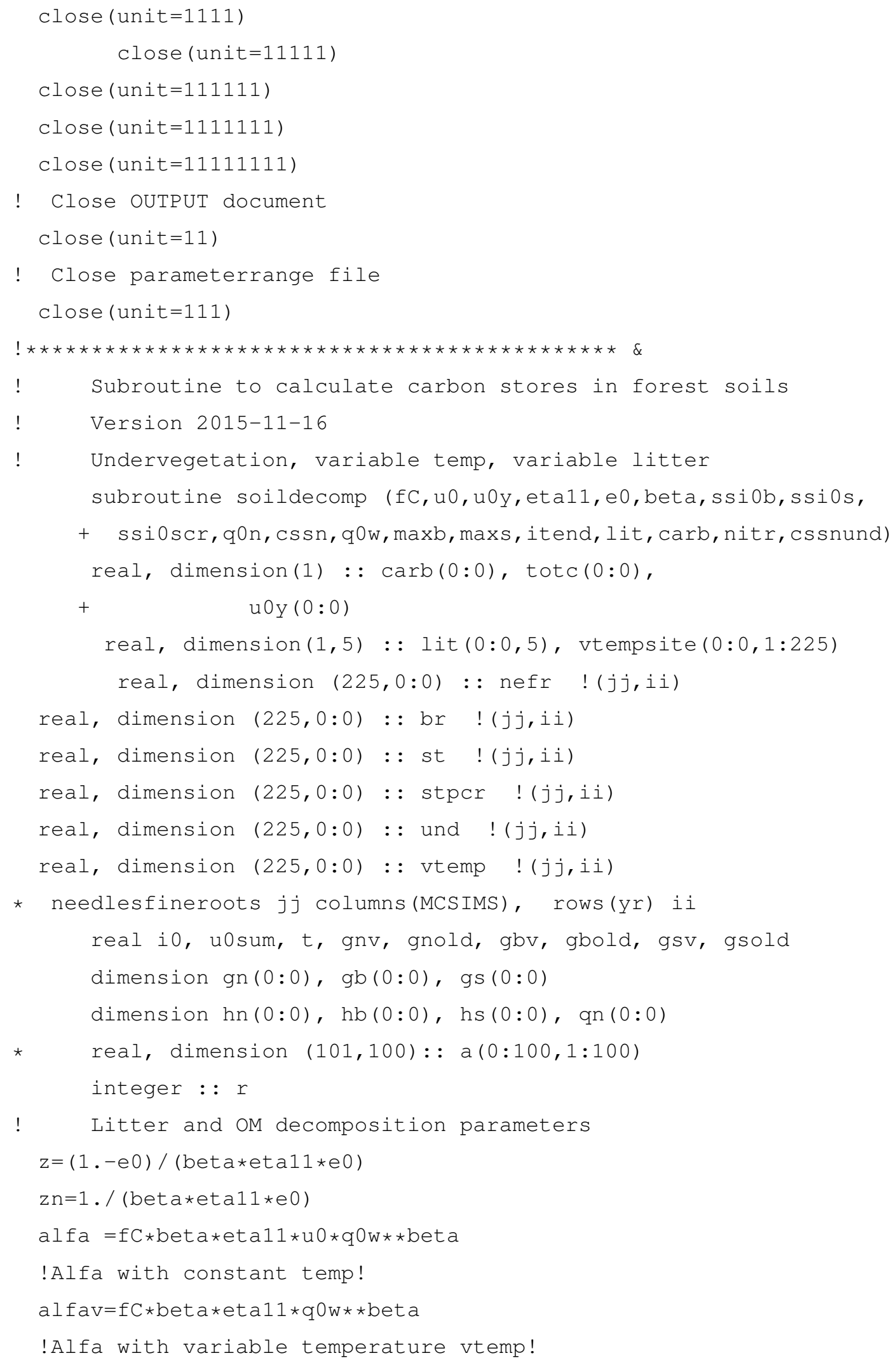




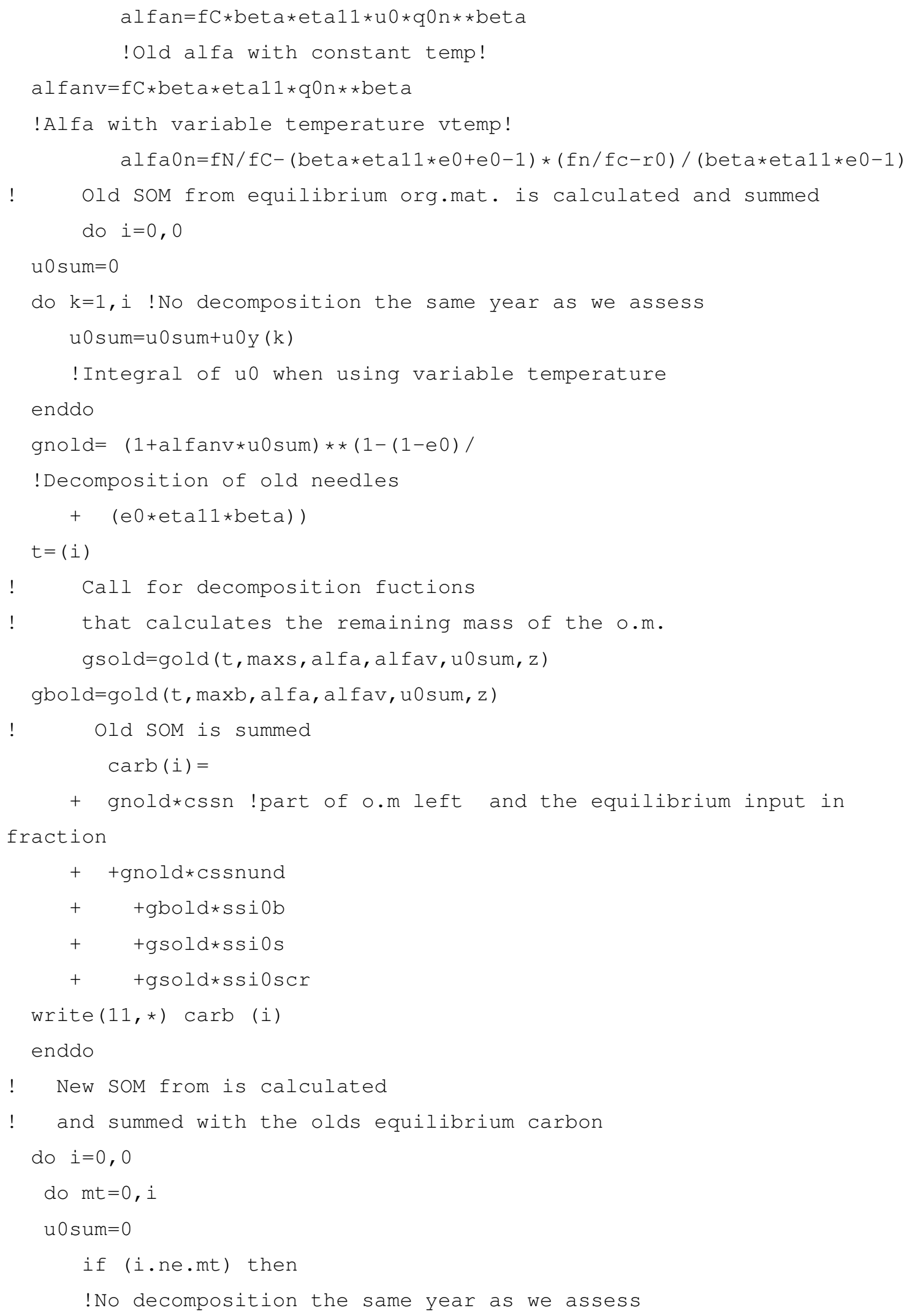




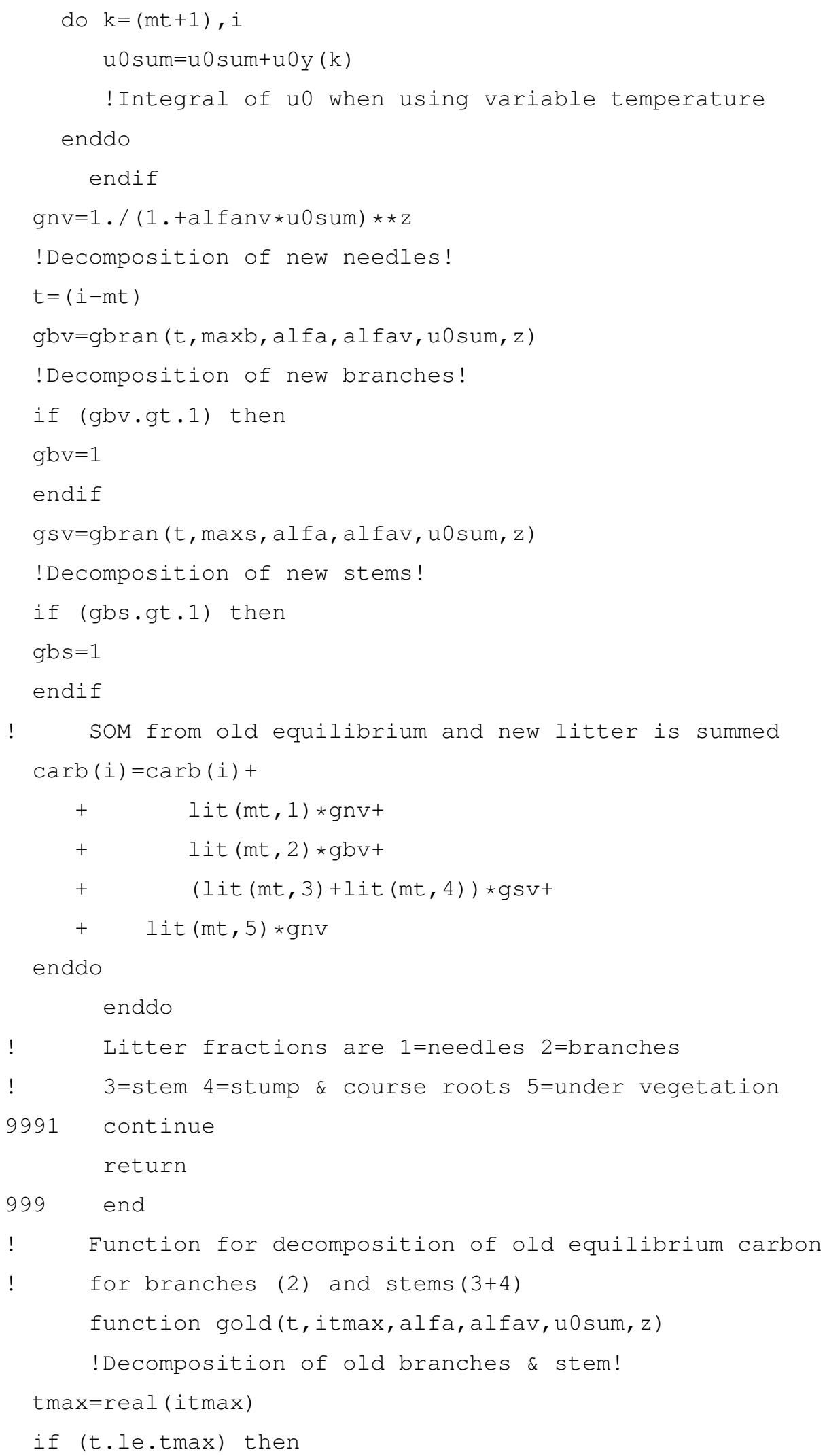




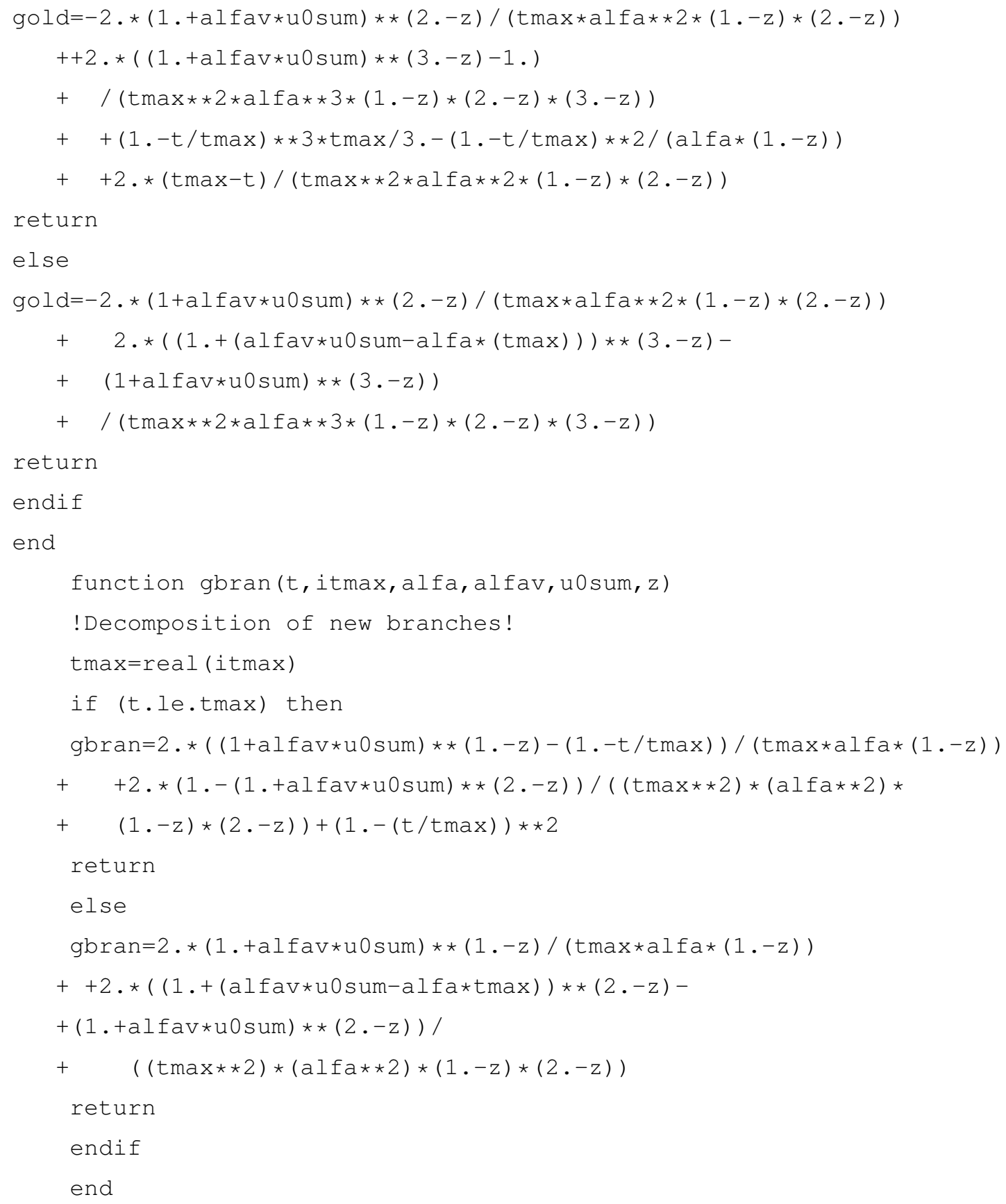

\subsection{CENTURY model}

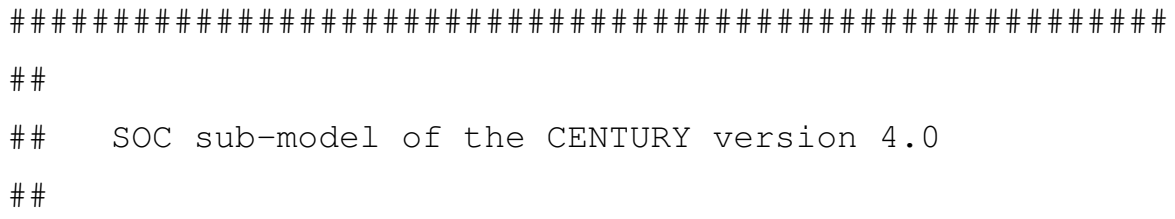




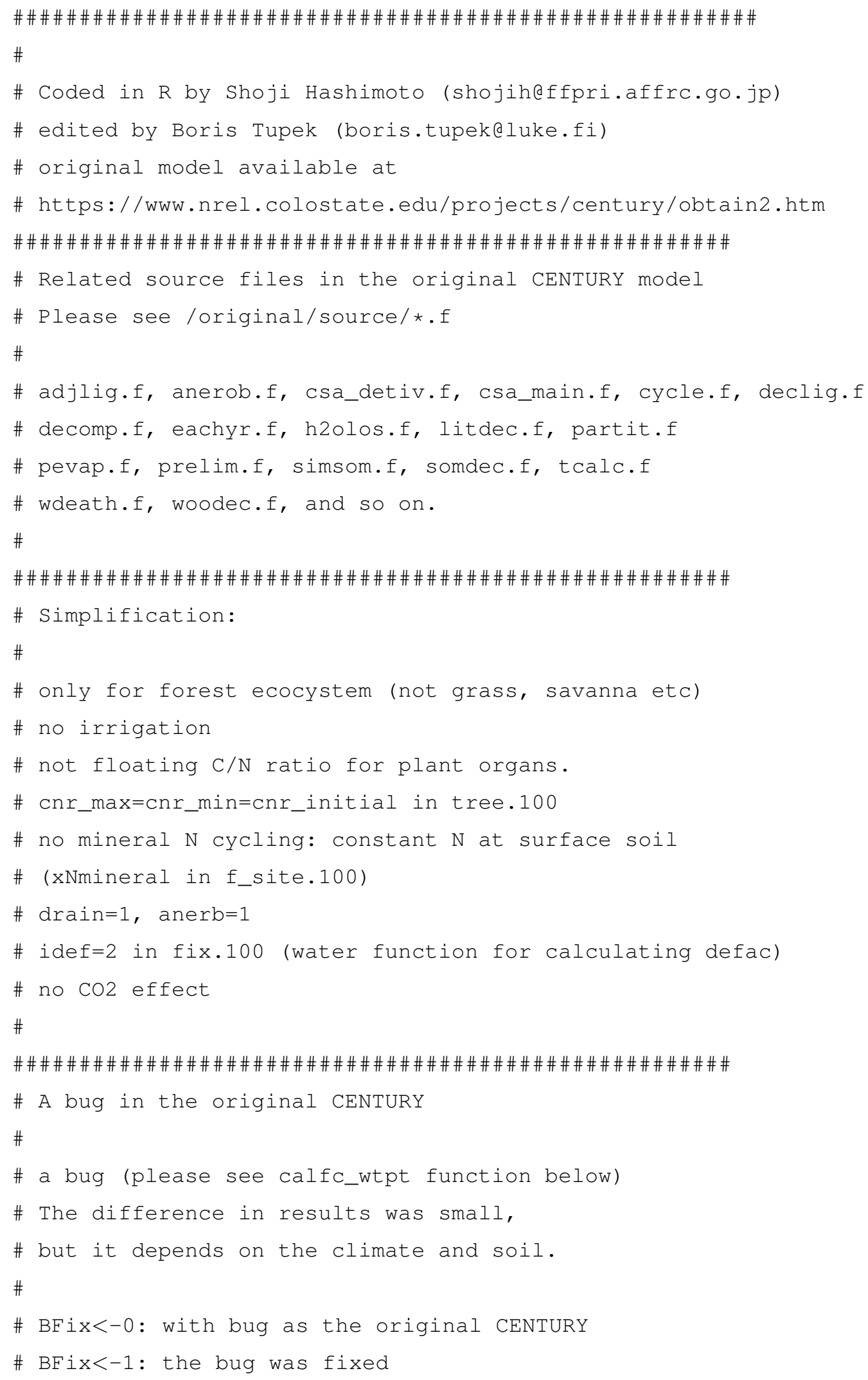




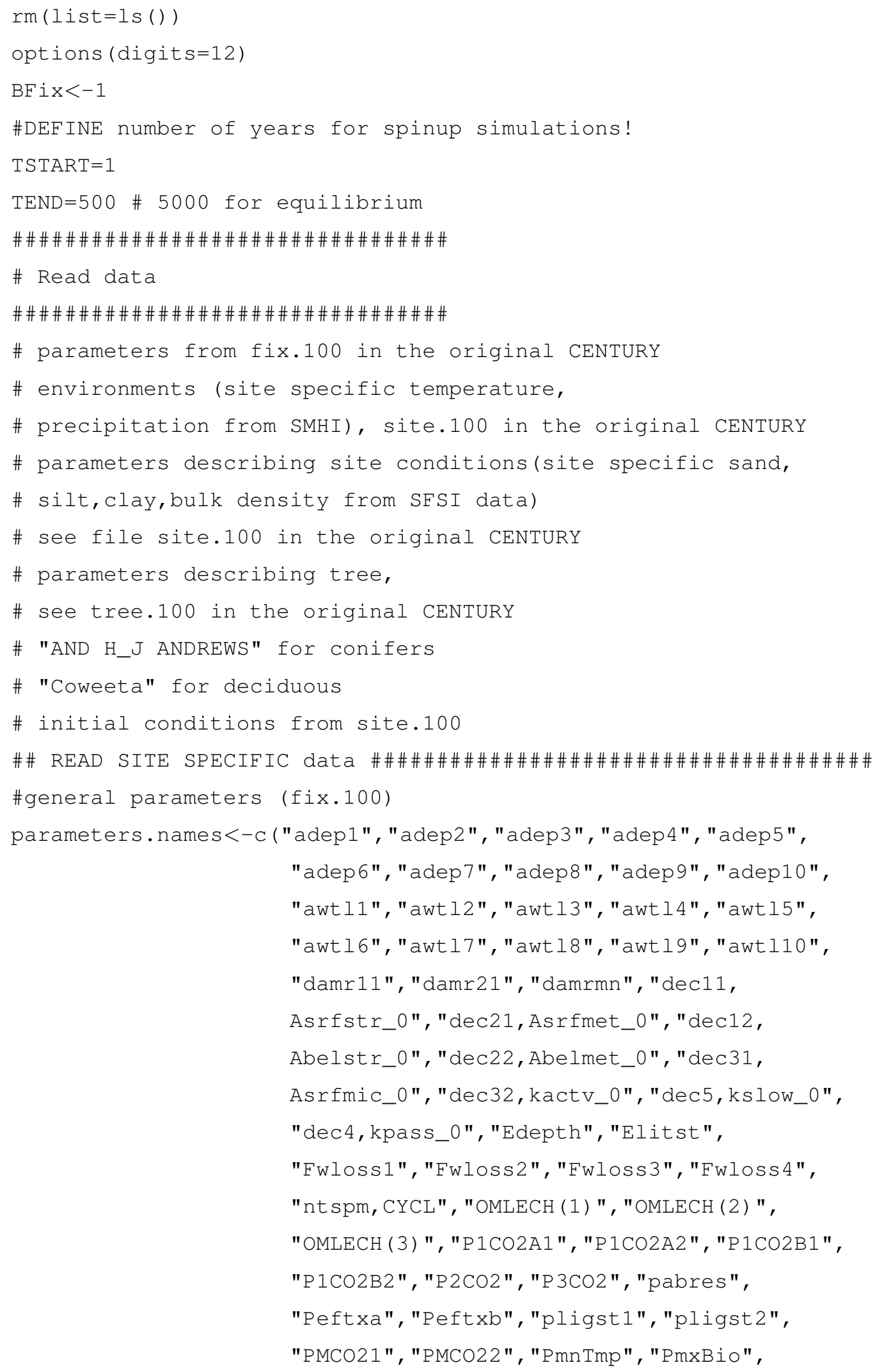




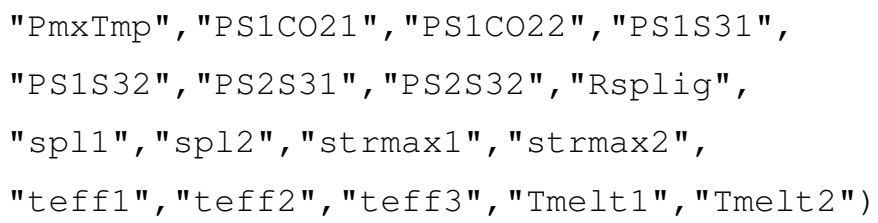

init <- data.frame (V1=init.values, V2=init.names) \#site (site.100)

site.parameters.names <-c("sitlat", "sitlog", 


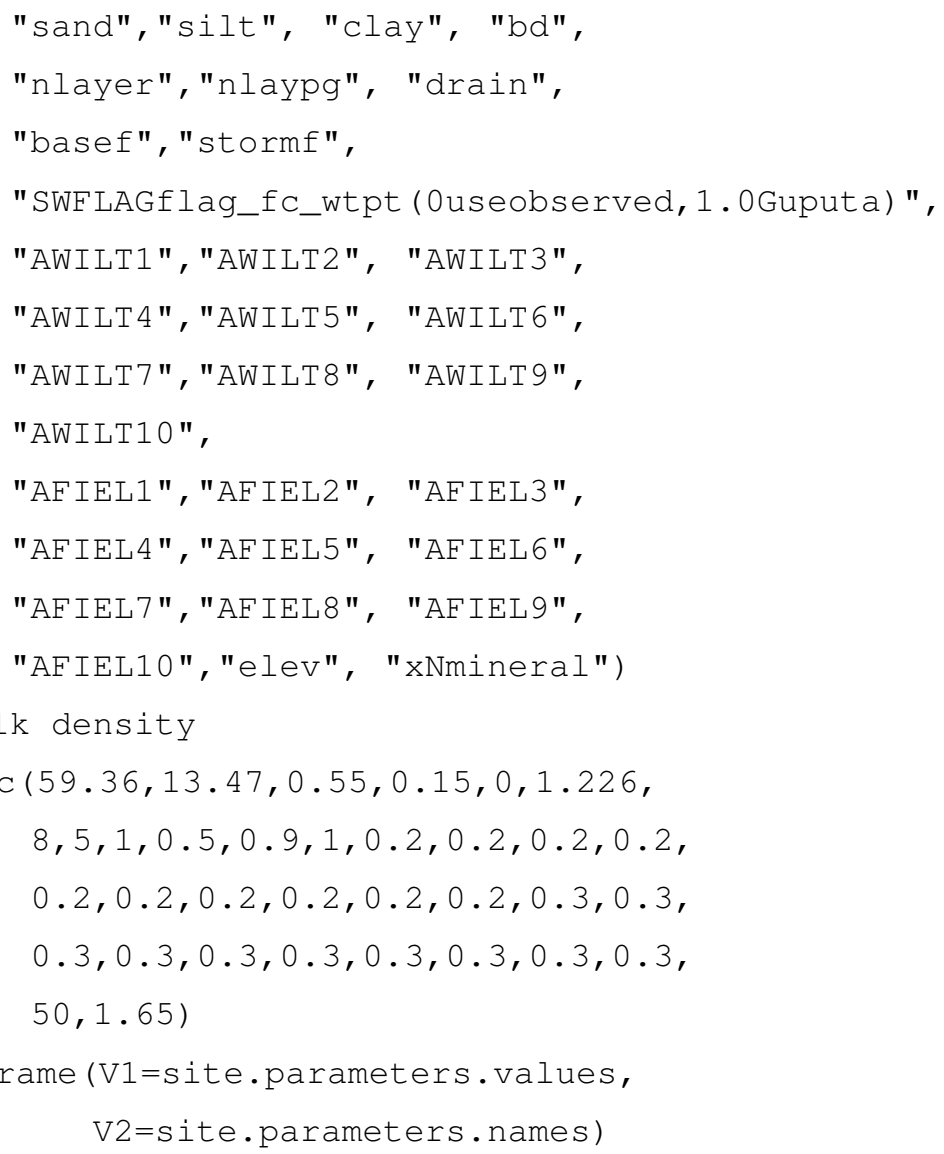


"Tmax (11) degree", "Tmax (12) degree")

envi.parameters.values <-c(3.395,2.695,2.884,3.051,3.306,

$4.471,4.623,6.016,5.494,5.221$,

$5.659,3.858,-6.647,-7.235,-4.201$,

$-0.121,4.97,9.538,11.74,11.038,7.266$,

$3.379,-1.027,-5.32,-0.782,-0.375,3.613$,

$9.369,15.549,19.758,21.351,20.219$,

$15.489,9.915,4.286,0.584)$

envi.parameters <- data.frame (V1=envi.parameters.values,

$\mathrm{V} 2=$ envi.parameters.names)

\#tree

tree.parameters.names <-c("cerfor $(1: 2: 3,1,1)$, cnr_fol",

"cerfor $(1: 2: 3,3,1)$, chr_bra",

"cerfor $(1: 2: 3,4,1)$, chr_ste",

"cerfor $(1: 2: 3,2,1)$, chr_fir",

"cerfor $(1: 2: 3,5,1)$, chr_cor",

"DECW1, kwood1_0, bra", "DECW2,

kwood2_0, ste", "DECW3, kwood3_0, cor",

"forrtf", "leafdr1", "leafdr2",

"leafdr3", "leafdr4", "leafdr5",

"leafdr6","leafdr7", "leafdr8",

"leafdr9", "leafdr10", "leafdr11",

"leafdr12",

"wdlig1, cfol_lig", "wdlig3, cbra_lig",

"wdlig4, cste_lig", "wdlig2, cfir_lig",

"wdlig5, ccor_lig",

"wooddrlfol", "wooddr3bra",

"wooddr4ste", "wooddr2fir", "wooddr5cor")

tree.parameters.values <-c $(20,99,140,40,83,1.5,0.5,0.6$,

$0.5,0,0,0,0.002,0.006,0.012$,

$0.013,0.039,0.175,0.664,0.066$,

$0.023,0.223,0.25,0.25,0.25,0.25$,

$1,0.01,0.002,0.04,0.004)$

tree.parameters $<-$ data.frame (V1=tree.parameters.values,

$\mathrm{V} 2=$ tree $\cdot$ parameters . names)

\# biomass components gC.m-2

biomass.in $<-$ data.frame(id=1, 


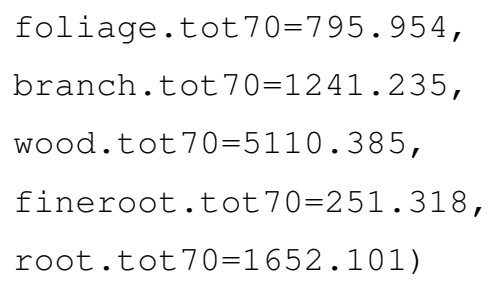




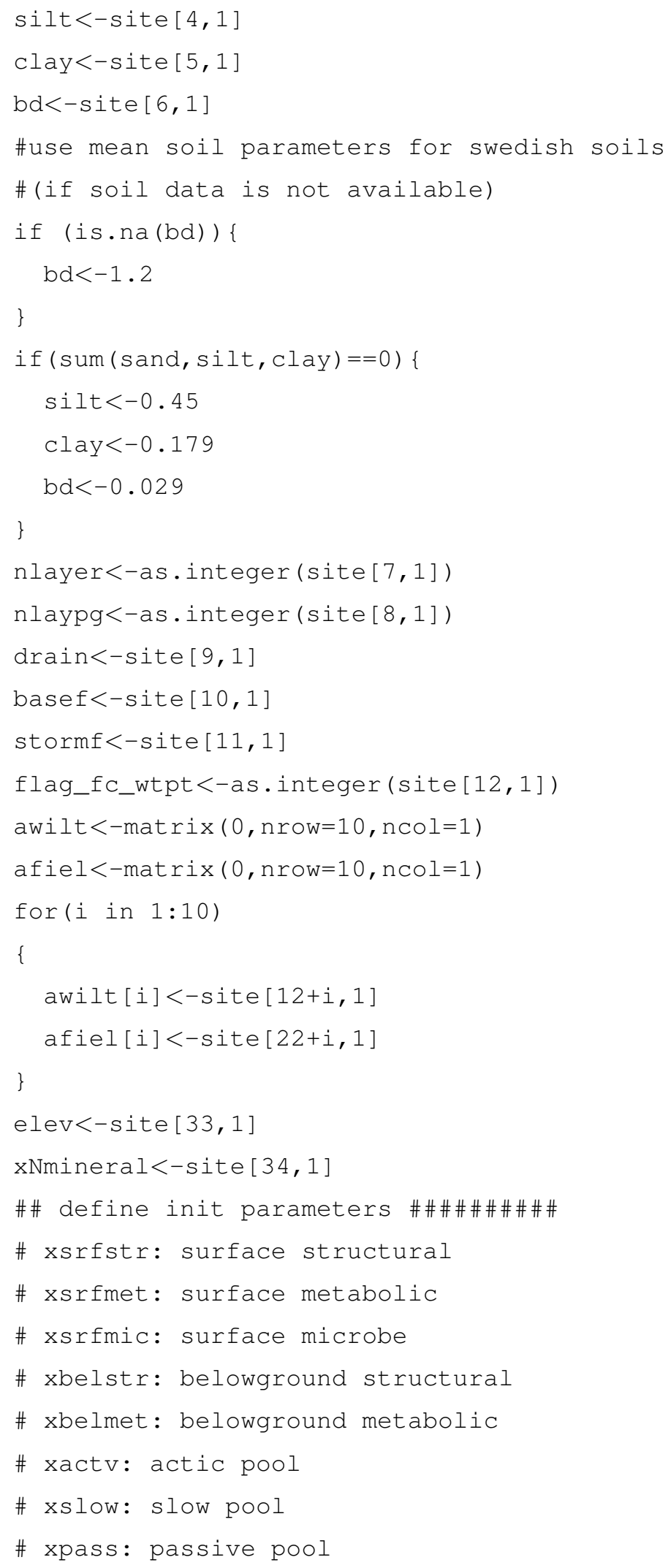




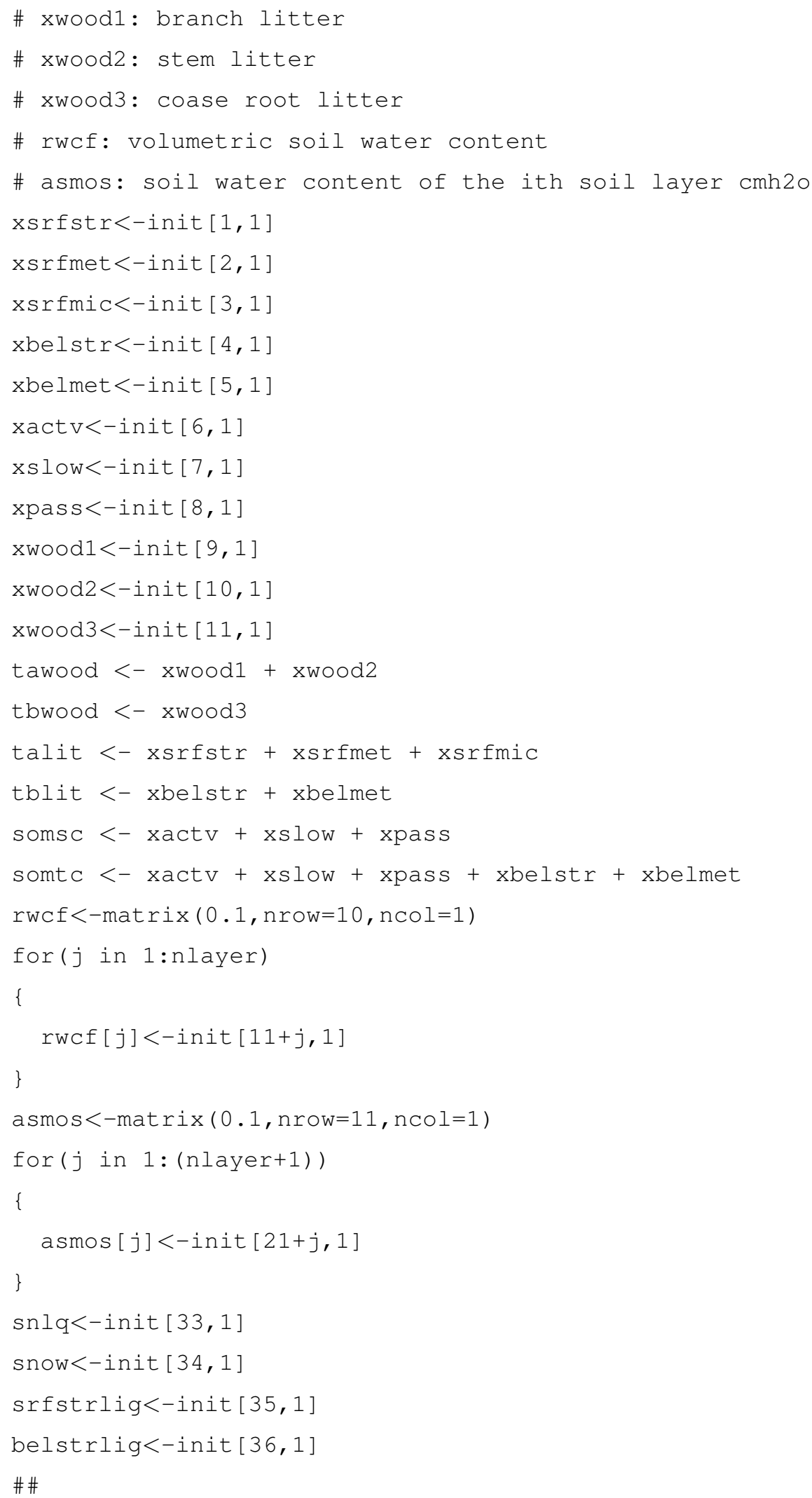




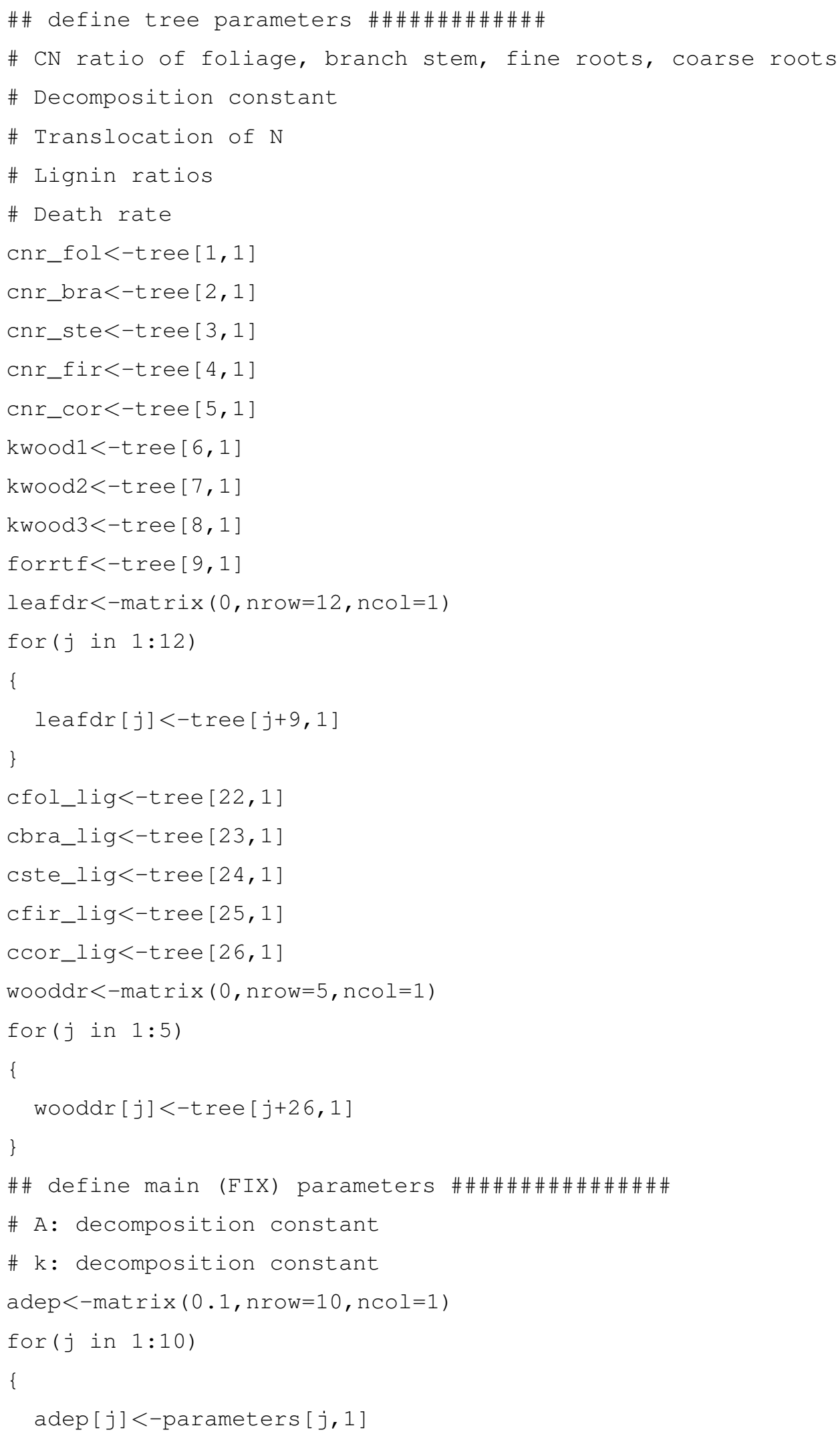




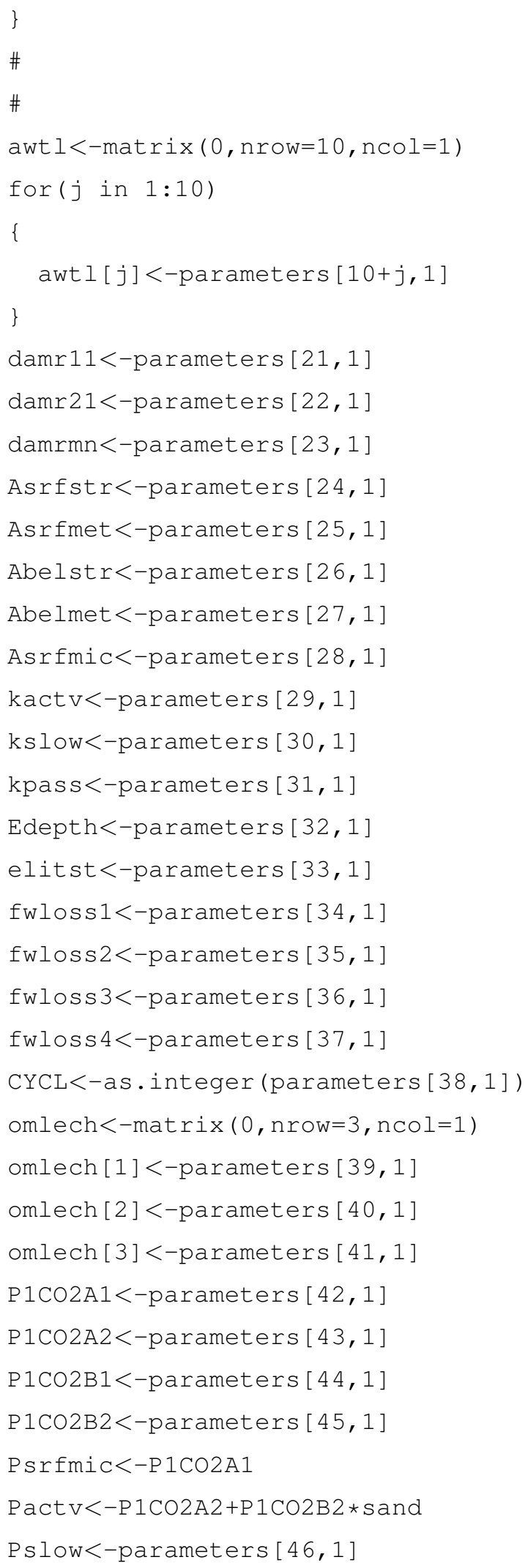




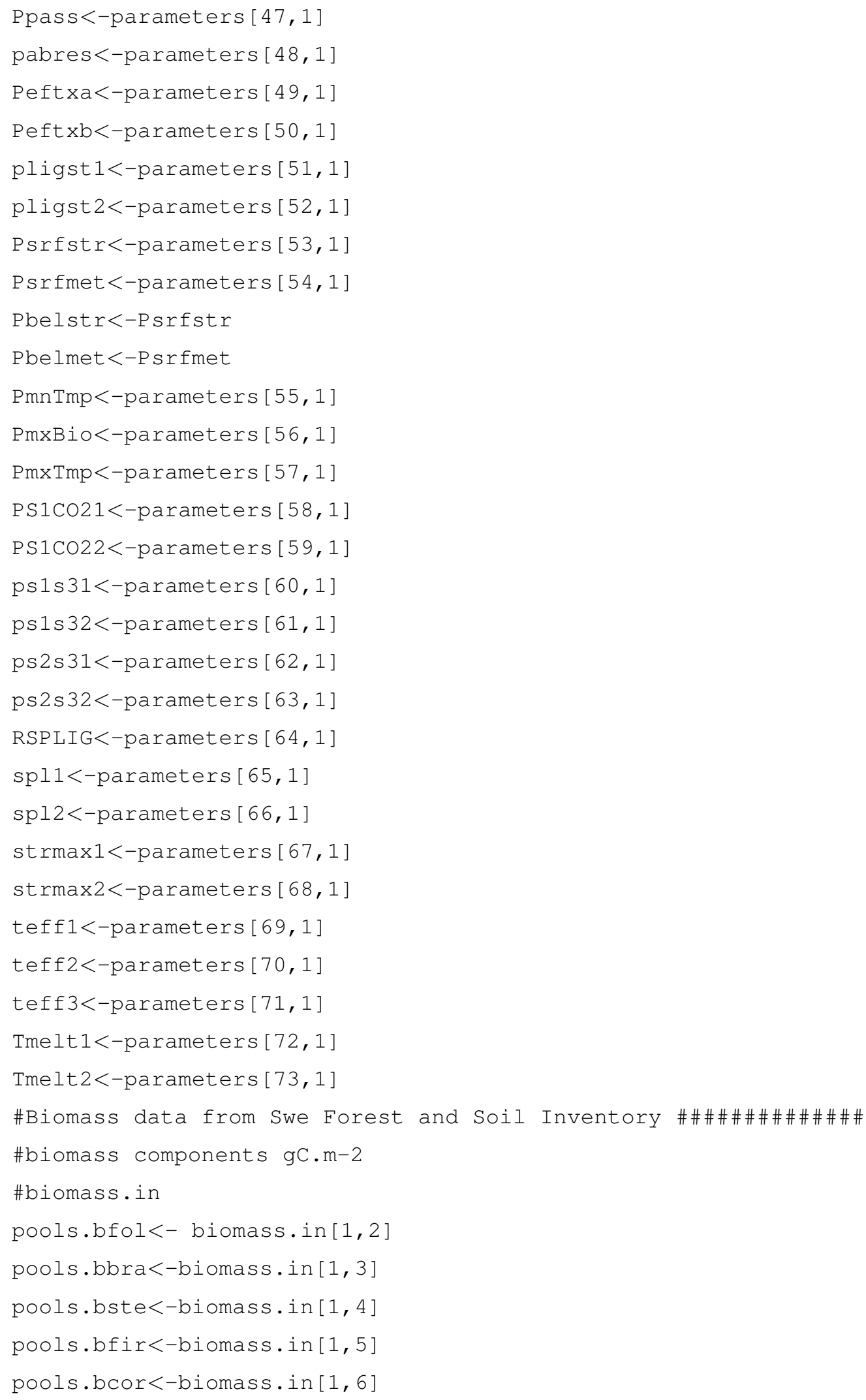




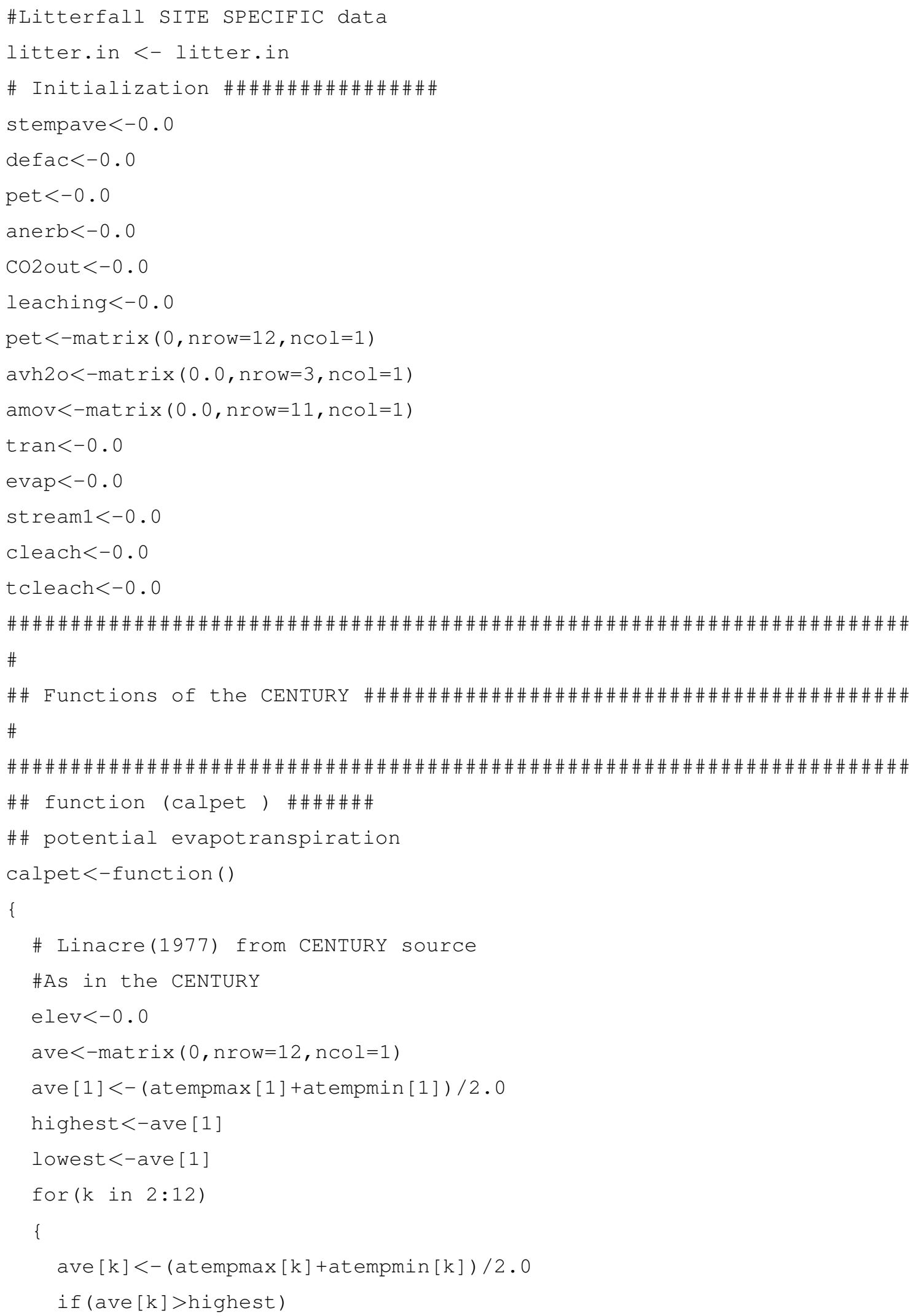




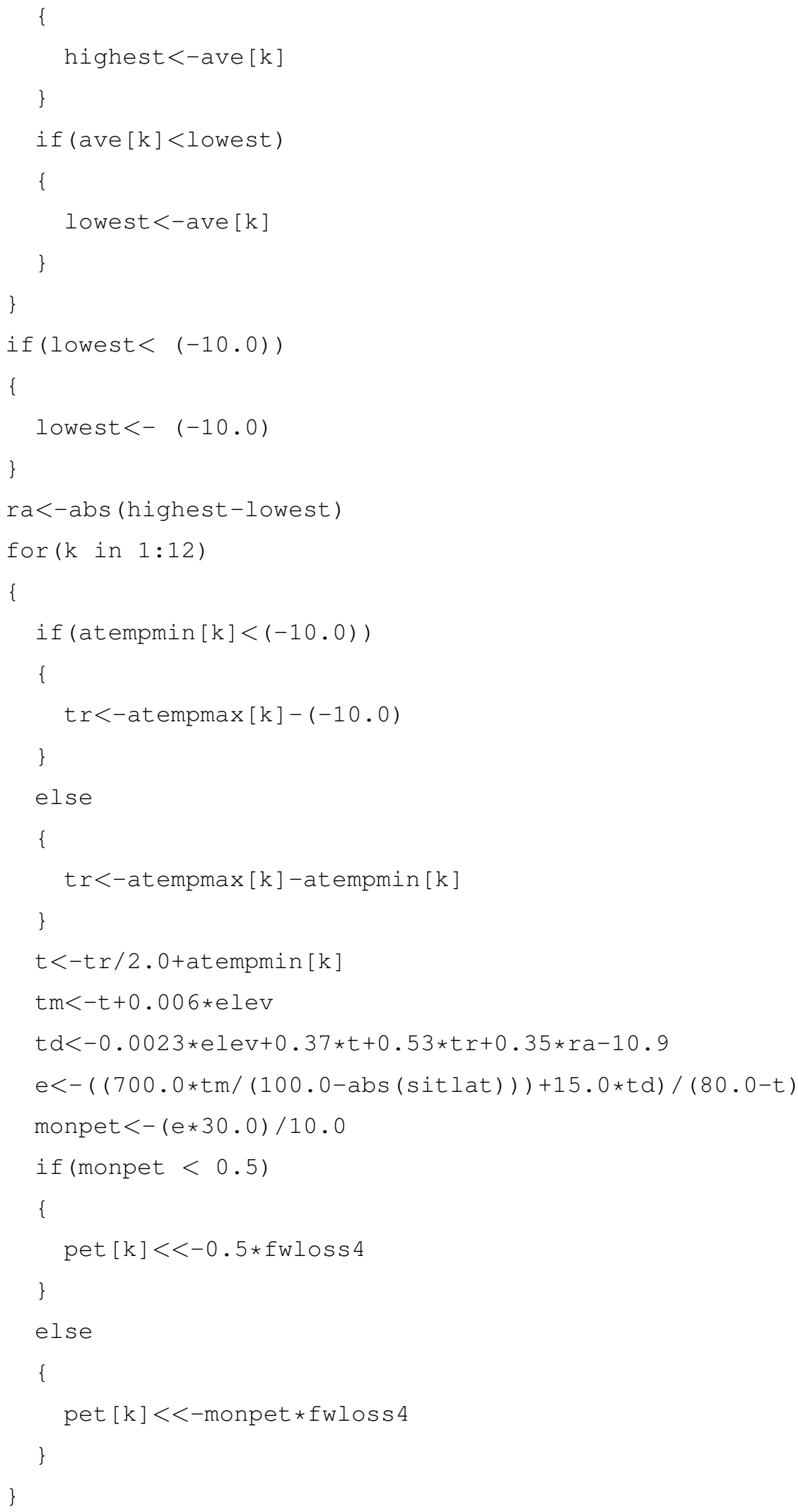




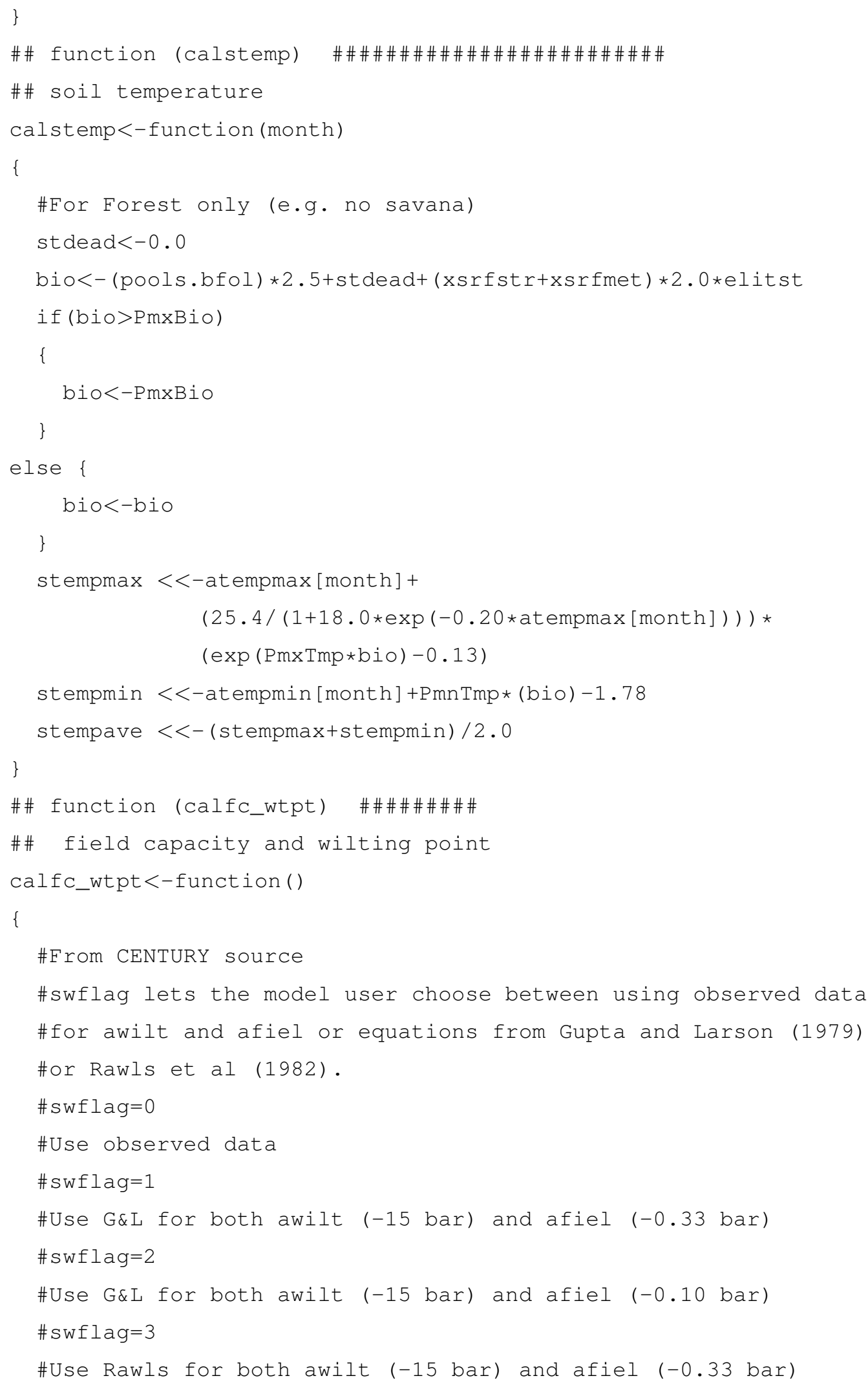




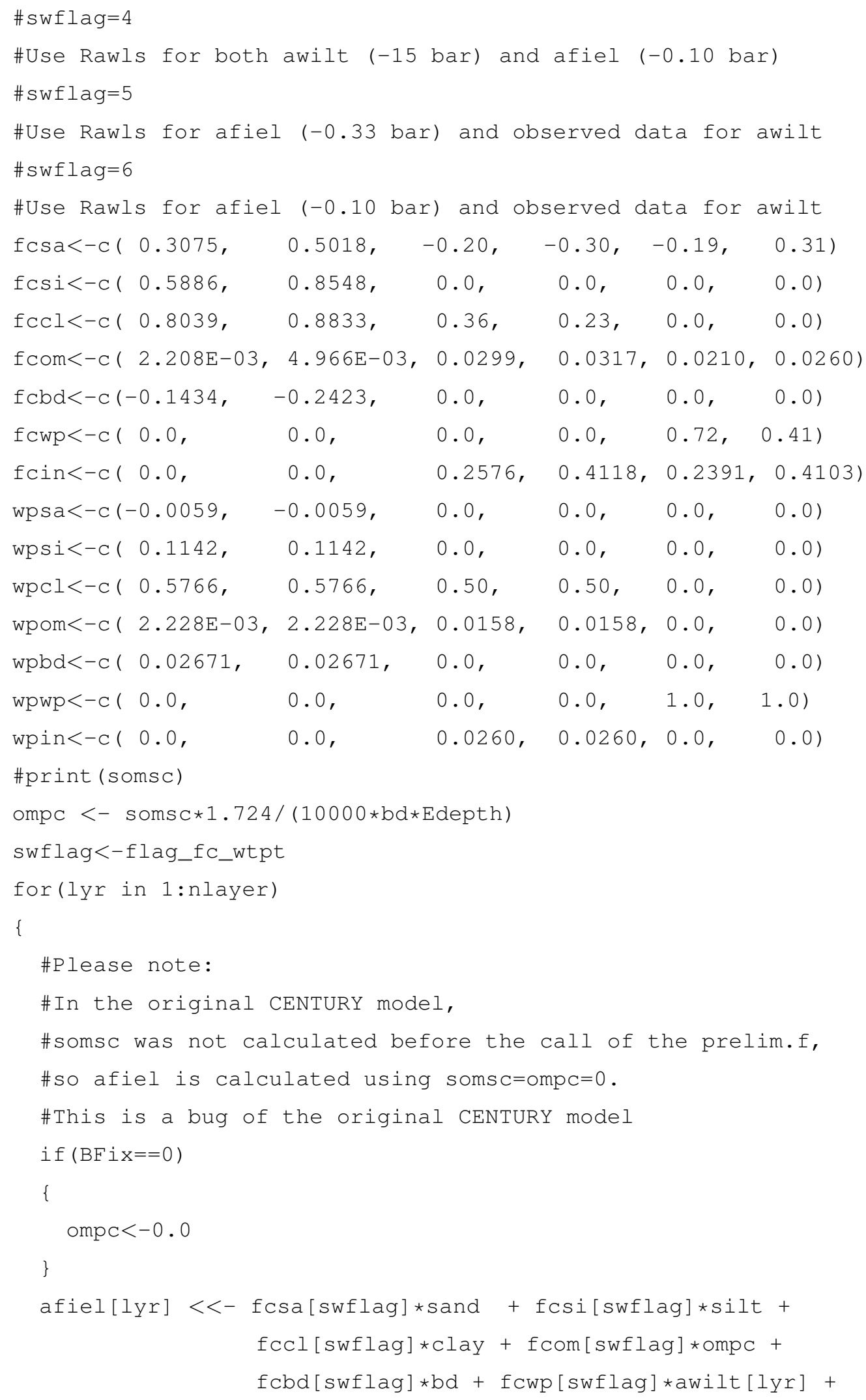




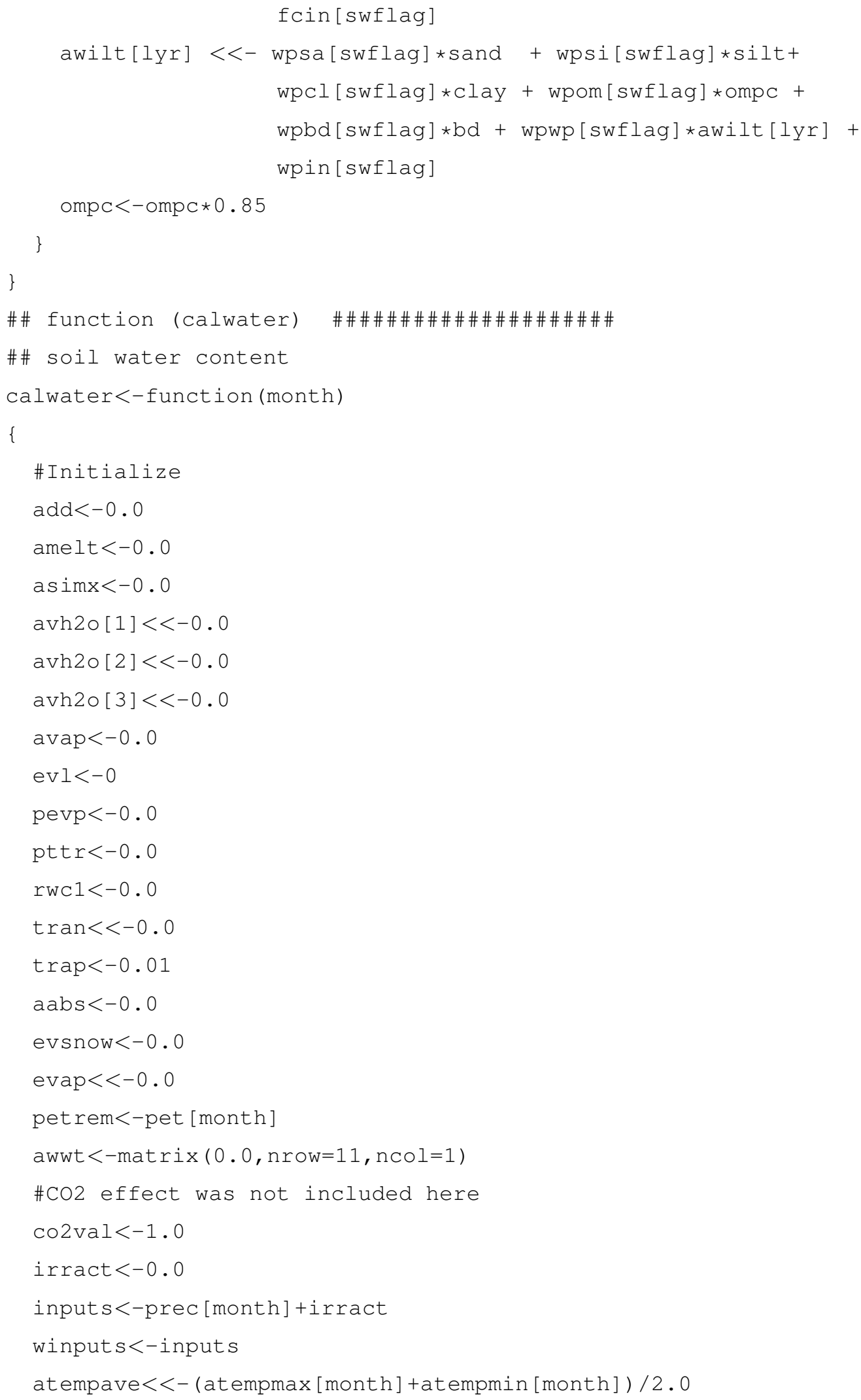




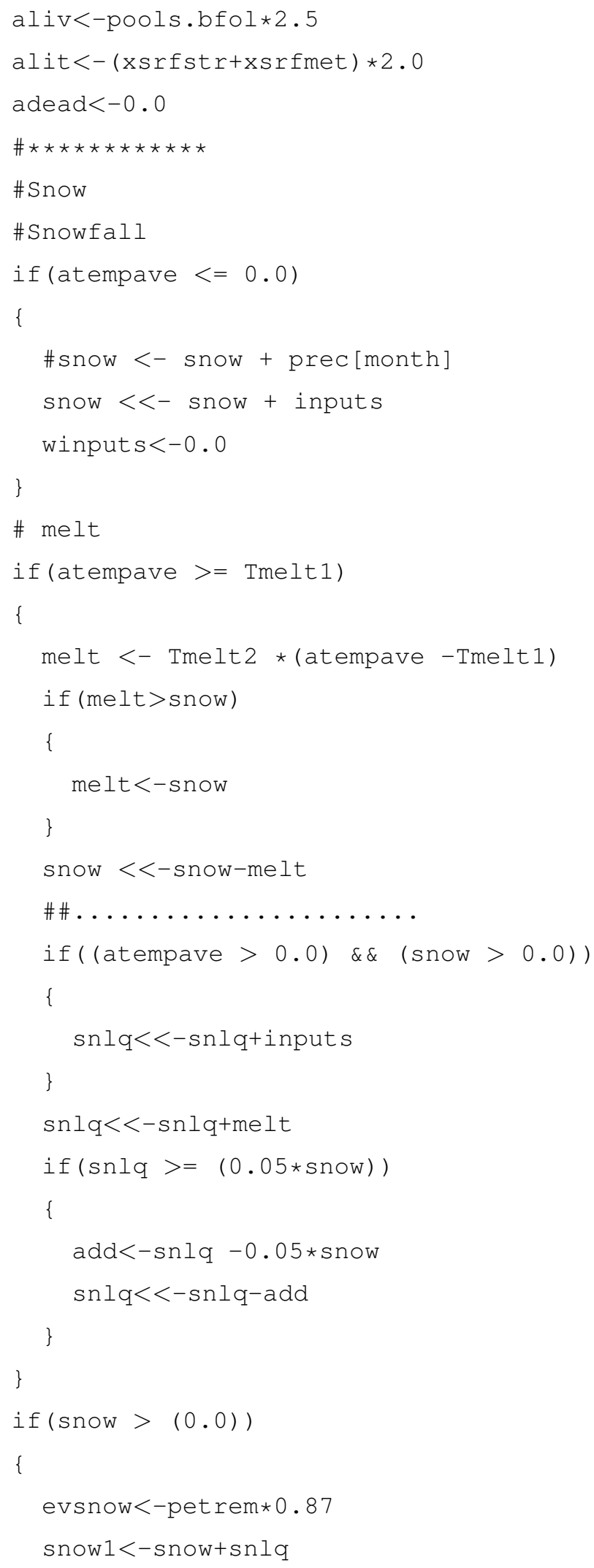




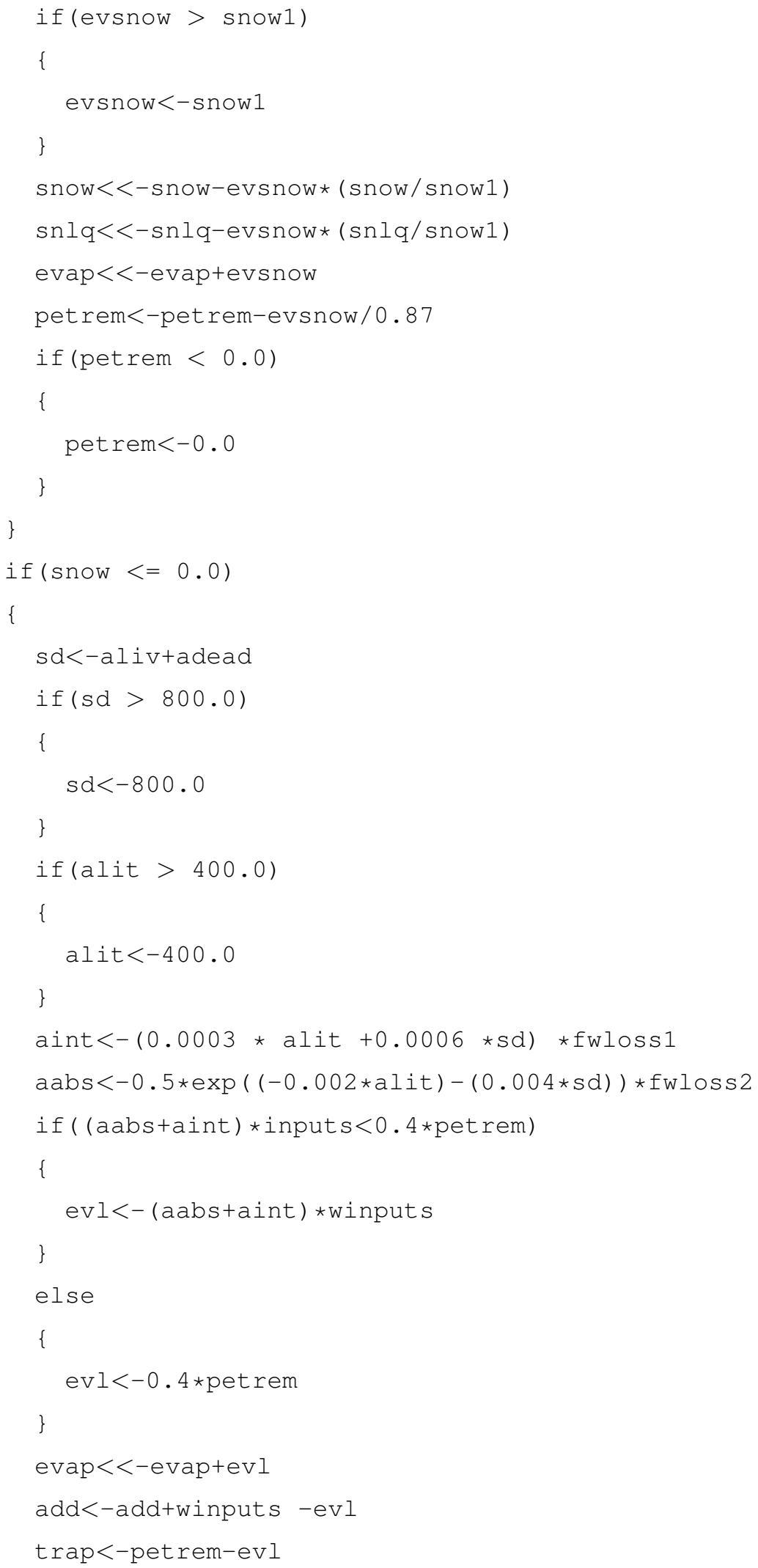




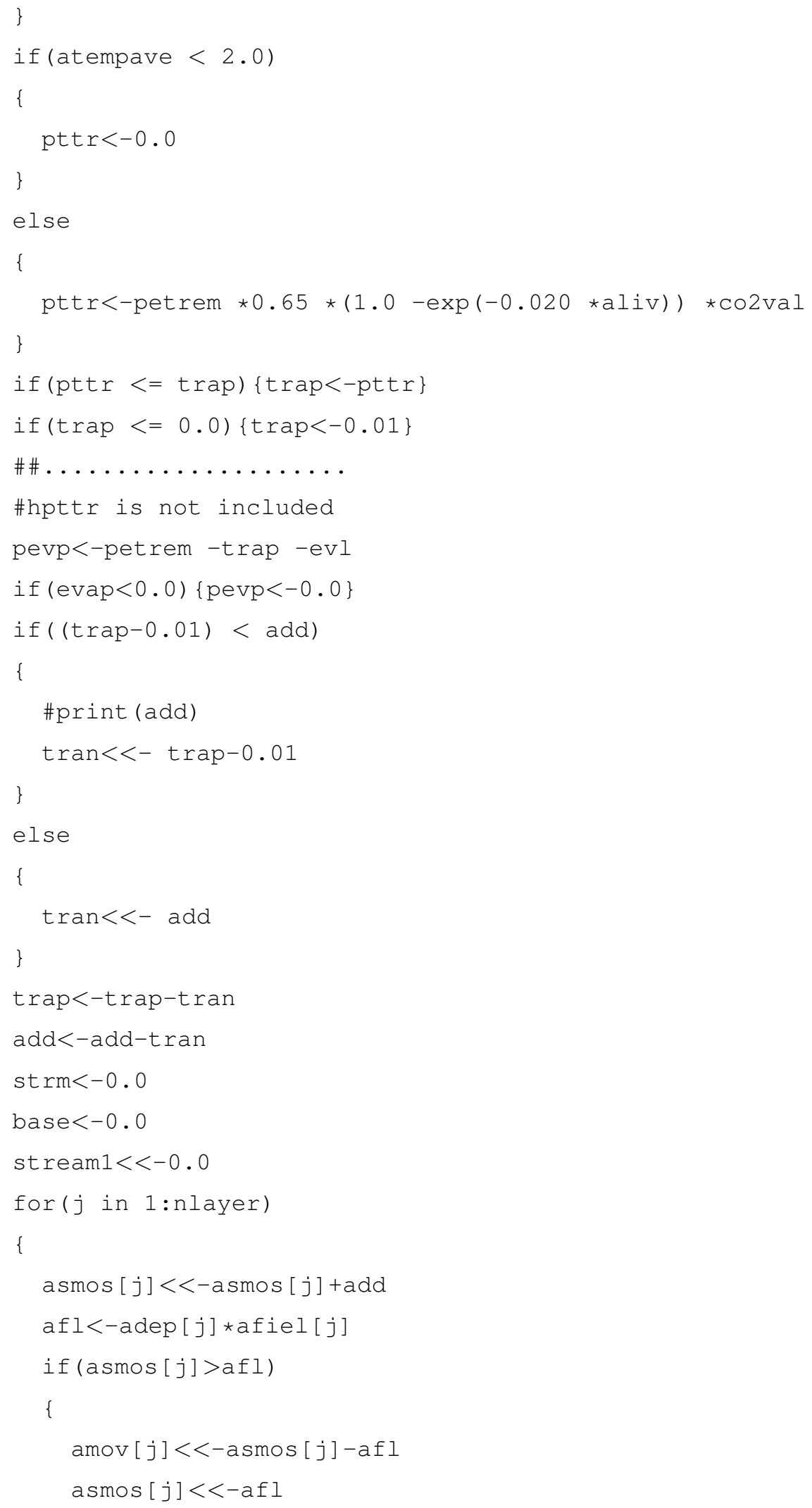




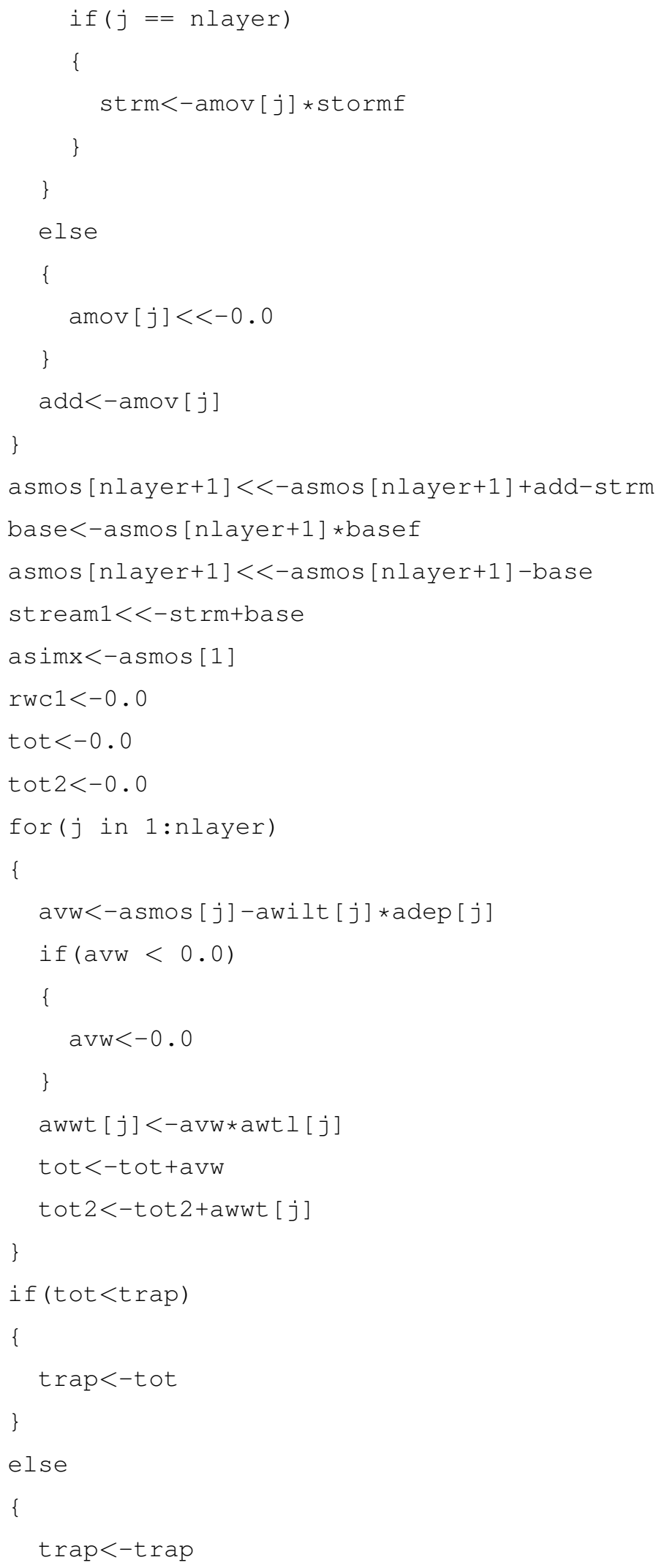




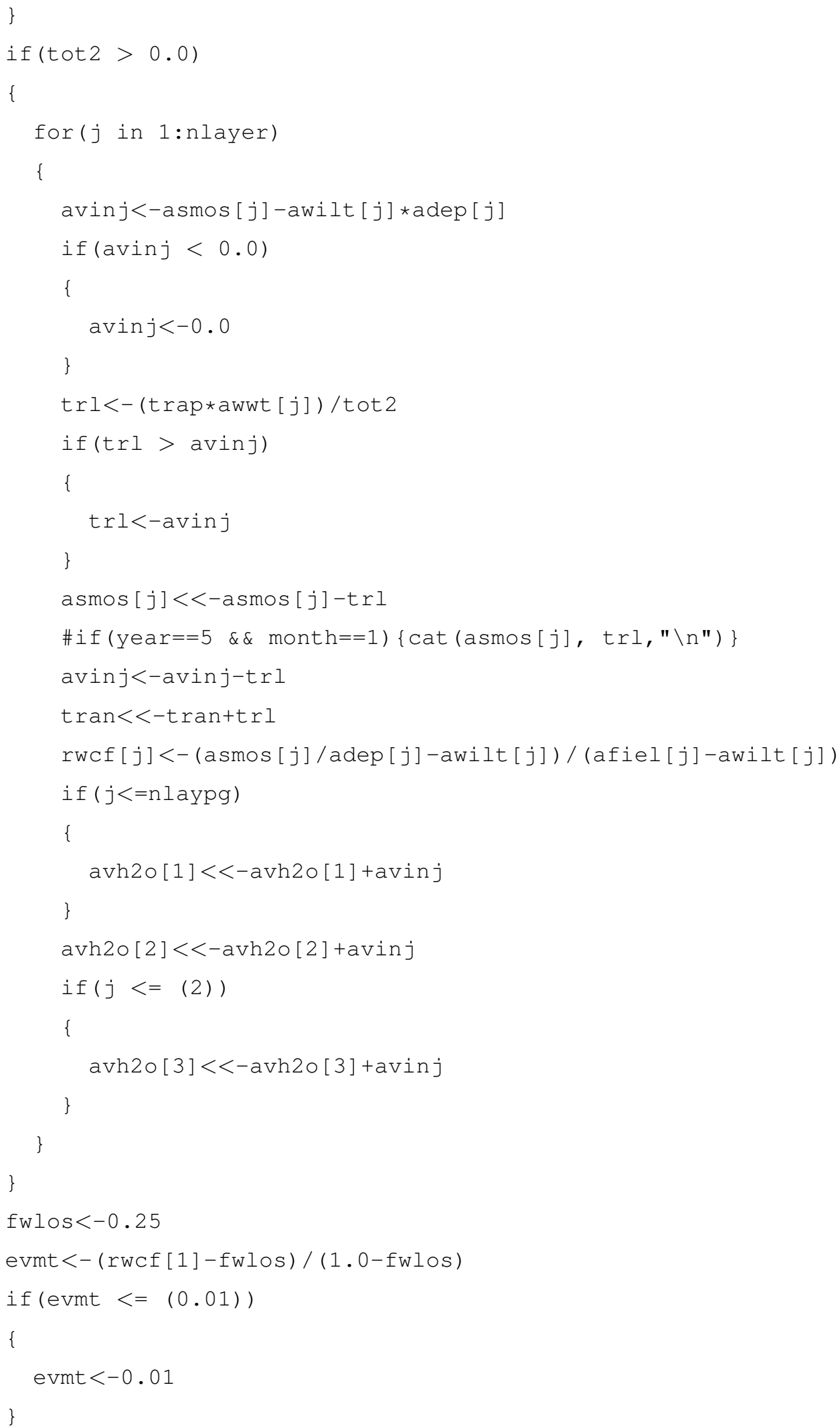




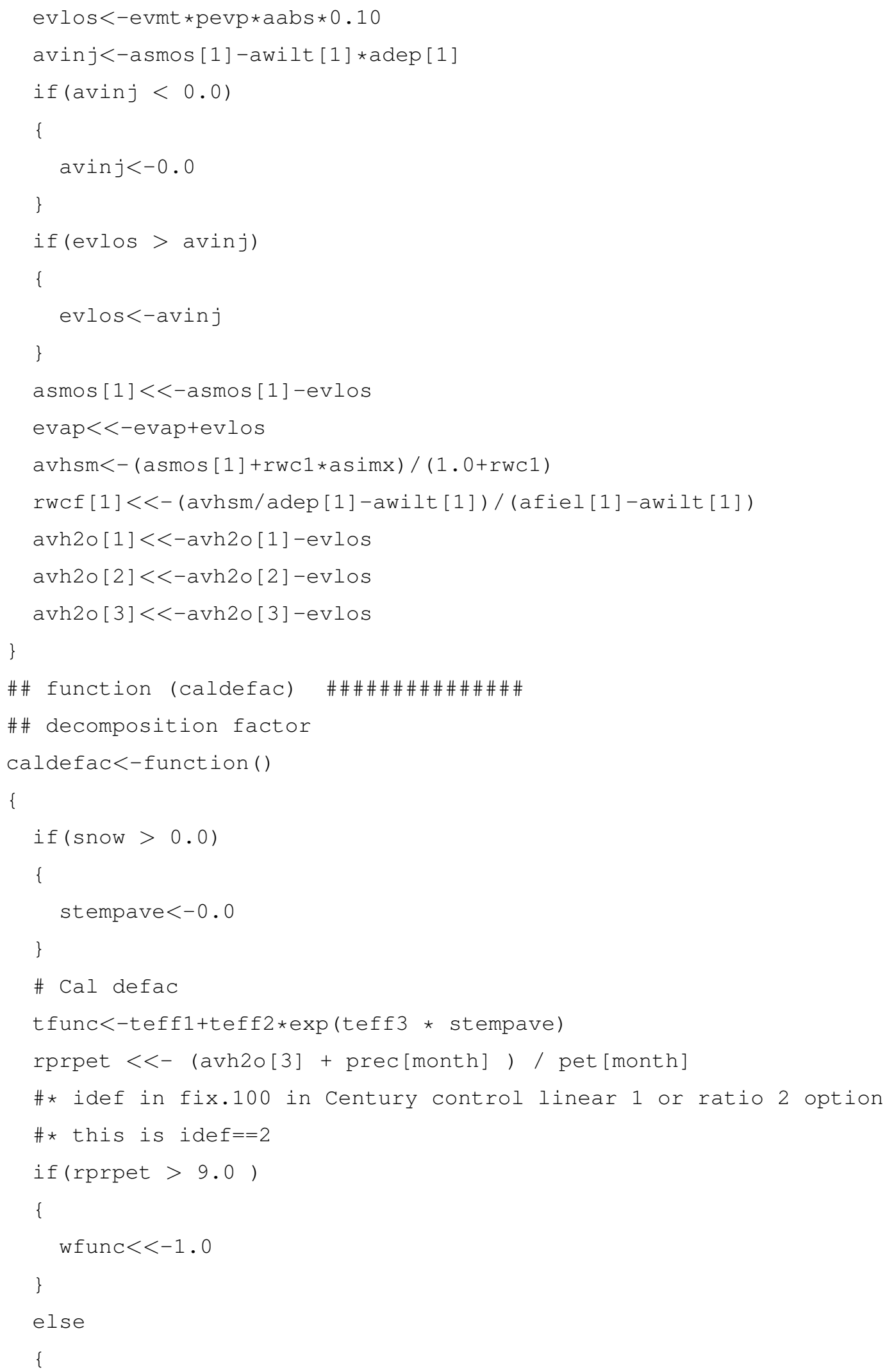




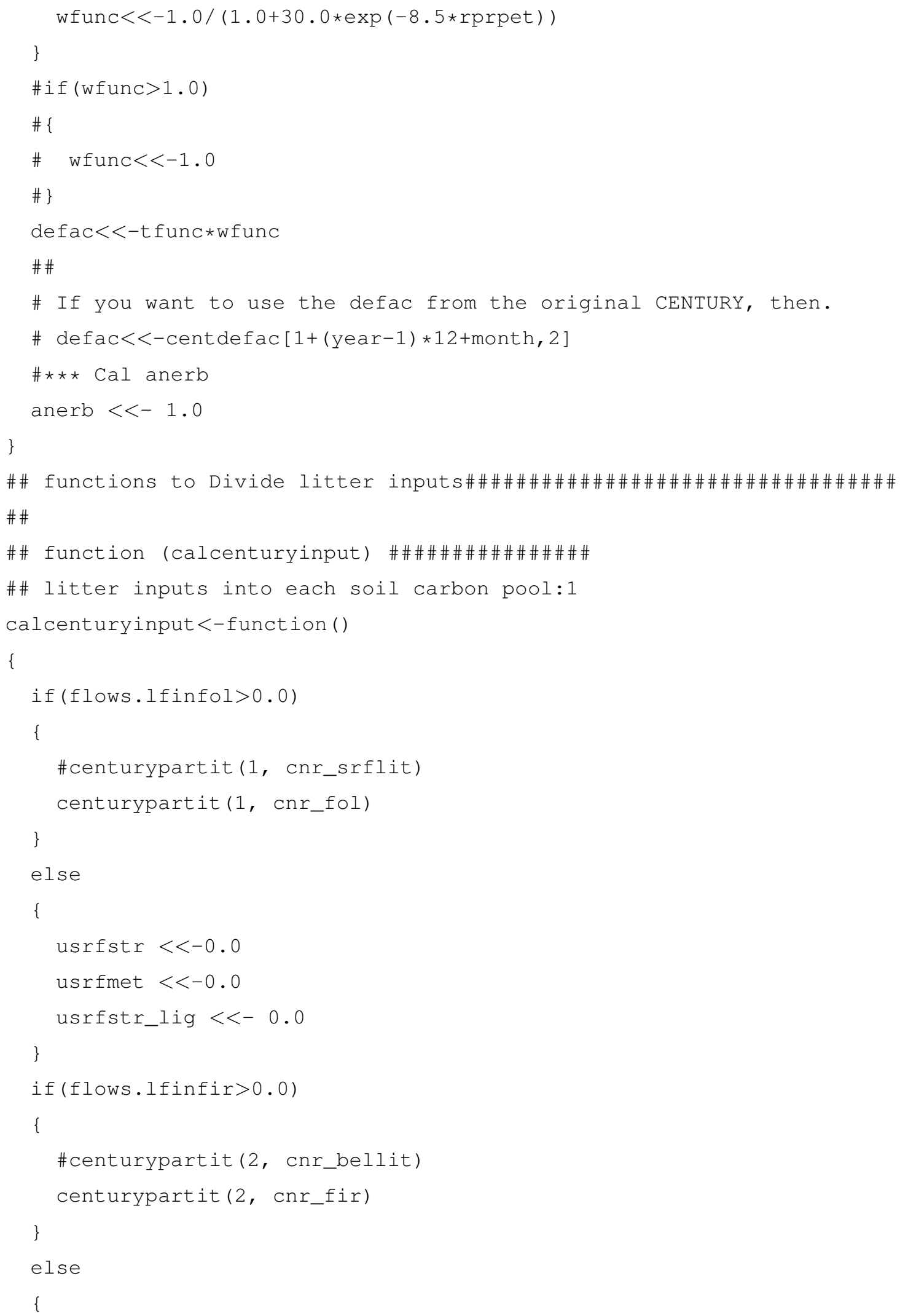




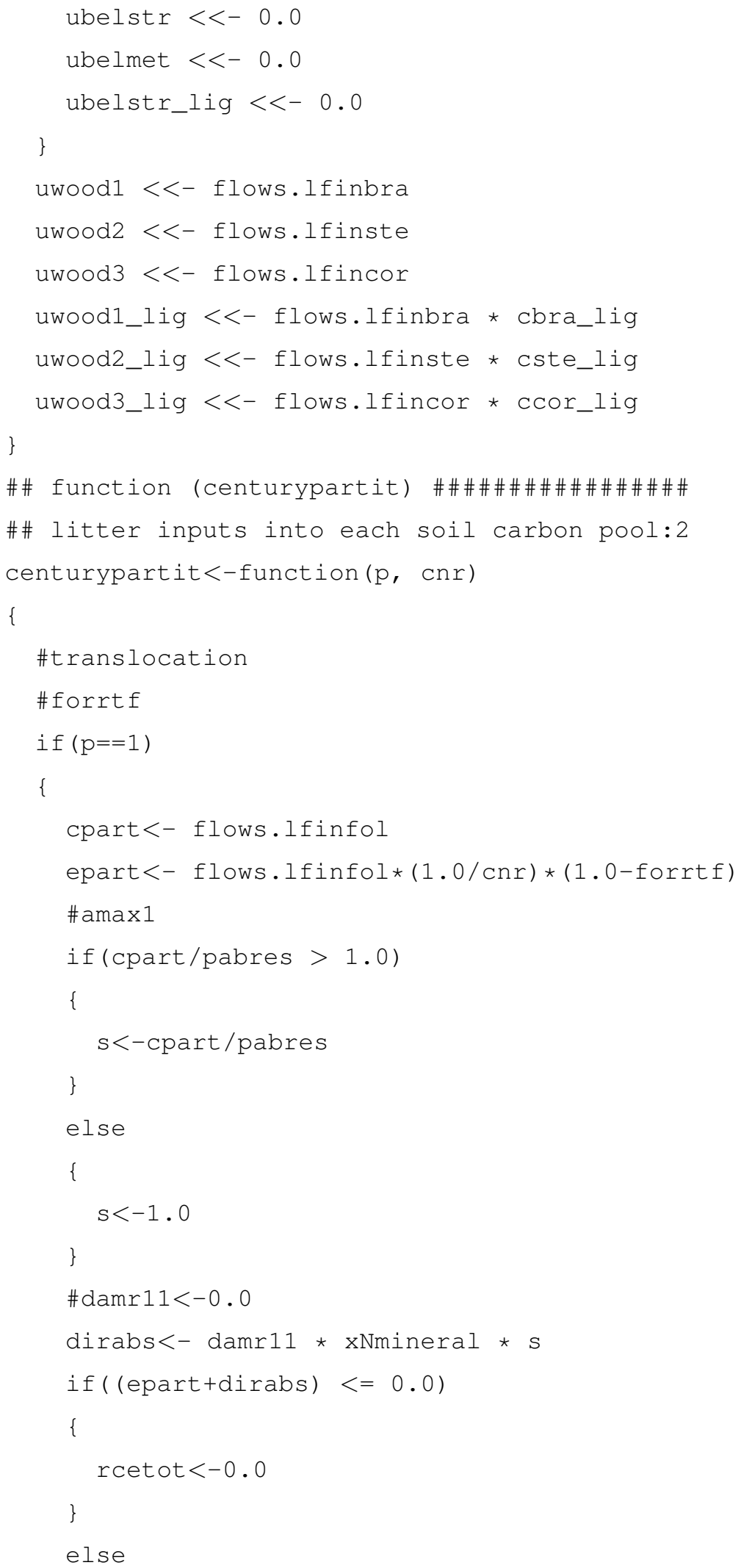




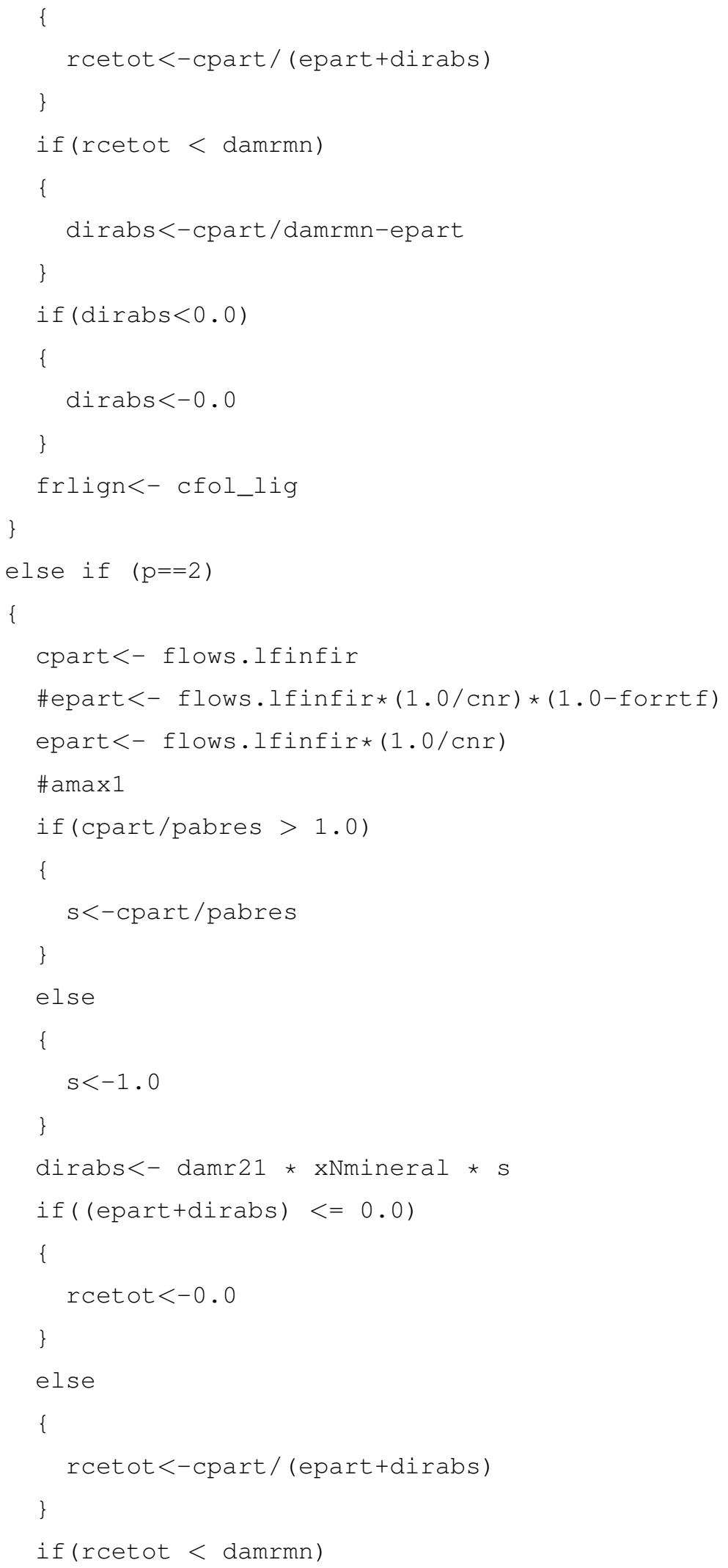




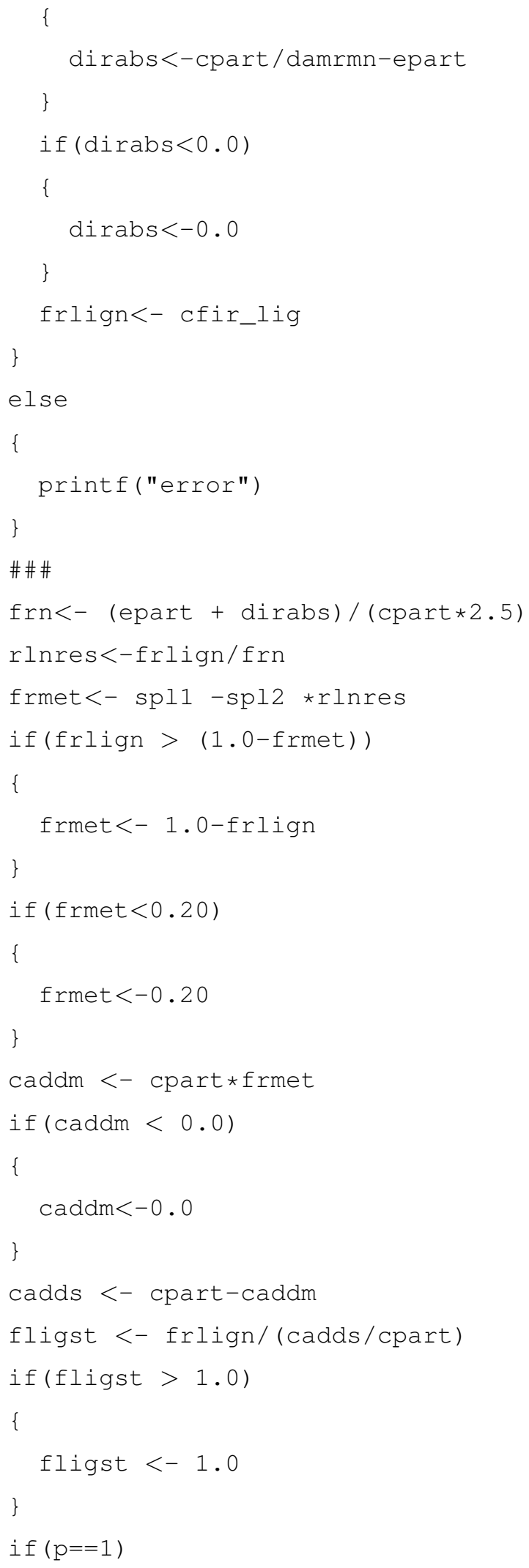




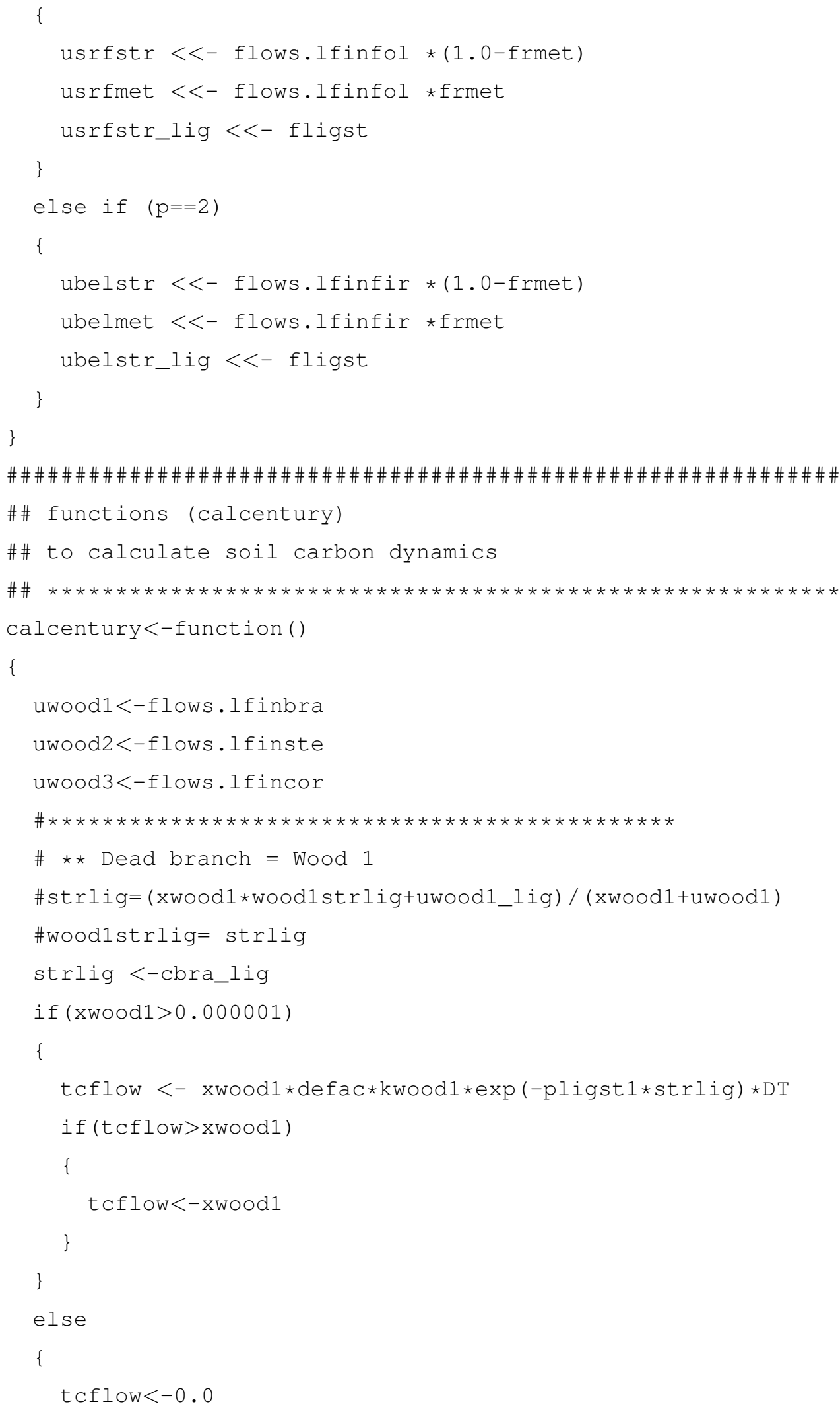




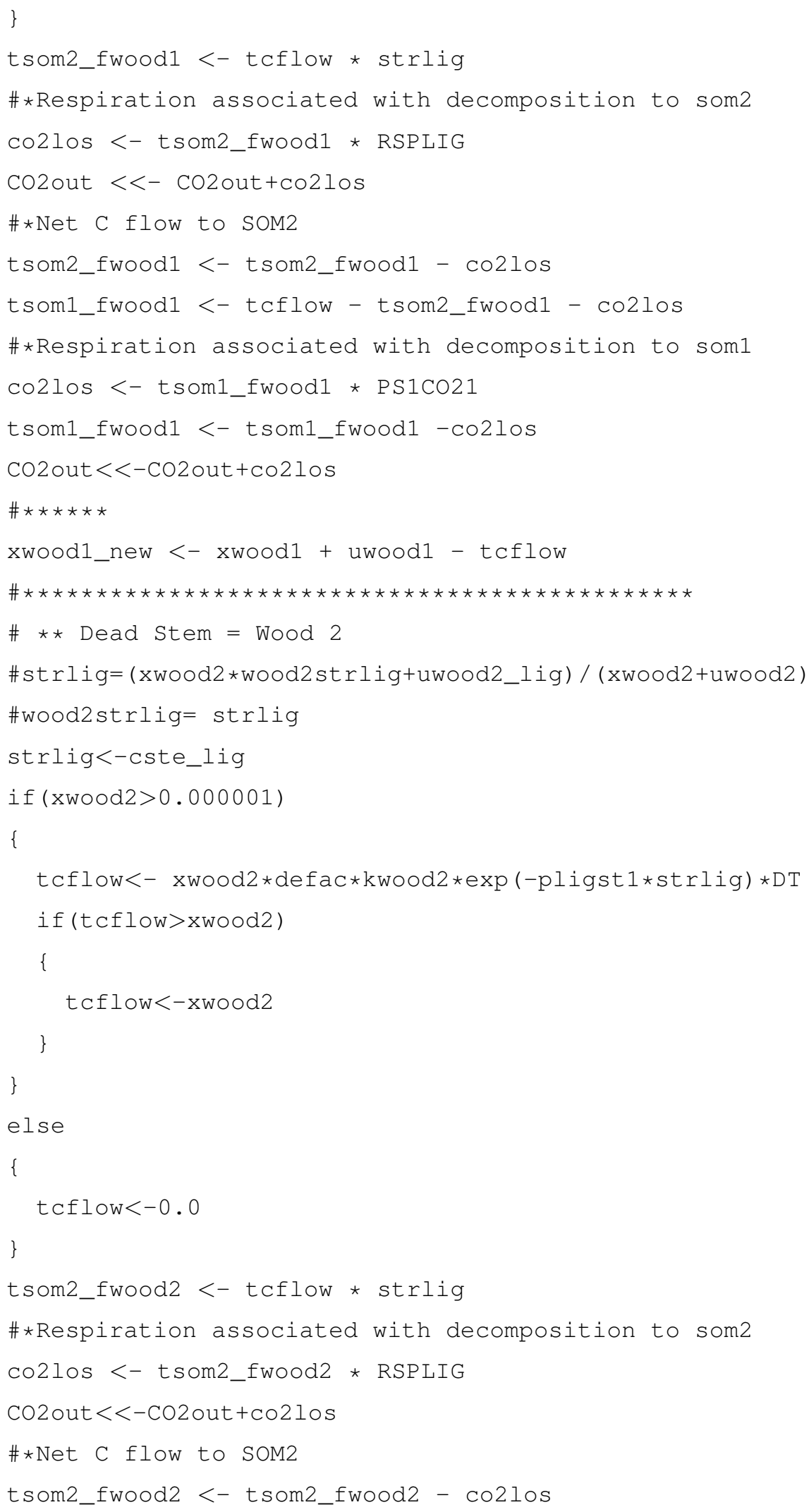




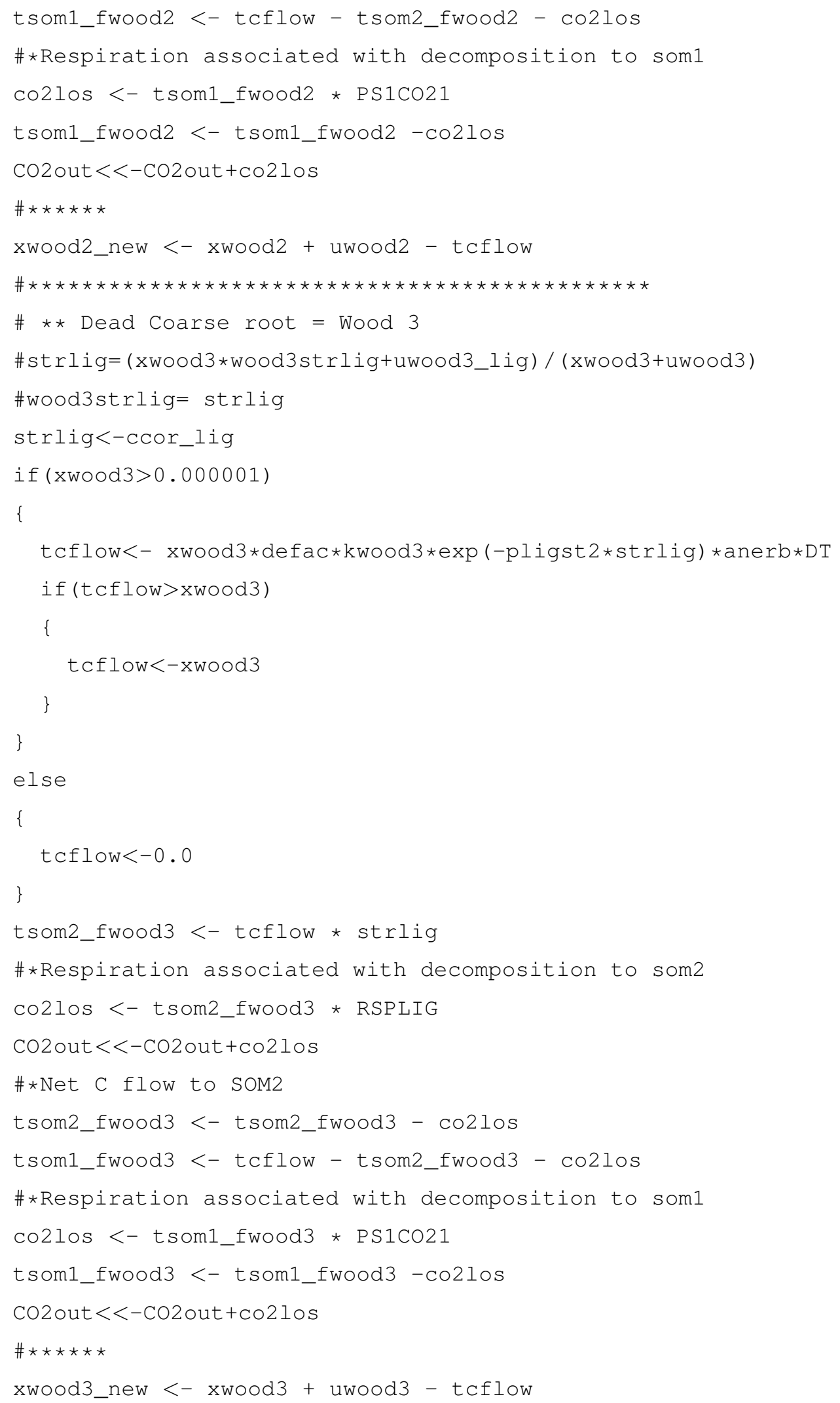




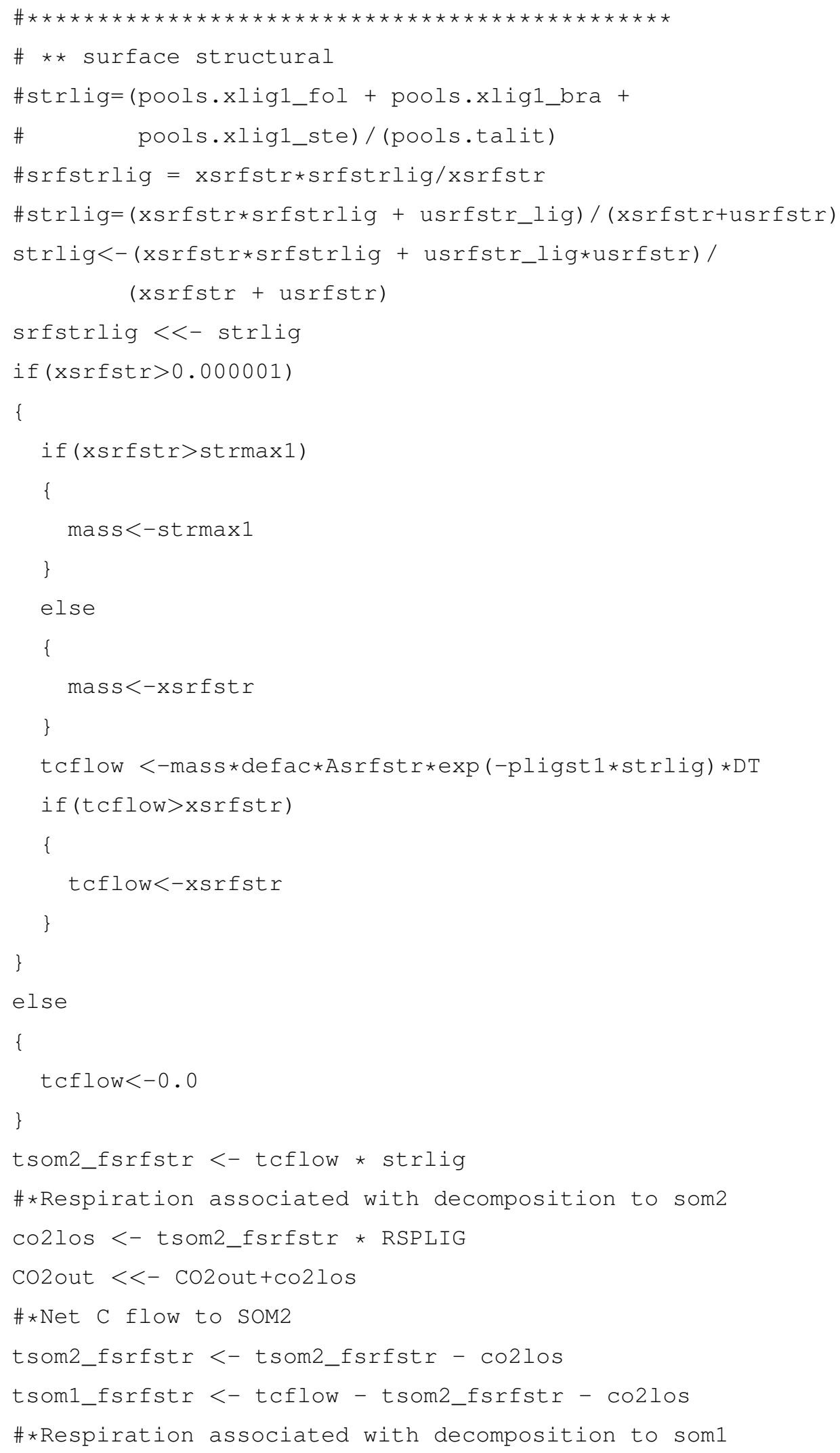




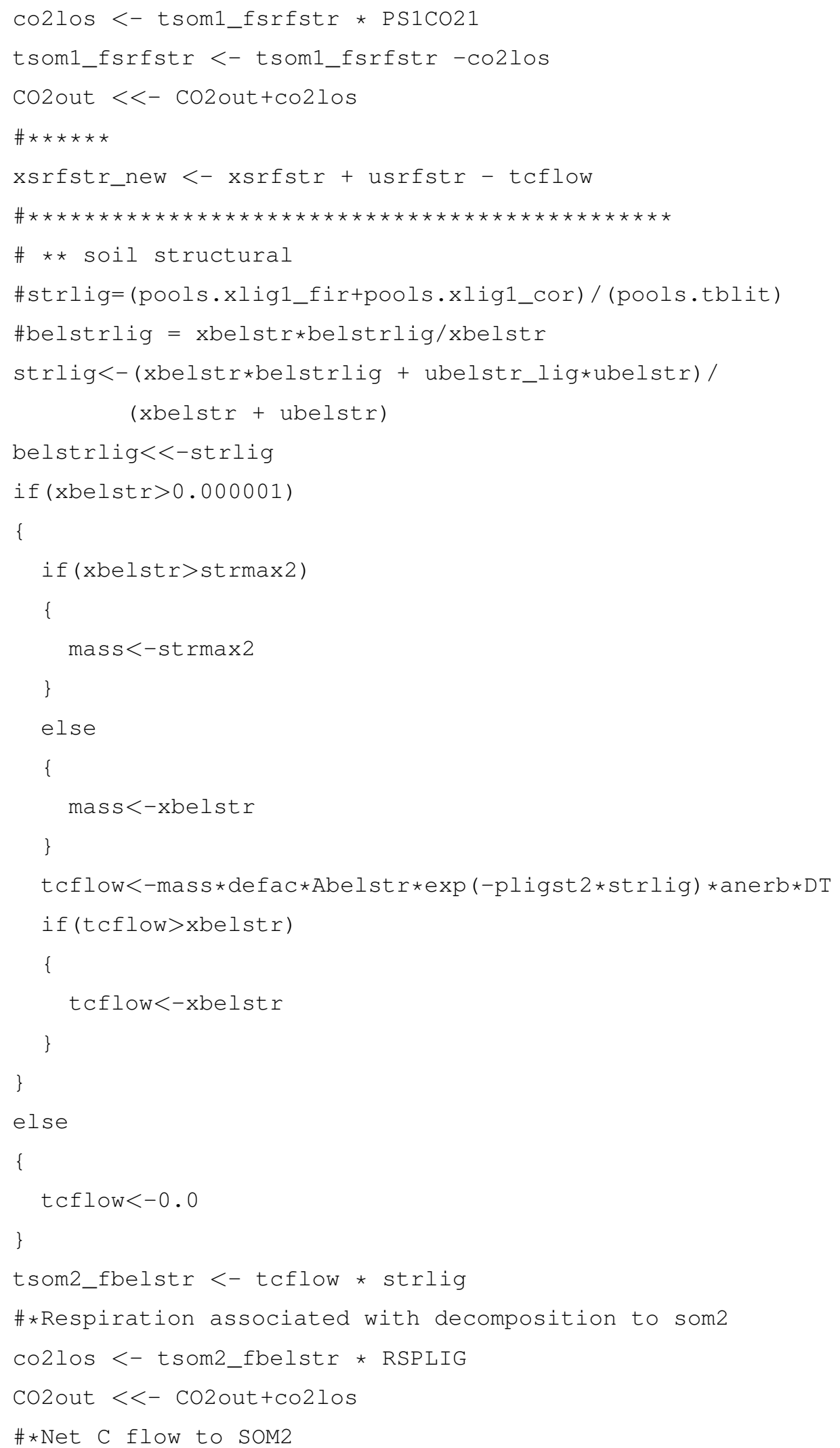




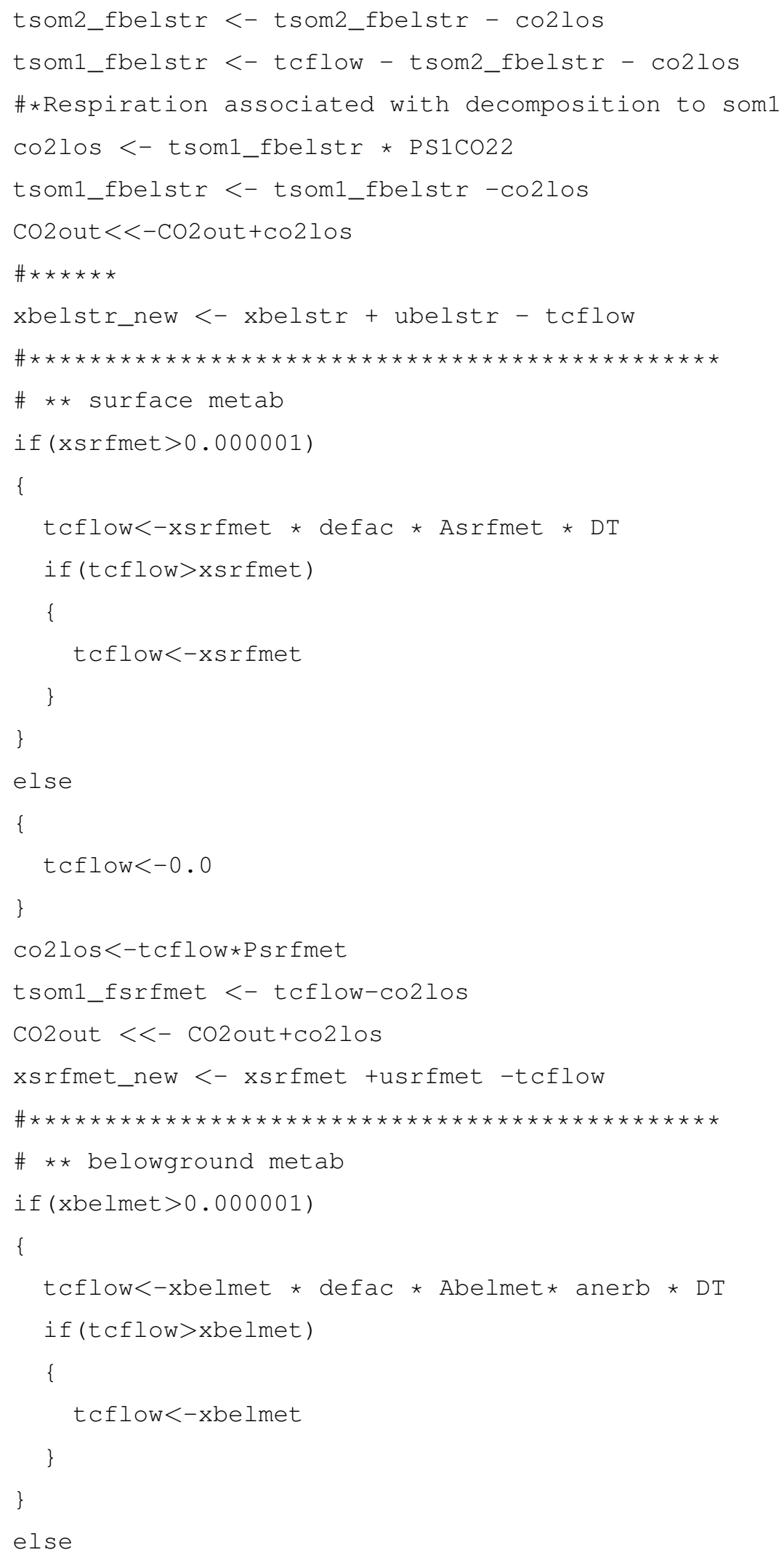




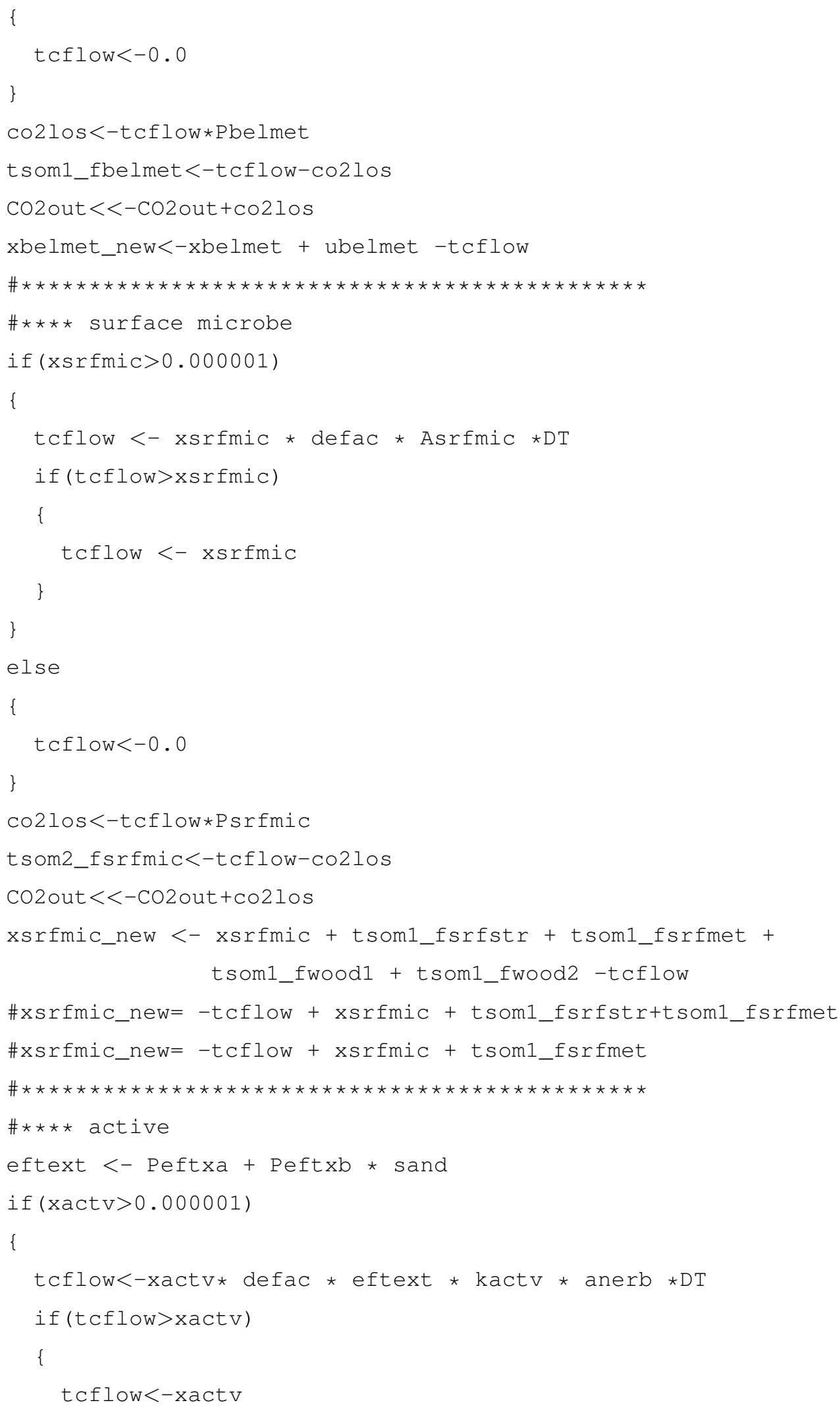




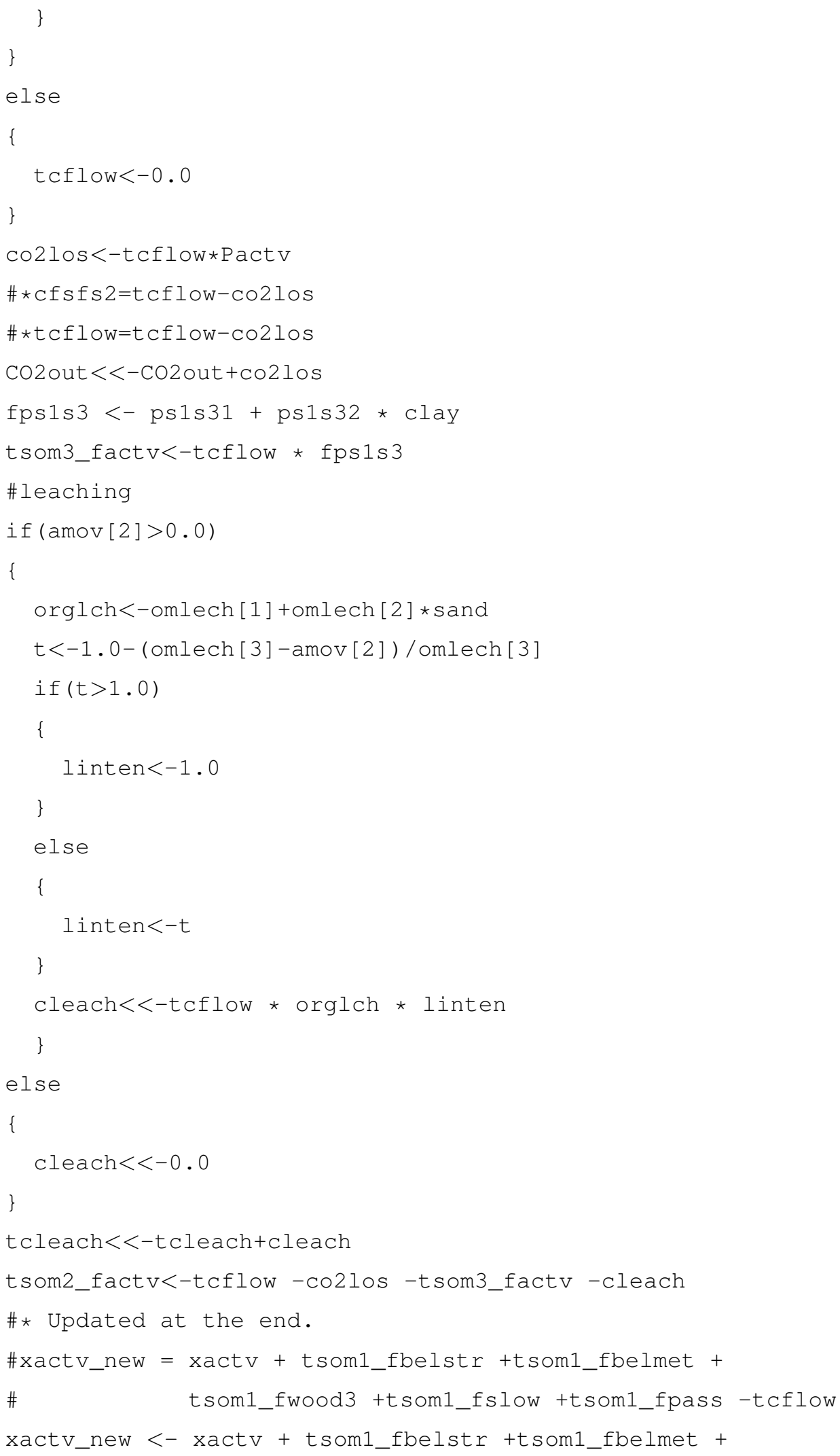




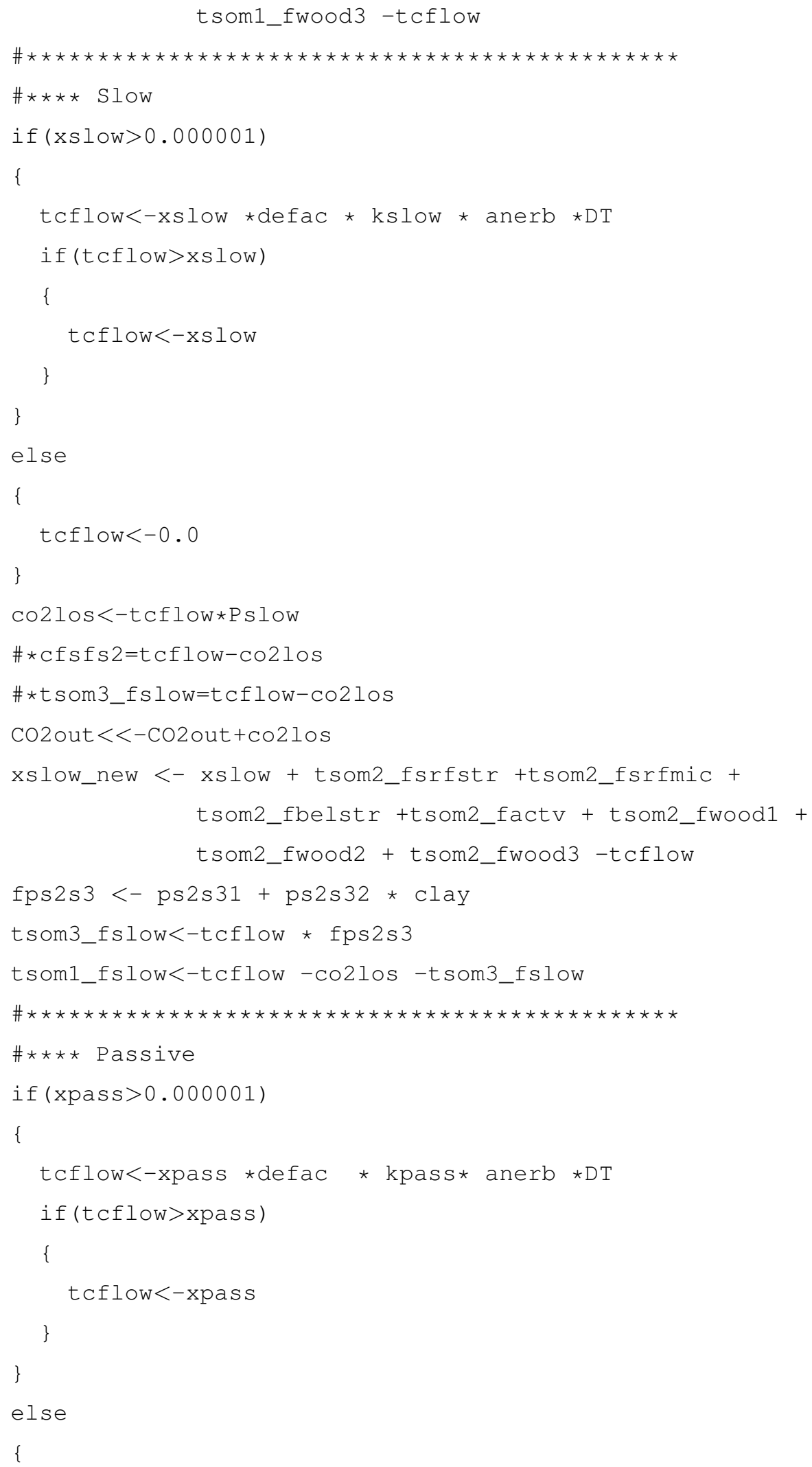




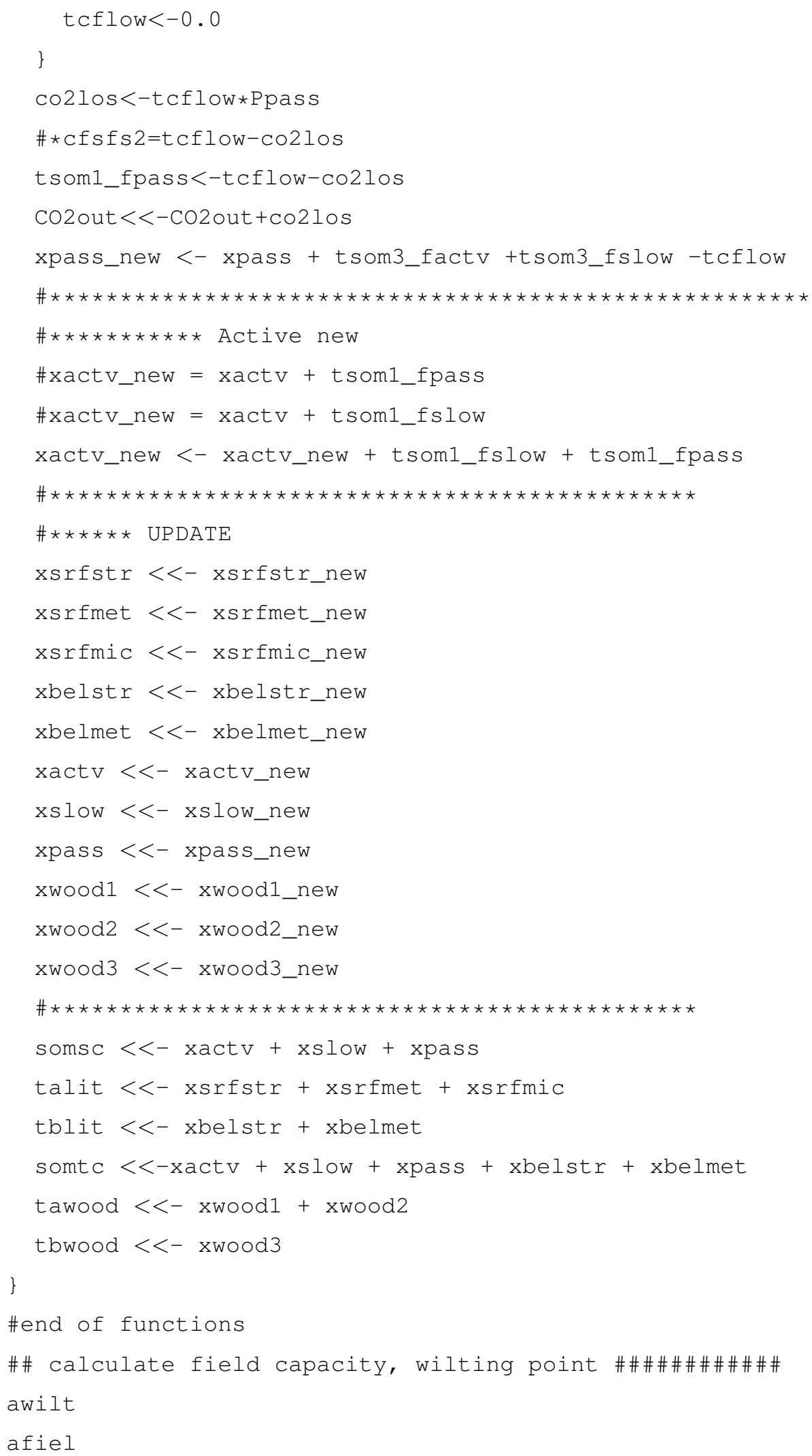




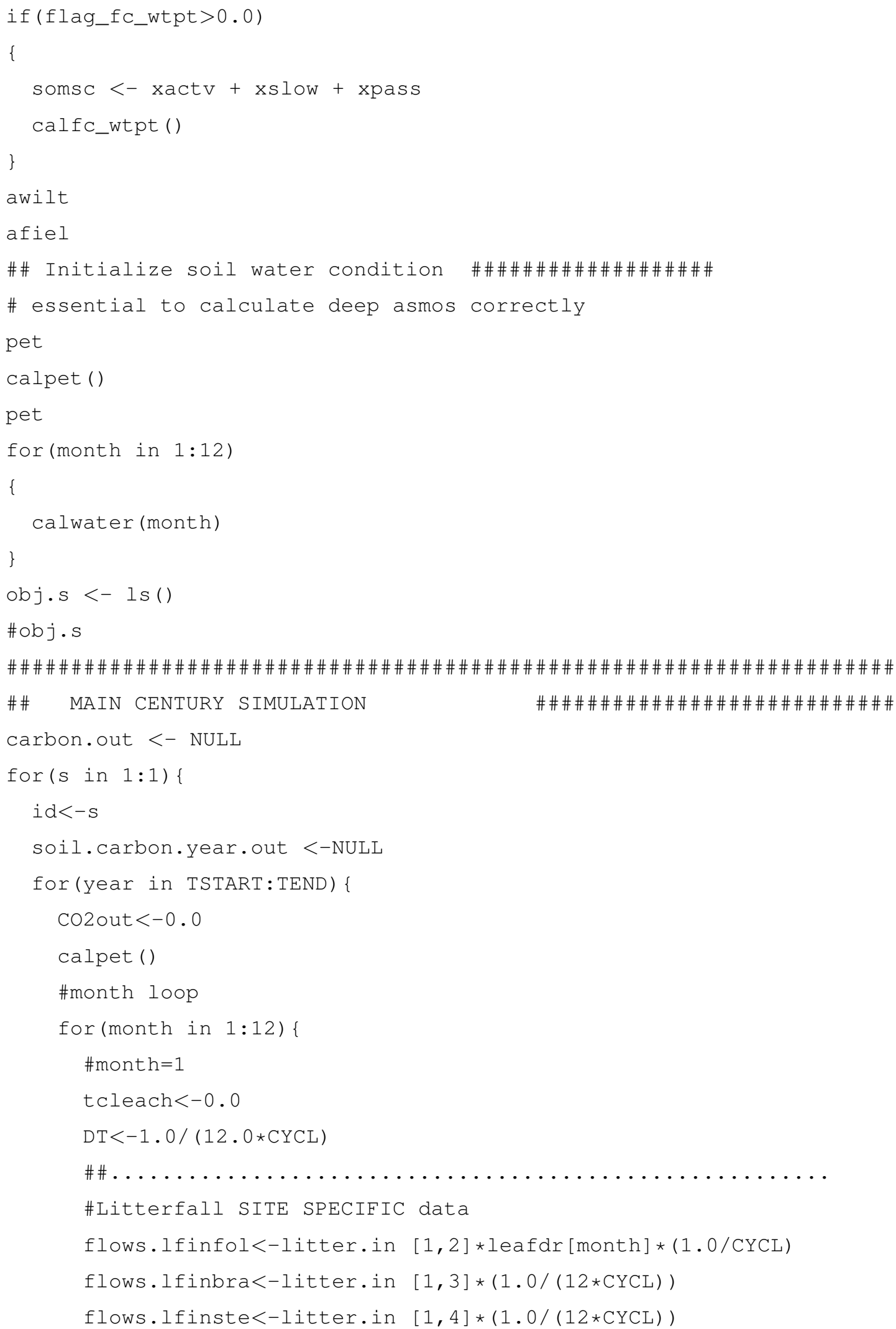




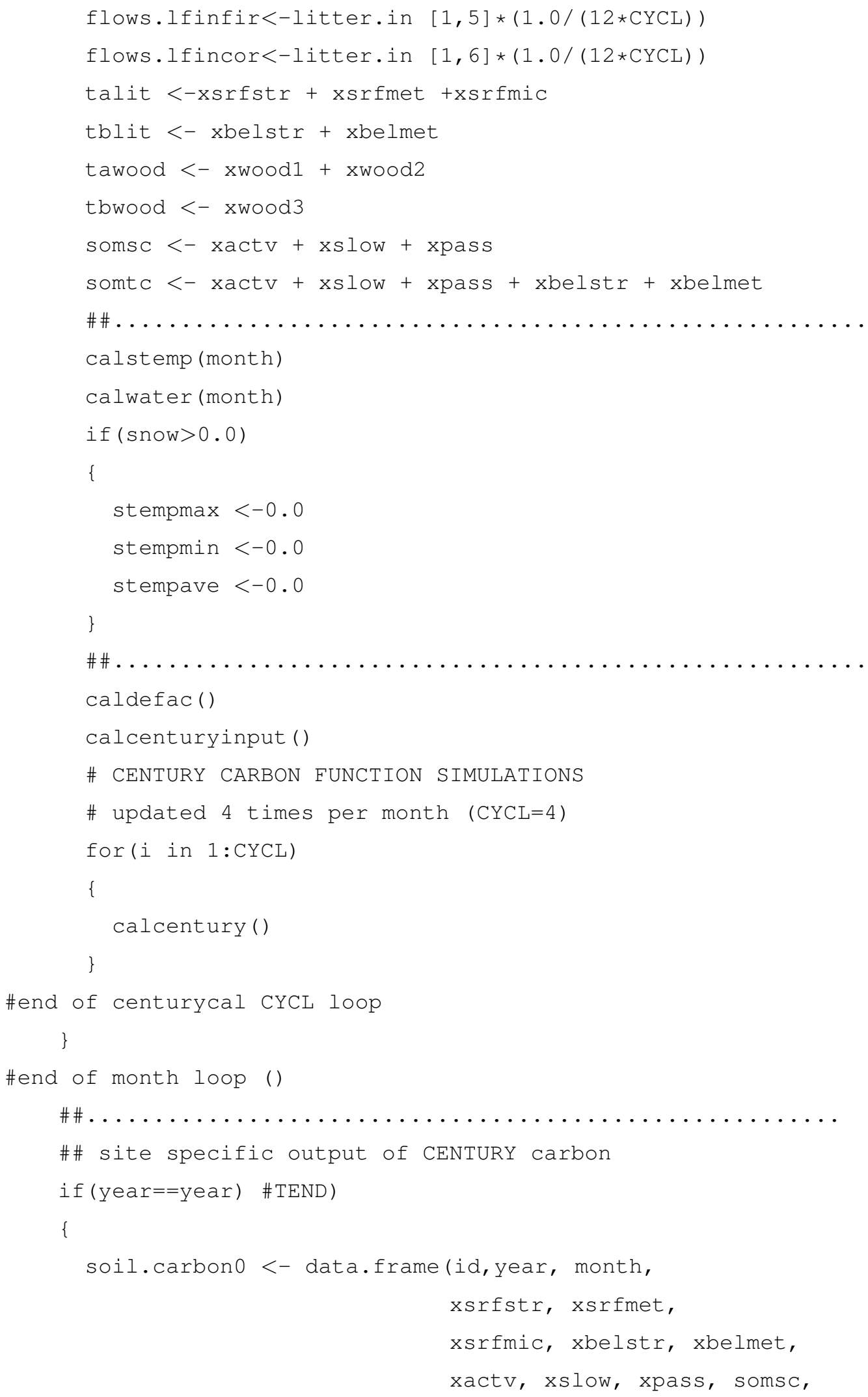




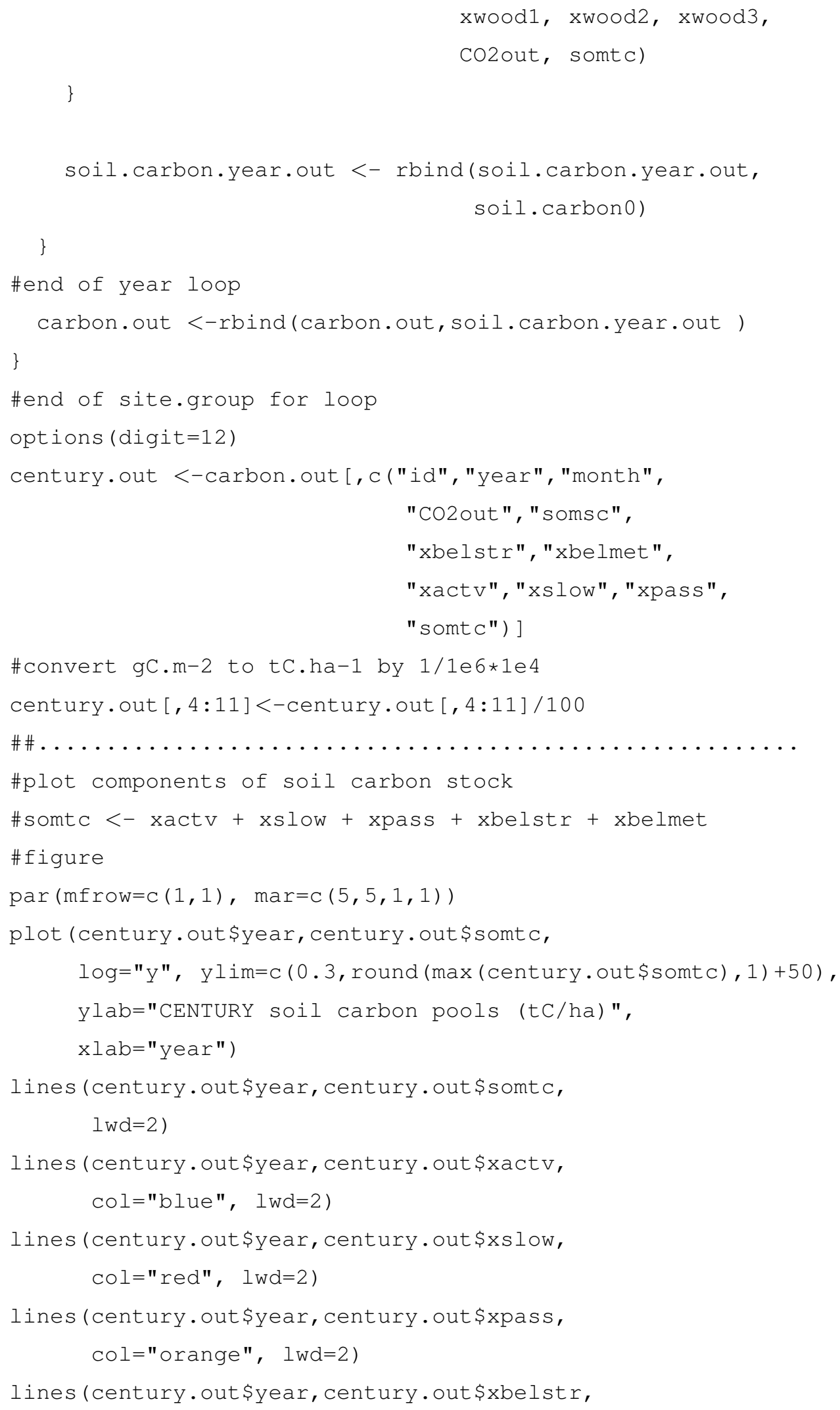




$$
\text { col="grey", lwd=2) }
$$

lines (century. out \$year, century . out \$xbelmet, col="magenta", lwd=2)

legend ("bottomright",

c("total", "active", "slow", "passive",

"bg.structural","bg.metabolic"),

col=c ("black", "blue", "red", "orange", "grey", "magenta"),

$\mathrm{pch}=\mathrm{C}(1, \mathrm{NA}, \mathrm{NA}, \mathrm{NA}, \mathrm{NA}, \mathrm{NA})$,

lwd=2, lty=1, border="white", bg="white" ) 
Table S1. Statistical characteristics (mean, standard error) of basic variables for groups of soils derived by recursive partitioning including soil variables (see Fig. 2a), compared with interpretation of carbon, moisture, and fertility of groups.

\begin{tabular}{|c|c|c|c|c|c|c|c|c|c|c|c|}
\hline $\mathrm{N}$ of soil samples in groups & & 959 & 909 & 136 & 335 & 182 & 296 & 180 & 8 & 142 & 83 \\
\hline \multirow[t]{2}{*}{ Total SOC $\left(\mathrm{tC} \mathrm{ha}^{-1}\right)$} & Mean & 65.1 & 81.8 & 130.2 & 86.2 & 126.4 & 103.9 & 136.8 & 268.6 & 143.7 & 203.1 \\
\hline & SE & 1 & 1.3 & 5.1 & 2.6 & 4.8 & 2.8 & 4.2 & 23.7 & 6.7 & 9.8 \\
\hline \multirow[t]{2}{*}{ SOC mineral $\left(\mathrm{tC} \mathrm{ha}^{-1}\right)$} & Mean & 45.4 & 56.4 & 86.9 & 68.5 & 98.4 & 73.2 & 92.4 & 230.6 & 108.8 & 153.3 \\
\hline & SE & 1.6 & 2.1 & 8.2 & 4.9 & 9.1 & 4.5 & 7 & 33 & 12.8 & 21.6 \\
\hline \multirow[t]{2}{*}{$\mathrm{C} / \mathrm{N}$} & Mean & 13.4 & 18.6 & 15.4 & 10.7 & 8.1 & 23.8 & 21.7 & 23.1 & 23.3 & 32.6 \\
\hline & SE & 0.3 & 0.4 & 0.8 & 0.2 & 0.2 & 0.5 & 0.5 & 1.9 & 0.6 & 2 \\
\hline \multirow[t]{2}{*}{$\mathrm{H} 100(\mathrm{~m})$} & Mean & 20.8 & 24.3 & 24.7 & 25.4 & 26.6 & 22.2 & 29.9 & 31 & 23.6 & 24 \\
\hline & SE & 0.2 & 0.2 & 0.5 & 0.4 & 0.4 & 0.3 & 0.3 & 0.5 & 0.5 & 0.6 \\
\hline \multirow[t]{2}{*}{ Total Litter $\left(\mathrm{tC} \mathrm{ha}^{-1}\right)$} & Mean & 2.7 & 3.3 & 3.4 & 3.5 & 3.6 & 3.1 & 4 & 3.8 & 3.2 & 3.5 \\
\hline & SE & 0 & 0 & 0.1 & 0.1 & 0.1 & 0 & 0.1 & 0.2 & 0.1 & 0.1 \\
\hline \multirow[t]{2}{*}{ Temperature air $(\mathrm{C})$} & Mean & 3.3 & 4.8 & 5.1 & 5.1 & 5.8 & 4.5 & 7.3 & 7.3 & 5.3 & 6.4 \\
\hline & SE & 0.1 & 0.1 & 0.2 & 0.1 & 0.1 & 0.1 & 0.1 & 0.2 & 0.2 & 0.2 \\
\hline \multirow[t]{2}{*}{ Long-term moisture (\%) } & Mean & 20.2 & 22.4 & 26 & 23.6 & 26.2 & 22.9 & 22.9 & 21.3 & 21.8 & 25.7 \\
\hline & SE & 0.2 & 0.2 & 0.6 & 0.3 & 0.5 & 0.4 & 0.4 & 1.3 & 0.5 & 0.7 \\
\hline \multirow{2}{*}{ Precipitation (mm y-1) } & Mean & 698.8 & 712.9 & 697.1 & 644.1 & 630.3 & 693 & 817.2 & 1173.2 & 687.9 & 619.4 \\
\hline & SE & 5.7 & 7 & 18.8 & 10.4 & 12.5 & 10.8 & 21.2 & 162 & 18.1 & 27 \\
\hline \multirow[t]{2}{*}{$\mathrm{CEC}\left(\mathrm{mmol}_{c} \mathrm{~kg}^{-1}\right)$} & Mean & 4.7 & 12.1 & 11.6 & 49.2 & 91.5 & 24 & 23.5 & 24.5 & 59.7 & 98.7 \\
\hline & SE & 0.1 & 0.1 & 0.2 & 2.6 & 5.1 & 0.3 & 0.3 & 1.7 & 3.2 & 7.6 \\
\hline \multirow[t]{2}{*}{$\mathrm{pH}$} & Mean & 5.2 & 5.1 & 5.1 & 5.5 & 5.6 & 5 & 4.8 & 4.6 & 4.9 & 6 \\
\hline & SE & 0 & 0 & 0 & 0 & 0.1 & 0 & 0 & 0.1 & 0.1 & 0.2 \\
\hline \multirow[t]{2}{*}{ Clay content $(\%)$} & Mean & 0.8 & 1.1 & 4.2 & 5.9 & 21.5 & 1.7 & 2.4 & 2.5 & 2.4 & 8 \\
\hline & SE & 0.1 & 0.1 & 0.5 & 0.5 & 1 & 0.3 & 0.3 & 1.3 & 0.4 & 1.2 \\
\hline \multirow[t]{2}{*}{ Silt content (\%) } & Mean & 15.1 & 14.5 & 29 & 27.2 & 57.8 & 16.4 & 17.9 & 18.8 & 17.1 & 32.5 \\
\hline & SE & 0.3 & 0.3 & 1.5 & 1.2 & 1.4 & 0.7 & 0.7 & 3.2 & 1 & 3 \\
\hline Carbon & & low & medium & high & medium & high & medium & high & extra & high & extra \\
\hline Moisture & & dry-fresh & fresh & moist-fresh & fresh & moist-fresh & fresh & fresh & fresh & fresh & moist-fresh \\
\hline Fertility & & low & medium & medium & medium & high & low & high & high & medium & medium \\
\hline Soil group & & 1 & 2 & 3 & 4 & 5 & 6 & 7 & 8 & 9 & 10 \\
\hline
\end{tabular}


Table S2. Statistical characteristics (mean, standard error) of basic environmental and soil variables for regression tree of data groups classified by recursive partitioning with data excluding soil variables (see Fig. 3).

\begin{tabular}{|c|c|c|c|c|c|c|}
\hline Number of samples & & 735.0 & 932.0 & 796.0 & 711.0 & 56.0 \\
\hline \multirow[t]{2}{*}{ Total soil carbon $\left(\mathrm{tC} \mathrm{ha}^{-1}\right)$} & Mean & 67.1 & 85.4 & 96.5 & 120.1 & 179.0 \\
\hline & SE & 1.4 & 1.5 & 2.0 & 2.4 & 12.5 \\
\hline \multirow[t]{2}{*}{$\mathrm{C} / \mathrm{N}$} & Mean & 15.0 & 15.8 & 16.8 & 18.1 & 35.2 \\
\hline & SE & 0.3 & 0.3 & 0.4 & 0.4 & 3.2 \\
\hline \multirow[t]{2}{*}{ H100 (m) } & Mean & 19.0 & 19.7 & 27.0 & 30.1 & 18.7 \\
\hline & SE & 0.1 & 0.1 & 0.1 & 0.2 & 0.3 \\
\hline \multirow[t]{2}{*}{ Total Litter $\left(\mathrm{tC} \mathrm{ha}^{-1}\right)$} & Mean & 2.3 & 2.8 & 3.6 & 4.0 & 3.0 \\
\hline & SE & 0.0 & 0.0 & 0.0 & 0.0 & 0.1 \\
\hline \multirow[t]{2}{*}{ Soil water content $(\%)$} & Mean & 20.2 & 24.2 & 22.0 & 22.6 & 22.3 \\
\hline & SE & 0.2 & 0.2 & 0.2 & 0.2 & 1.0 \\
\hline \multirow[t]{2}{*}{ Temperature air (C) } & Mean & 2.4 & 2.7 & 6.4 & 7.2 & 7.2 \\
\hline & SE & 0.1 & 0.1 & 0.0 & 0.0 & 0.0 \\
\hline \multirow[t]{2}{*}{$\mathrm{pH}$} & Mean & 5.2 & 5.2 & 5.3 & 4.9 & 7.2 \\
\hline & SE & 0.0 & 0.0 & 0.0 & 0.0 & 0.1 \\
\hline \multirow[t]{2}{*}{ Sand content (\%) } & Mean & 52.7 & 51.5 & 47.2 & 55.1 & 36.2 \\
\hline & SE & 0.5 & 0.5 & 0.8 & 0.6 & 4.0 \\
\hline \multirow[t]{2}{*}{ Clay content $(\%)$} & Mean & 0.8 & 2.6 & 6.1 & 3.0 & 5.8 \\
\hline & SE & 0.1 & 0.2 & 0.4 & 0.2 & 1.1 \\
\hline \multirow[t]{2}{*}{ Silt content (\%) } & Mean & 14.6 & 19.2 & 25.3 & 20.0 & 29.5 \\
\hline & SE & 0.3 & 0.5 & 0.8 & 0.5 & 4.1 \\
\hline Group & & low-C & median-C & median-C & hig-C & extra-C \\
\hline \multirow[t]{2}{*}{ acronym } & & cold.pine & cold.other & warm.rainy & warm.rainy & warm.dry \\
\hline & & & & low-N & high-N & \\
\hline
\end{tabular}


Table S3. Species and classes of ground vegetation grouped into functional types (1-dwarfshrubs, 2-herbs, 3-grasses, 4-mosses and 5-lichens).

Functional type Ground vegetation

1 Vaccinium myrtillus, Vaccinium vitis-idaea,Arctostaphylos uva-ursi, Empetrum nigrum ssp,

Calluna vulgaris, Erica tetralix, Vaccinium uliginosum, Rhododendron tomentosum, Andromeda polifolia,

Vaccinum oxycoccus/microcarpum, Other field layer plants

Gymnocarpium dryopteris, Oxalis acetosella, Anemone nemorosa, Maianthemum bifolium,

Chamaenerion angustifolium, Anthriscus sylvestris, Melampyrum pratense/sylvaticum, Equisetum sylvaticum,

Menyanthes trifoliata, Rubus chamaemorus, Phegopteris connectilis, Hepatica nobilis, Geum rivale, Urtica dioica,

Rumex acetosa, Stellaria nemorum, Stellaria holostea, Silene dioica, Aconitum lycoctonum subsp. septentrionale,

Actaea erythrocarpa, Trollius europaeus, Cardamine bulbifera, Filipendula ulmaria, Mercurialis perennis,

Sanicula europaea, Aegopodium podagraria, Librar, Galium odoratum, Lamiastrum galeobdolon, Stachys sylvatica,

Cirsium palustre, Cirsium heterophyllum, Lactuca alpina, Lactuca muralis, Crepis paludosa, Paris quadrifolia,

Neottia ovata, Geranium sylvaticum, Rubus idaeus, Other large grown ferns

3

Broad-leaved grass, Narrow-leaved grass, Carex globularis, Other sedges

4

Pteridium aquilinum, Lycopdiaceae, Spagnum spp, Polytrichum commune, Pleurozium schreberi,

Hylocomium splendens, Other bryophytes

5

Cladonia, Stereocaulon spp, Cladina spp, Cladonia and Cladina, Other lichens 

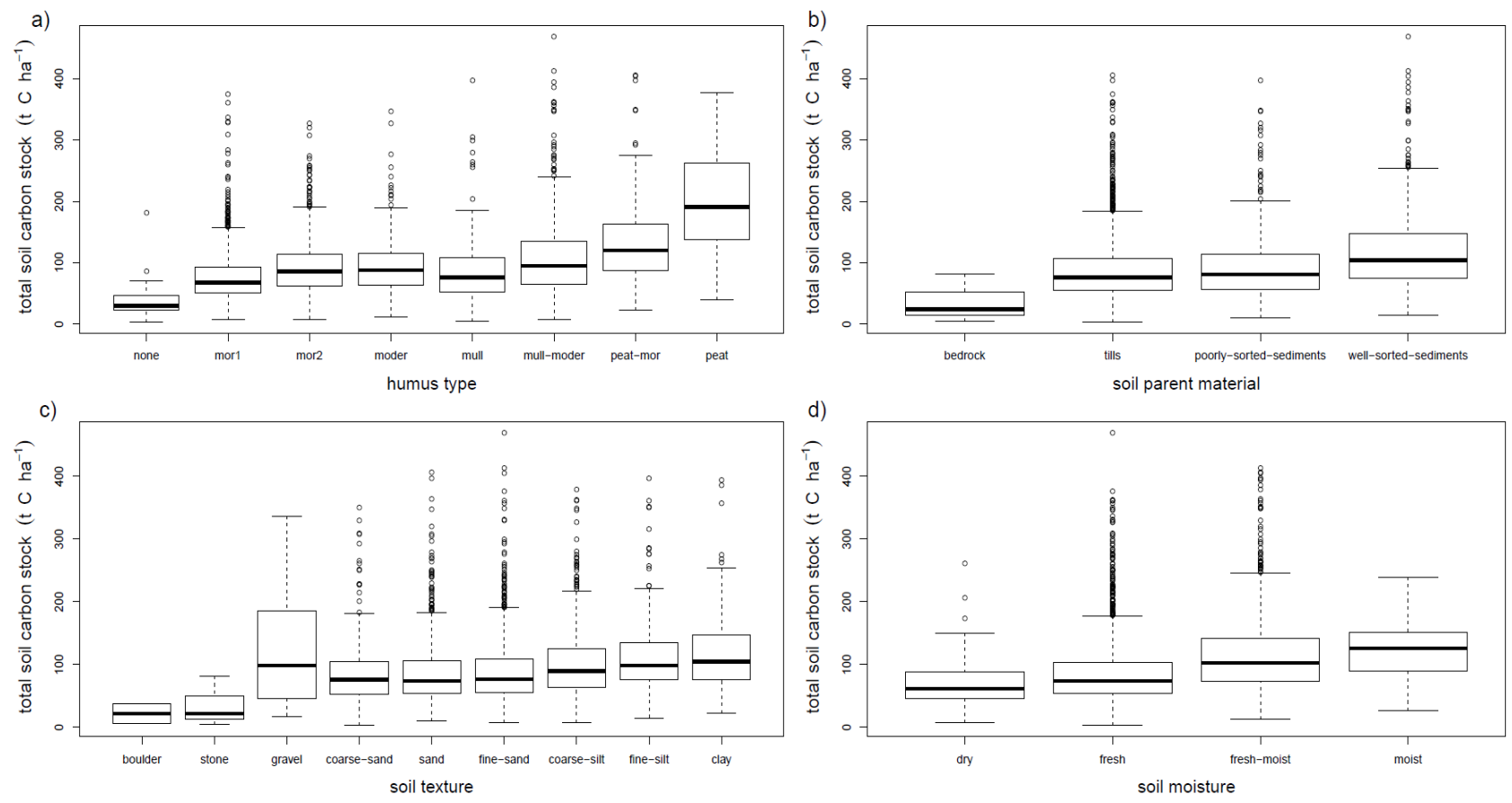

Figure S1. Boxplot main levels (minimum, 1st quantile, median, 3rd quantile, maximum, and dots for outliers) of the total soil carbon stock ( $\mathrm{tC} \mathrm{ha}^{-1}$ ) for SFSI categorical data on a) humus type, b) soil parent material, c) soil texture, and d) soil moisture. 


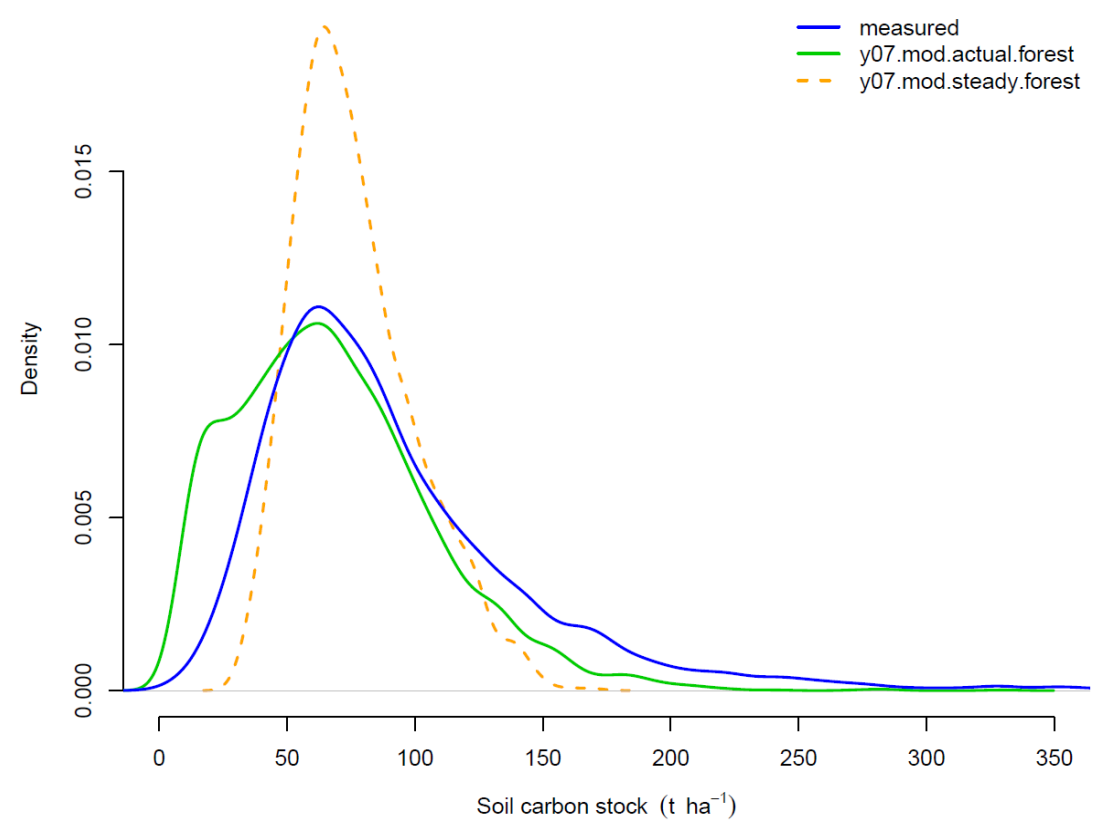

Figure S2. Density function of soil carbon stock measurements (measured) and the simulated soil carbon by the soil carbon model Yasso07 run with observed state forest and litter inputs (y07.mod.observed.forest) and with the equilibrium forest and litter inputs (y07.mod.steady.forest). 


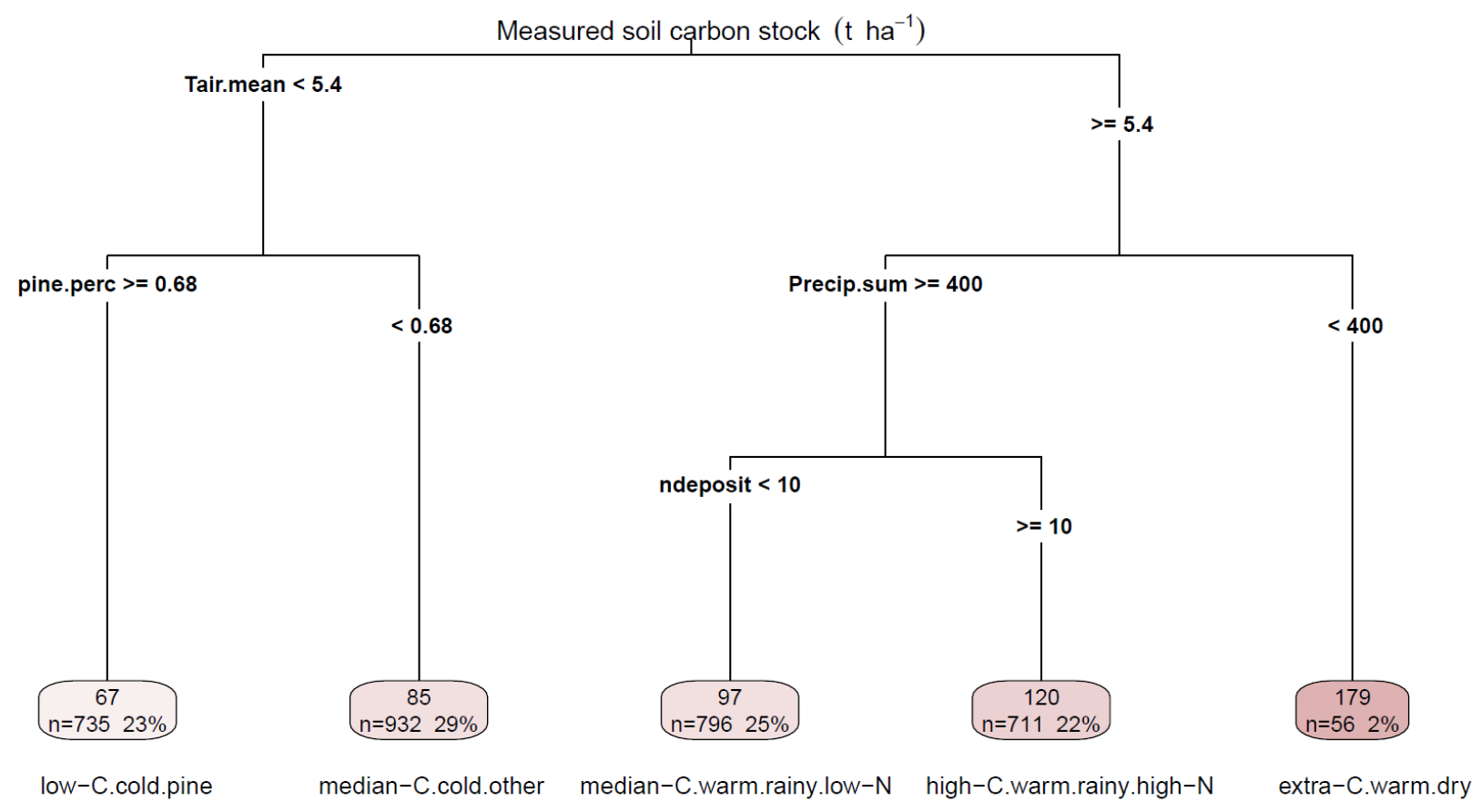

Figure S3. Classification/regression tree for the measured soil carbon stock $\left(\mathrm{tC} \mathrm{ha}^{-1}\right)$ and site environmental characteristics excluding soil physicochemical properties; the annual air temperature (Tair.mean, ${ }^{\circ} \mathrm{C}$ ), the fraction of pine trees of the total canopy (pine.perc), the annual precipitation sum (Precip.sum, mm), and the nitrogen deposition (ndeposit, $\mathrm{kgN} \mathrm{ha}^{-1} \mathrm{y}^{-1}$ ). The values in the leaves of the tree show for the distinct environmental conditions mean soil carbon stock $\left(\mathrm{tC} \mathrm{ha}^{-1}\right)$, number and percentage of samples. The group acronyms are shown below the leaves of the regression tree. 


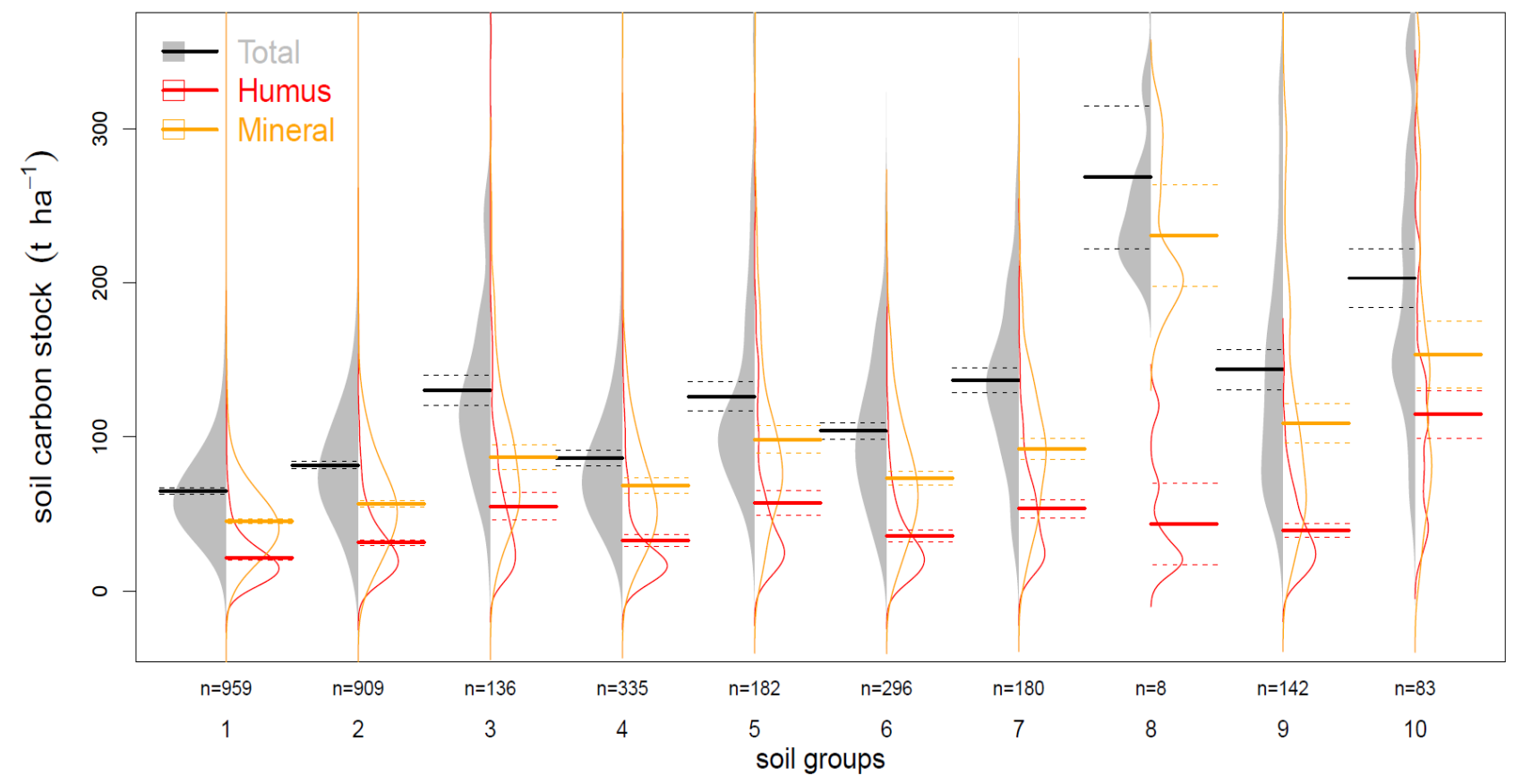

Figure S4. Density functions for 10 physicochemical groups of the soil carbon (SOC) stock (tC ha ${ }^{-1}$ ) Swedish forest soil inventory measurements for soil depth up to $1 \mathrm{~m}$ (total, grey fill) and for the soil humus horizon and mineral soil horizon. The thin lines are the density distributions. The thick lines are the group means and dashed lines are their confidence intervals. The $\mathrm{n}$ is number of samples. For description of group levels of SOC stocks, moisture, and fertility see Fig. 2 and Table S1. 


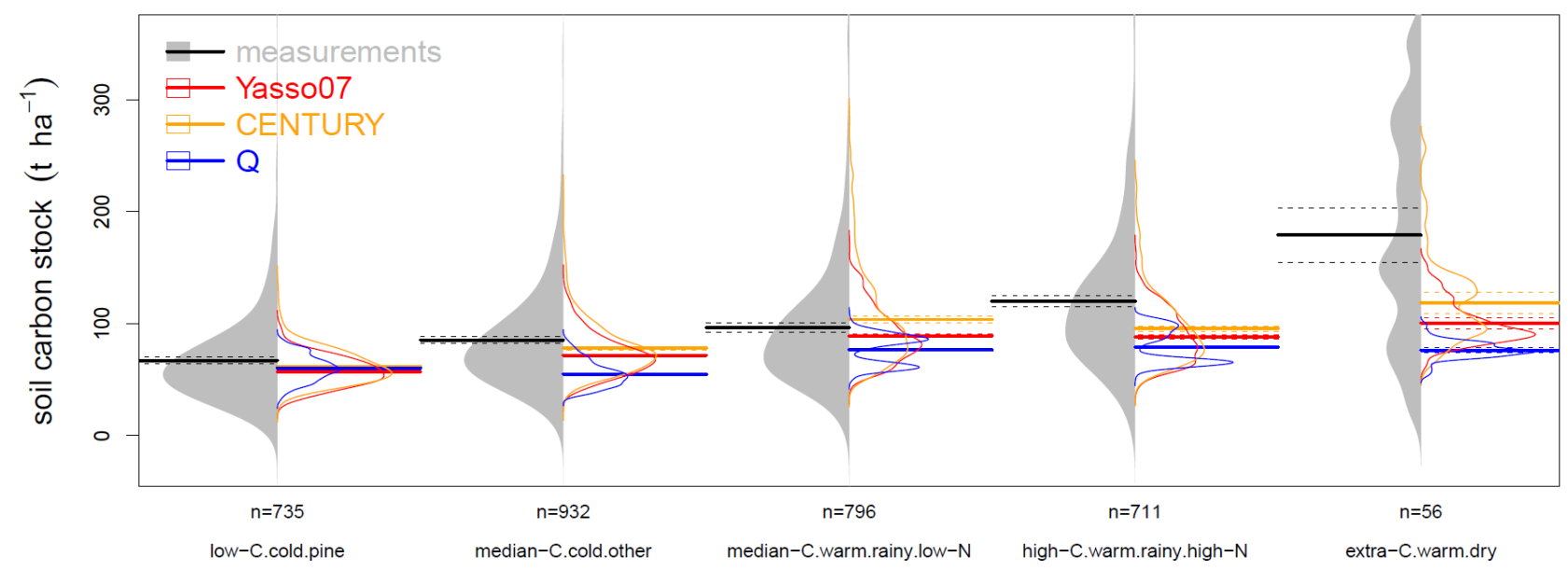

Figure S5. Bean plot of density functions for 5 groups of the soil carbon $\left(\mathrm{tC} \mathrm{ha}^{-1}\right)$ measurements (C.measured, grey fill) and soil carbon estimates simulated by the soil carbon models Yasso07, CENTURY, and Q with the litter input derived from the equilibrium forest. The thin lines are the density distributions. The thick lines are the group means and dashed lines are their confidence intervals. The $\mathrm{n}$ is number of samples. For description of group acronyms based on levels of SOC stocks, temperature, percentage of pine in canopy, precipitation, and nitrogen deposition see Fig.S3 and Table S2.

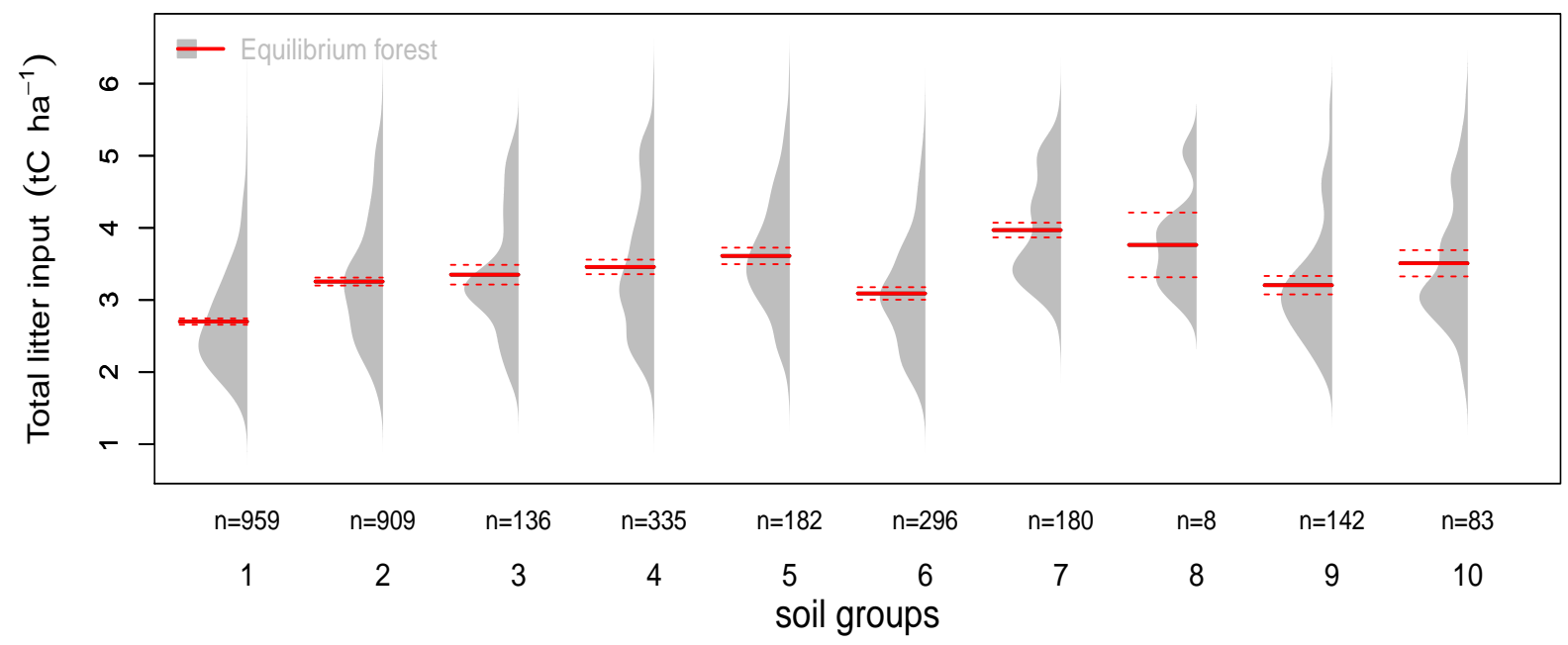

Figure S6. Density functions for 10 physicochemical groups of the total annual plant litter input ( $\mathrm{tC} \mathrm{ha}^{-1}$ ) of equilibrium forest. The thick lines are the group means and dashed lines are their confidence intervals. The $\mathrm{n}$ is number of samples. For description of group levels of SOC stocks, moisture, and fertility see Fig.2 and Table S1. 

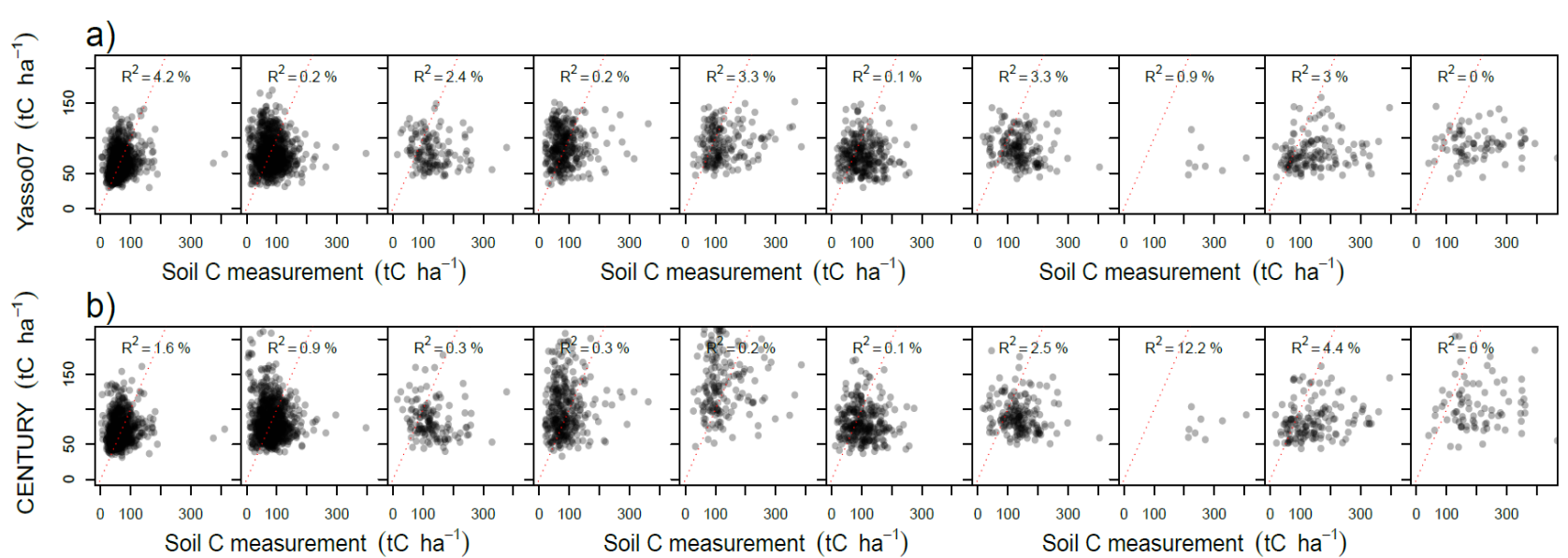

c)

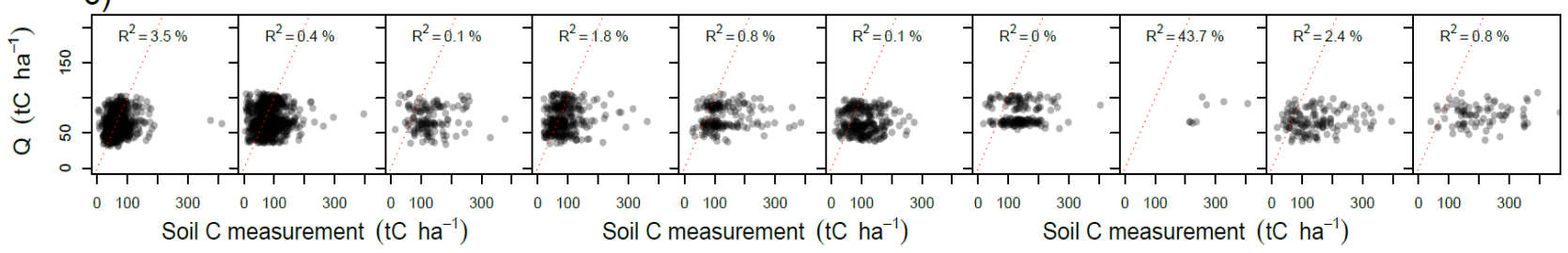

Figure S7. Scatter plots between model soil organic carbon stock $\left(\mathrm{tC} \mathrm{ha}^{-1}\right)$ measurements and a) Yasso07 and CENTURY, b) Yasso07 and Q, and c) CENTURY and Q for 10 physicochemical groups of Fig.2.

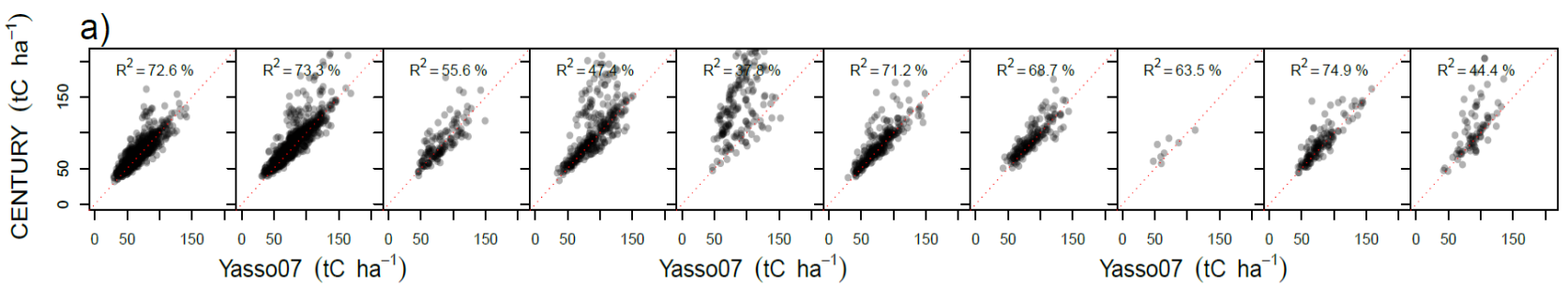

b)

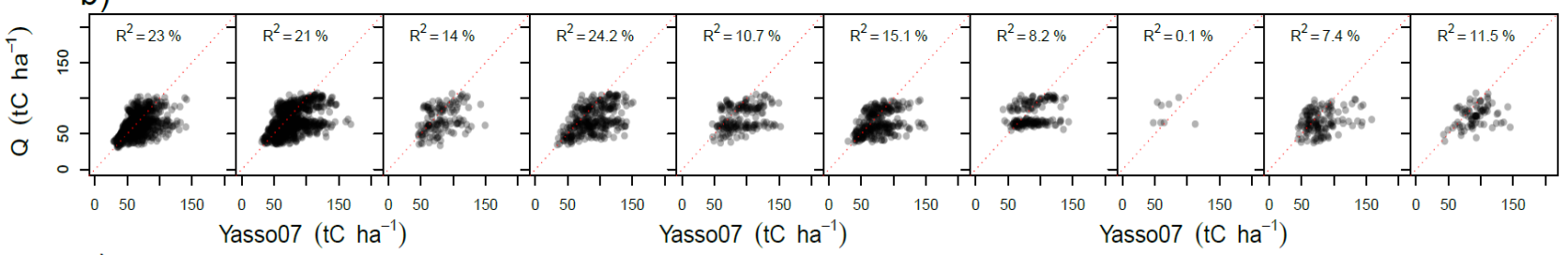

C)

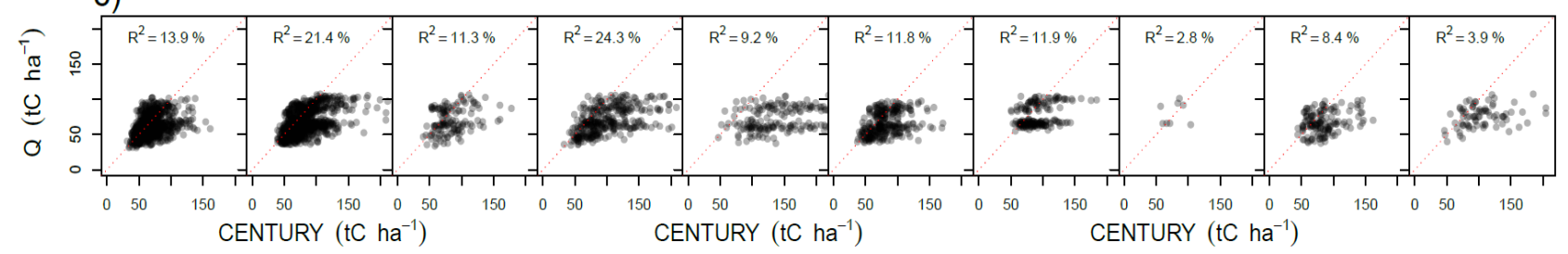

Figure S8. Scatter plots between model soil organic carbon estimates $\left(\mathrm{tC} \mathrm{ha}^{-1}\right)$ of a) Yasso07 and CENTURY,

b) Yasso07 and Q, and c) CENTURY and Q for 10 physicochemical groups of Fig.2. 

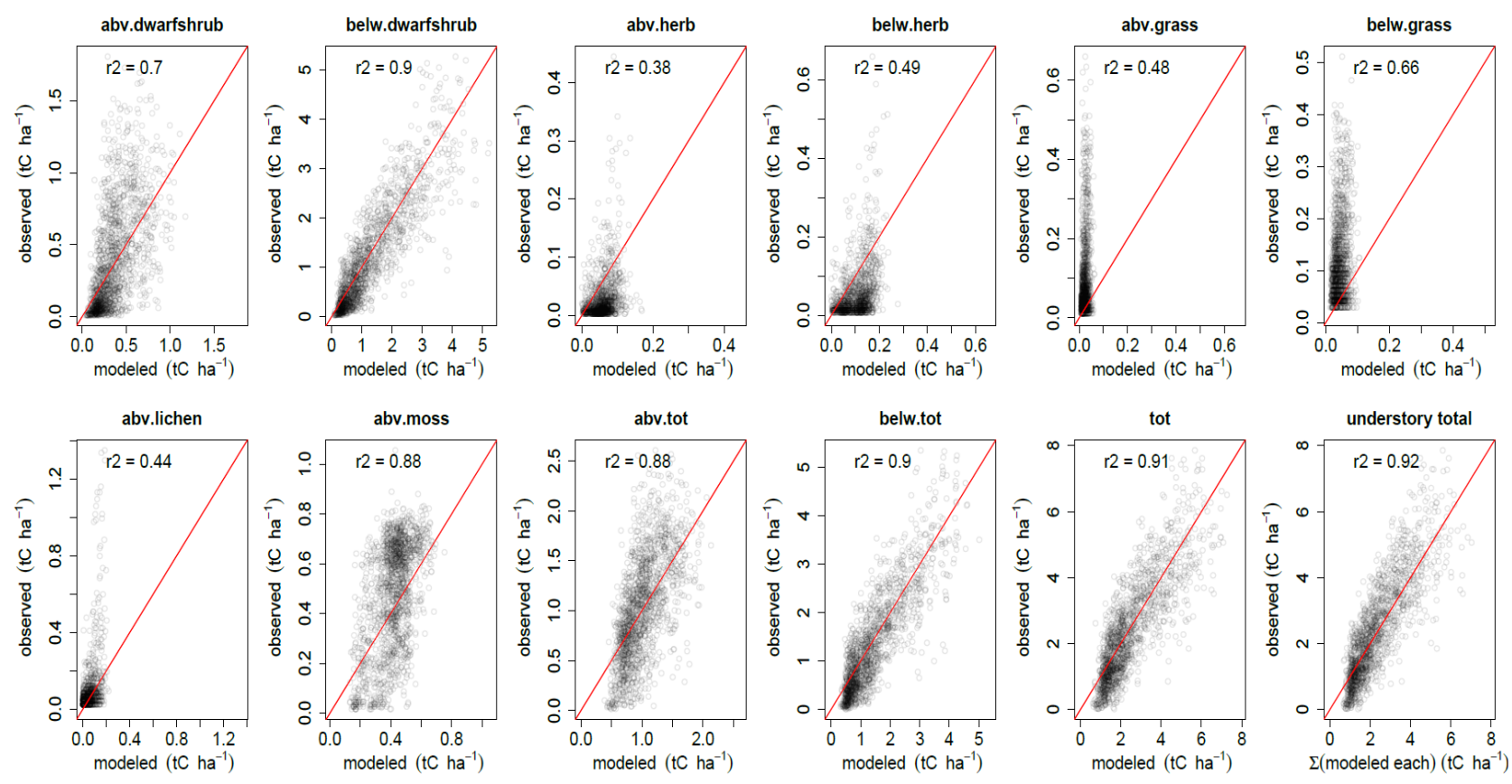

Figure S9. Scatter plots for the dry weight biomass $\left(\mathrm{tC} \mathrm{ha}^{-1}\right)$ of the functional types of understory vegetation for Swedish Forest Inventory plots in observed state being close to the estimated long-term mean conditions "equilibrium". On the $\mathrm{x}$-axis is the biomass modelled by the understory vegetation dry weight biomass $\left(\mathrm{tC} \mathrm{ha}^{-1}\right)$ models and on the $\mathrm{y}$-axes is the observed coverage multiplied by the coverage/biomass conversion functions. The abbreviations "abv", "belw", and "tot" mean aboveground, belowground and total. The last panel for "understory total" shows high agreement between the sums of each modeled functional types and the sums of all functional types. The $r^{2}$ values represent the coefficient of determination indicating how close the modeled values fit the observed values. 

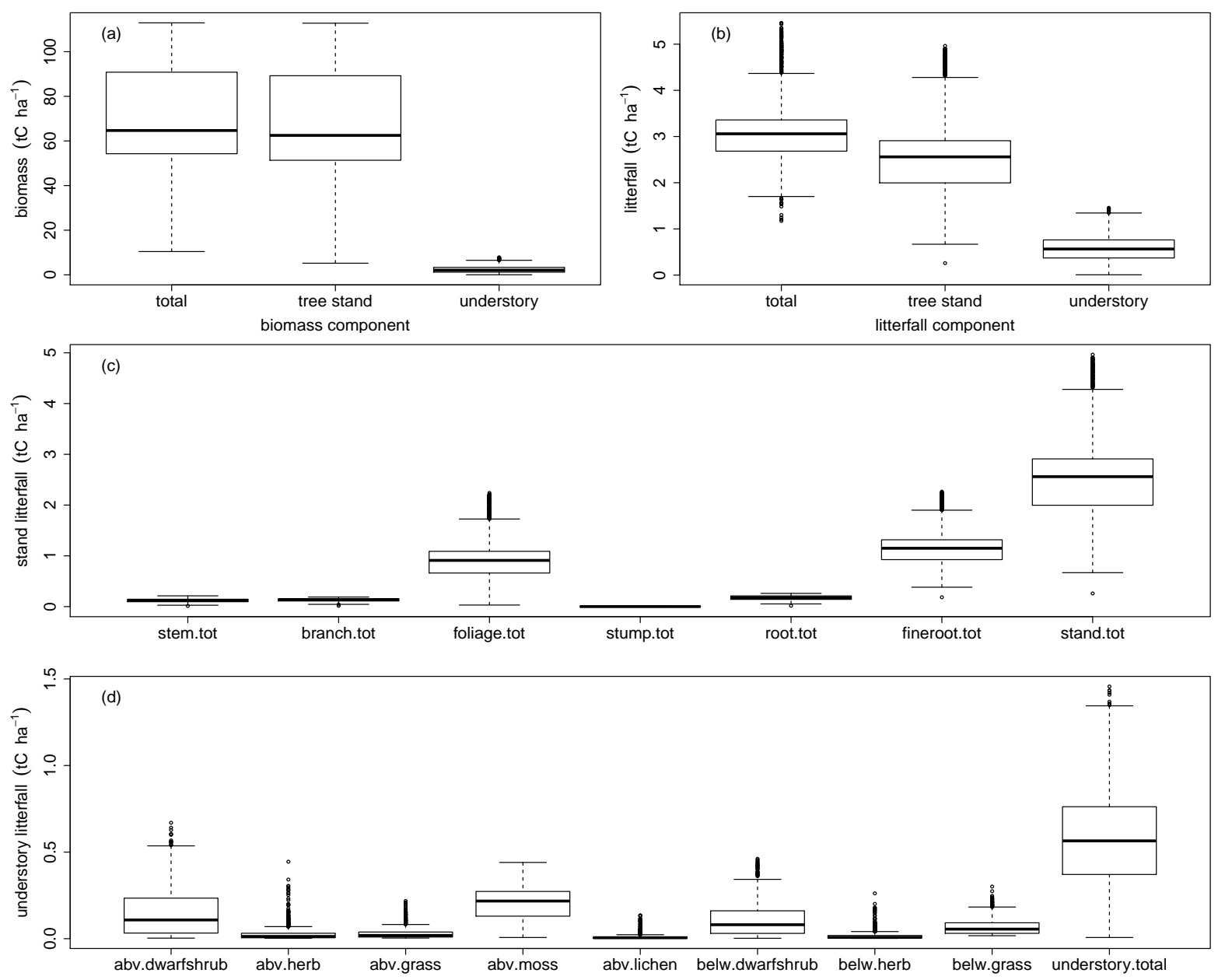

Figure S10. The tree stand and understory forest (a) biomass, (b) litterfall, (c) stand litterfall and (d) understory litterfall (all in $\mathrm{tC} \mathrm{ha}^{-1}$ ) for Swedish Forest Inventory plots with available understory coverage observations and in their observed state close to the estimated long-term mean conditions "equilibrium". 
a) deciduous
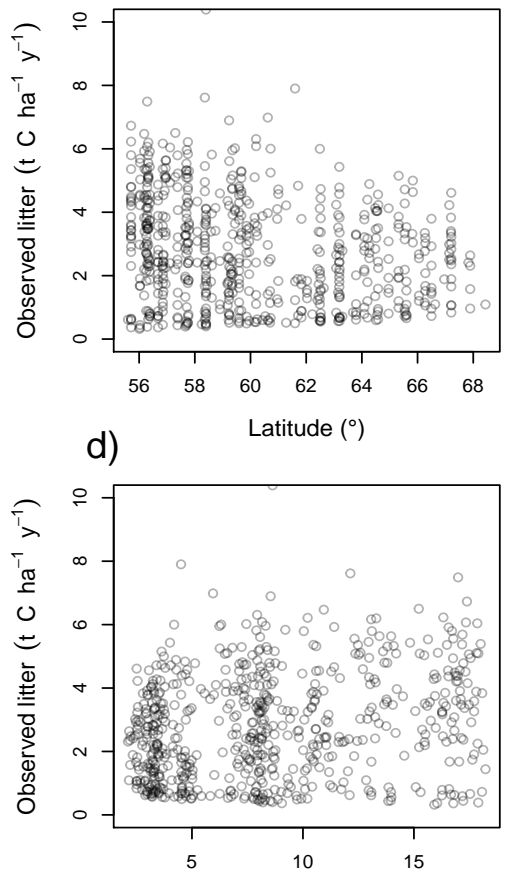

Nitrogen deposition $\left(\mathrm{kg} \mathrm{N} \mathrm{ha}^{-1} \mathrm{y}^{-1}\right)$ g)
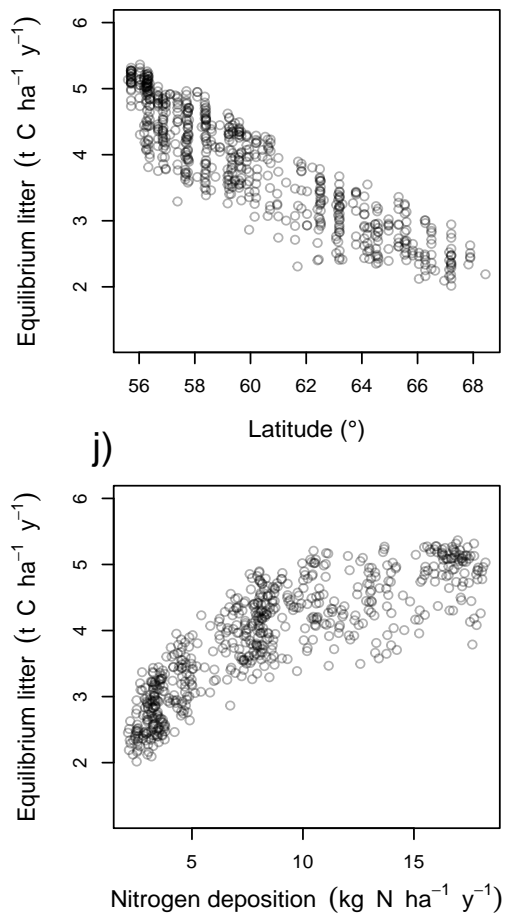

b) pine
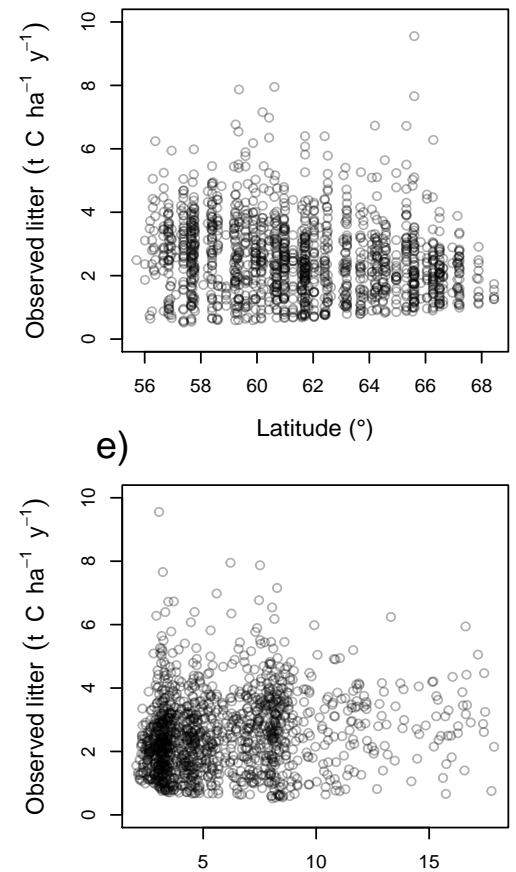

Nitrogen deposition $\left(\mathrm{kg} \mathrm{N} \mathrm{ha}^{-1} \mathrm{y}^{-1}\right)$

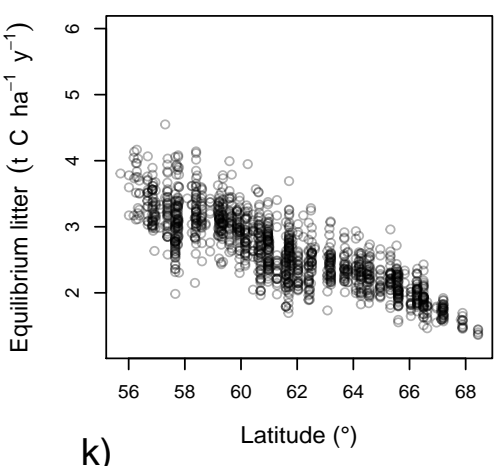

k)

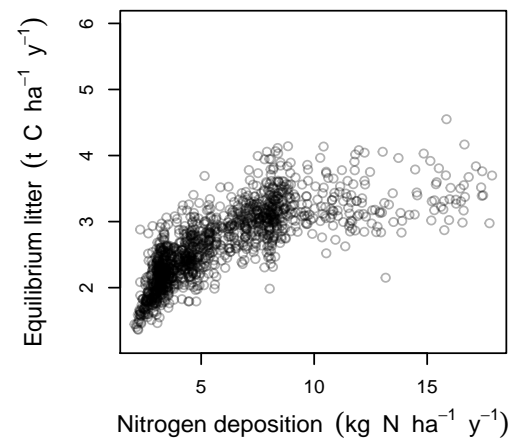

c) spruce
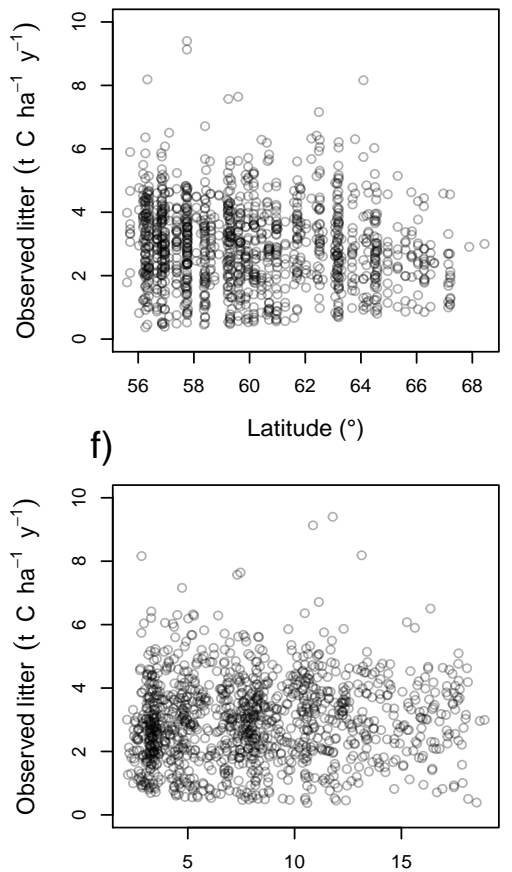

i) Nitrogen deposition ( $\left.\mathrm{kg} \mathrm{N} \mathrm{ha}^{-1} \mathrm{y}^{-1}\right)$ i)
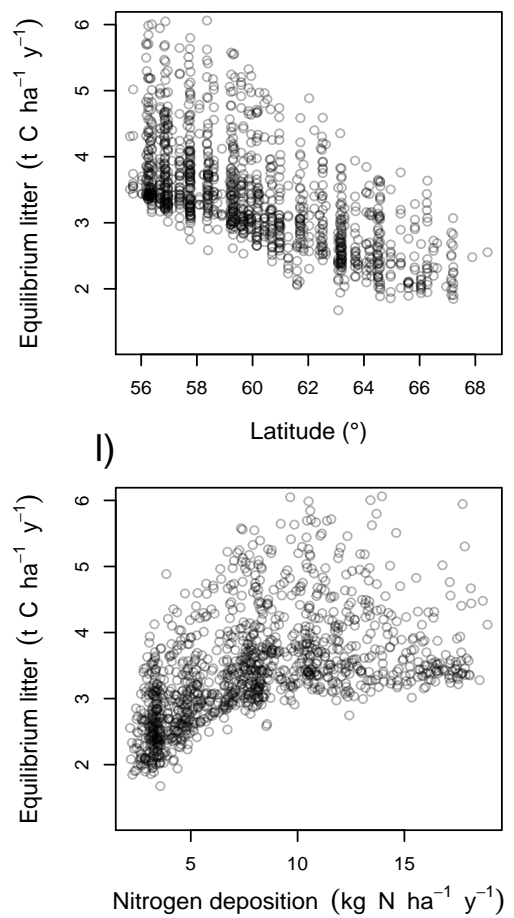

Figure S11. Scatterplots between Latitude $\left(^{\circ}\right)$ and the observed state forest litterfall $\left.\left.\left(\mathrm{tCha}^{-1} \mathrm{y}^{-1}\right) \mathrm{a}\right), \mathrm{b}\right)$, c) or long-term mean "equilibrium" forest litterfall $\left.\left.\left.\left(\mathrm{tC} \mathrm{ha}^{-1} \mathrm{y}^{-1}\right), \mathrm{g}\right) \mathrm{h}\right), \mathrm{i}\right)$; and scatterplots between Nitrogen deposition $\left(\mathrm{kgNha}^{-1} \mathrm{y}^{-1}\right)$ and the observed forest litterfall $\left.\left.\left(\mathrm{tC} \mathrm{ha}^{-1} \mathrm{y}^{-1}\right) \mathrm{d}\right), \mathrm{e}\right)$, f) or long-term mean "equilibrium" forest litterfall $\left.\left.\left.\left(\mathrm{tC} \mathrm{ha}^{-1} \mathrm{y}^{-1}\right) \mathrm{j}\right), \mathrm{k}\right), \mathrm{l}\right)$ for deciduous species, Scots pine, and Norway spruce dominated stands. 

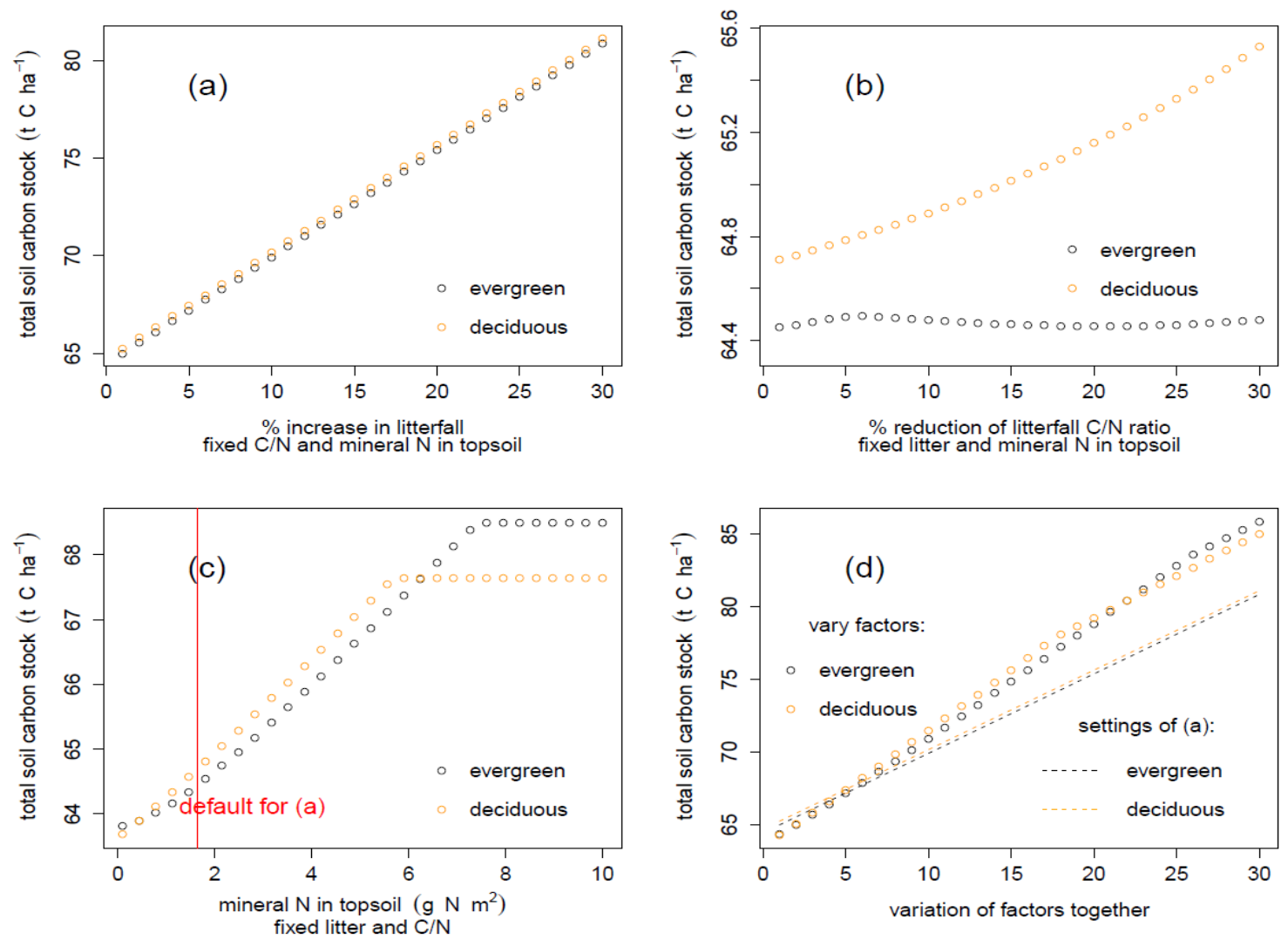

Figure S12. Sensitivity of simulated SOC stocks $\left(\mathrm{tC} \mathrm{ha}^{-1}\right)$ of CENTURY model to variation in litterfall (a), $\mathrm{C} / \mathrm{N}$ ratio of litterfall (b), topsoil mineral $\mathrm{N}\left(\mathrm{gN} \mathrm{m}^{-2}\right)$ (c), and to variation of factors together (d). SOC stocks of CENTURY are output of spin up simulation up to 1000 years. 